\title{
SRSF10 is essential for progenitor spermatogonia expansion by regulating alternative splicing
}

\section{Running title: Srsf10 controls spermatogenesis by alternative splicing}

3 Wenbo Liu ${ }^{1,2^{*} \#}\left|{\text { Xukun } \mathrm{Lu}^{3 *} \mid \text { Zheng-Hui Zhao }}^{4 *}\right|$ Qian-Nan $\mathrm{Li}^{4} \mid$ Yue Xue ${ }^{4} \mid$ Zheng Gao ${ }^{1,2} \mid$ Si-Min Sun ${ }^{4} \mid$ Wen-

4 Long Lei ${ }^{4} \mid$ Lei Li $^{1,2} \mid$ Geng An ${ }^{1,2} \mid$ Hanyan Liu ${ }^{1,2} \mid$ Zhiming Han ${ }^{4}$ Ying-Chun Ouyang ${ }^{4}$ Yi Hou ${ }^{4}$ Zhen-Bo

5 Wang $^{4 \#} \mid$ Qing-Yuan Sun ${ }^{5 \#} \mid$ Jianqiao Liu ${ }^{1,2 \#}$

$6 \quad{ }^{1}$ Department of Obstetrics and Gynecology, Center for Reproductive Medicine, Key Laboratory for Major

7 Obstetric Diseases of Guangdong Province, The Third Affiliated Hospital of Guangzhou Medical University,

8 Guangzhou 510150, China.

$9 \quad{ }^{2}$ Key Laboratory for Reproductive Medicine of Guangdong Province, The Third Affiliated Hospital of 10 Guangzhou Medical University, Guangzhou 510150, China.

$11{ }^{3}$ Center for Stem Cell Biology and Regenerative Medicine, MOE Key Laboratory of Bioinformatics, School of 12 Life Sciences, Tsinghua University, Beijing 100084, China.

$13{ }^{4}$ State Key Laboratory of Stem Cell and Reproductive Biology, Institute of Zoology, Chinese Academy of 14 Sciences, Beijing, 100101, China.

$15{ }^{5}$ Fertility Preservation Lab, Guangdong-Hong Kong Metabolism \& Reproduction Joint Laboratory, 16 Reproductive Medicine Center, Guangdong Second Provincial General Hospital, Guangzhou, 510317, China

$17{ }^{*}$ These authors contributed equally to this work

\#Correspondence

19 Email: liuwenbo@gzhmu.edu.cn

20 Email: wangzb@ioz.ac.cn

21 Email: sunqy@gd2h.org.cn

22 Email: liujqssz@gzhmu.edu.cn 


\section{Abstract}

25 Alternative splicing expands the transcriptome and proteome complexity and plays essential roles in tissue development and human diseases. However, how alternative splicing regulates spermatogenesis remains largely unknown. Here, using germ cell-specific knockout mouse model, we demonstrated that the splicing factor Srsfl0 is essential for spermatogenesis and male fertility. Depletion of Srsf10 in germ cells had little effect on the formation of SSCs but impeded the expansion of progenitor spermatogonia, leading to the failure of spermatogonia differentiation and meiosis initiation. This was further evidenced by the decreased expression of progenitor cell markers in bulk RNA-seq, and much less progenitor and differentiating spermatogonia in singlecell RNA-seq data. Furthermore, the expression of genes involved in cell cycle was abnormal in all subtypes of spermatogonia identified in single-cell RNA-seq data. Notably, using isolated spermatogonia, we found that Srsf10 depletion disturbed the alternative splicing of hundreds of genes, which were preferentially associated with cell cycle, mitotic cell cycle checkpoint and germ cell development, including Dazl, Kit, Ret, Sycp1, Nasp and Bora. These data suggest that SRSF10 is critical for the expansion of progenitor spermatogonia by regulating alternative splicing, expanding our understanding of the mechanism underlying spermatogenesis.

40 Keywords: SRSF10; progenitor spermatogonia; alternative splicing; spermatogenesis; male fertility 


\section{Introduction}

42 Spermatogenesis is a complex and highly coordinated process during which spermatogonial stem cells (SSCs) give rise to haploid spermatozoa sustainably throughout life. The balance of self-renewal and differentiation of

SSCs is fundamental for maintenance of spermatogenesis throughout life. Over self-renewal of SSCs will lead to stem cell accumulation and impair spermatogenesis, and even induce tumor. Conversely, over-differentiation will lead to SSC exhaustion, and thus progressive loss of germ cells and Sertoli cell-only syndrome ${ }^{1}$. Around embryonic days 15 (E15) in mice, male germ cells do not enter meiosis but are arrested at the G0/G1 phase, and are referred to as pre-spermatogonia. The pre-spermatogonia resume mitotic proliferation after birth and migrate from the center to the peripheral basement membrane, entering the appropriate environment (stem cell niche) to develop into SSCs. SSCs can self-renew to sustain the stem cell pool or differentiate to generate progenitor cells destined to differentiation ${ }^{2,3}$. The stem cells and progenitor spermatogonia are collectively called undifferentiated spermatogonia which include A-single (As, single cells), A-paired (Apr, 2 cells interconnected by cytoplasmic bridges) and A-aligned (Aal, 4, 8 or 16 cells interconnected by cytoplasmic bridges) spermatogonia. Then, Aal spermatogonia transform into type A1 spermatogonia and further differentiate into

61 homeostasis of SSCs in this intricate process.

62 Alternative splicing (AS) is a very important and universal post-transcriptional regulatory mechanism to expand 
the diversity of transcripts and proteins from a limited number of genes ${ }^{6}$. Importantly, AS occurs more frequently

in higher mammals (90-95\% of human genes) and complex organs (brain, heart and testes) ${ }^{7,8}$, suggesting that AS contributes to the complexity of the organism. Large scale analysis based on Expressed Sequence Tags (ESTs) and deep sequencing revealed that AS was at an unusually high level in testes, where the transcription of the genome is substantially more widespread than in other organs $9,10,11$, indicating the regulatory functions of AS in the development of testes. Recently, single-cell RNA sequencing (scRNA-seq) revealed that the Gene Ontology (GO) terms of mRNA splicing and mRNA processing were enriched in the spermatogonia ${ }^{12}$. Moreover, many RNA splicing proteins were more highly expressed in type A spermatogonia and in pachytene spermatocyte cell clusters ${ }^{13,14}$. AS isoform regulation impact greatly on the germ cell transcriptome as cells transit from the mitotic to meiotic stages of spermatogenesis ${ }^{15}$, suggesting that AS may be very effective for the mitotic division of spermatogonia. Recently, the RNA helicase DDX5 is shown to play essential posttranscriptional roles in the maintenance and function of spermatogonia via regulating the splicing of functional genes in spermatogonia ${ }^{16}$. Mettl3-mediated m6A regulates the alternative splicing of genes functioning in spermatogenesis and is critical for spermatogonial differentiation and meiosis initiation ${ }^{17}$. Our previous study has also revealed that $B$ cas 2 regulates AS in spermatogonia and is involved in the meiosis initiation ${ }^{18}$. Despite these encouraging findings, our knowledge of the mechanistic regulation of spermatogenesis, such as what AS factors are involved in this complicated process is still very limited.

AS is regulated by cis-regulatory sequences in pre-mRNAs and trans-acting splicing factors which are mostly RNA-binding proteins that bind to the cis-regulatory sequences and regulate splice site selection ${ }^{19,20}$. Serine and arginine-rich (SR) proteins are one of the classic trans-acting splicing regulators which contain one or two RNArecognition motifs (RRM) in the $\mathrm{N}$-terminus and arginine/serine amino acid sequences (RS domain) in the Cterminus $^{21}$. SR proteins are often identified as positive splicing regulators that promote exon inclusion through 
interacting with many other splicing factors ${ }^{21,22}$. SRSF10 is an atypical SR protein functioning as a general splicing repressor when dephosphorylated ${ }^{23}$. In vitro assays show that SRSF10 is dephosphorylated to inhibit the splicing in mitotic cells or response to heat $\operatorname{shock}^{24,25}$. In vivo, Srsf10 knockout mice survived only until

E15.5 due to multiple cardiac defects as a result of dysregulation of cardiac-specific alternative splicing of triadin pre-mRNA which is required for $\mathrm{Ca}^{2+}$ handling in the embryonic heart ${ }^{26}$. SRSF10 also plays important roles in myoblast differentiation, glucose production and adipocyte differentiation by regulating the correct functional alternative splicing ${ }^{27,28,29}$. Thus, Srsf10 is critical for many physiological processes, but the role of Srsf10 in male germ cell development has not been elucidated.

In this study, we generated germ cell conditional Srsf 10 knockout mice and found that $\operatorname{Srsf10}$ was essential for spermatogenesis and male fertility. Depletion of Srsf10 in germ cells impeded the expansion of progenitor spermatogonia, leading to the failure of efficient differentiation of spermatogonia and meiosis initiation. Singlecell RNA-seq data confirmed that progenitors and differentiating spermatogonia were seriously lost in the Srsfl0 undifferentiated spermatogonia. Further analysis showed that SRSF10 was involved in alternative splicing of reveal that SRSF10 is involved in the alternative splicing of spermatogonia and male fertility.

\section{Results}

\section{Srsf 10 is essential for male fertility and spermatogenesis}

To explore the function of $\operatorname{Srsf10}$ in male fertility and spermatogenesis, we mated $\operatorname{Srsf} 10^{\mathrm{Floxed} / \text { Floxed }}\left(\operatorname{Srsf} 10^{\mathrm{F} / \mathrm{F}}\right)$ 
were used as experiment mice, while $\operatorname{Srsf} 10^{\mathrm{F} /+}$;Vasa-Cre mice were normal and used as the control in the

following experiments. SRSF10 and MVH, a germ cell-specific marker, were co-stained and the results showed

that SRSF10 expression was barely detected in MVH-positive cells of postnatal day 8 (P8) Srsf10 ${ }^{\text {cKO }}$ testes

(Figure 1B), indicating that $\operatorname{Srsf10}$ was specifically depleted in germ cells as early as P8.

The adult Srsf $10^{\text {cKO }}$ males looked grossly normal. Normal copulatory plugs could be observed when adult

$\operatorname{Srsf} 10^{\mathrm{cKO}}$ males were mated with wild-type females, but no pups were obtained (Table 1), indicating that

$\operatorname{Srsf} 10^{\mathrm{cKO}}$ males were infertile. Compared to control, the testes of adult $\operatorname{Srsf} 10^{\mathrm{cKO}}$ males were much smaller

(Figure 1C). The weight of testes and ratio of testes to body weight in $S r s f 10^{\mathrm{cKO}}$ males were significantly reduced

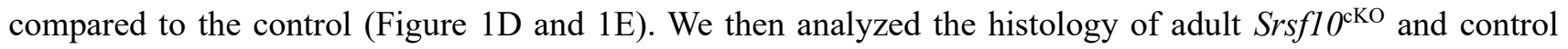

testes using hematoxylin and eosin (H\&E) staining. While all populations of spermatogonia, spermatocytes and

spermatids were observed in the control seminiferous tubules, fewer germ cells were observed and no

testes (Figure 1F). Moreover, no mature spermatozoa could be found in the cauda epididymis of $\operatorname{Srsf} 10^{\mathrm{cKO}}$ mice

(Figure 1G). To further identity of the remaining germ cells in $\operatorname{Srsf1} 0^{\mathrm{cKO}}$ testes, we co-stained these germ cells

with MVH and PLZF (an undifferentiated spermatogonia-specific marker) ${ }^{31}$. Immunofluorescence results showed that only sporadic $\mathrm{MVH}^{+} \mathrm{PLZF}^{+}$cells can be detected around the basement of seminiferous tubules from adult $\operatorname{Srsf10} 0^{\mathrm{cKO}}$ testes (Figure $1 \mathrm{H}$ ). Moreover, the number of $\mathrm{PLZF}^{+}$cells was significantly reduced in adult were left in the adult $\operatorname{Srsf} 10^{\mathrm{cKO}}$ testes. Similarly, testes from one-month-old $\operatorname{Srsf} 10^{\mathrm{cKO}}$ were also much smaller

is essential for male fertility and spermatogenesis. 
As no spermatocytes were observed in the seminiferous tubules of adult and one-month-old $\operatorname{Sr} s f 10^{\mathrm{cKO}}$ testes, we speculated that the meiosis process failed in $\operatorname{Srsf} 10^{\mathrm{cKO}}$ mice. To figure out which stage in spermatogenesis was affected after Srsf 10 deletion, we carefully analyzed the sections from P8, P10, P12, and P15 testes using H\&E staining ${ }^{32}$. At P8, Type A spermatogonia (A), intermediate spermatogonia (In) and type B spermatogonia

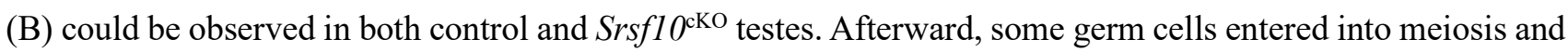
developed into leptotene spermatocytes in P10 control testes, and abundant zygotene and pachytene spermatocytes could be observed in P12 and P15 control testes, respectively (Figure 2A). However, rarely differentiated spermatocytes were detected in the seminiferous tubules of P10, P12 and P15 Srsf $10^{\text {cKO }}$ testes. Instead, some apoptotic cells were observed in the seminiferous tubules of P10 and P12 Srsf $10^{\text {cKO }}$ testes (Figure $2 \mathrm{~A})$, suggesting that meiosis initiation might be impaired in srsf 10 deleted mice.

To further confirm the above results, we co-stained MVH and SCP3, which was a component of the synaptonemal complex and the marker of meiosis prophase I at P12. Spermatocytes in the vast majority of seminiferous tubules had entered into meiosis prophase I as expected, and abundant $\mathrm{MVH}^{+} \mathrm{SCP} 3^{+}$germ cells could be detected in the center of control seminiferous tubules. However, only very few seminiferous tubules contained a tiny minority (about 3 to 5 ) of $\mathrm{MVH}^{+} \mathrm{SCP} 3^{+}$germ cells (Figure 2B). Statistically, the ratio of SCP3 seminiferous tubules in $\operatorname{Srsf} 10^{\text {cKO }}$ testes was significantly lower than the control at P12 $(0.16 \pm 0.048$ versus $0.81 \pm 0.043$, mean \pm SEM) (Figure 2C). Next, we detected the expression of the marker of homologous recombination $\gamma \mathrm{H} 2 \mathrm{AX}$, which can be another indicator of meiosis in P12 testes. Immunofluorescence results showed that $\gamma \mathrm{H} 2 \mathrm{AX}^{+}$cells were nearly undetectable in the seminiferous tubules of $\operatorname{Srsf} 10^{\mathrm{cKO}}$ testes (Figure 2D). Western blot showed that $\gamma \mathrm{H} 2 \mathrm{AX}$ was markedly elevated in control testes from P10 to P12, consistent with the entering into meiotic prophase I of many spermatocytes around this time. However, the expression of $\gamma \mathrm{H} 2 \mathrm{AX}$ changed little in $\operatorname{Srsf} 10^{\mathrm{cKO}}$ testes from P8 to P12 (Figure 2E), indicating failure of meiosis entrance. These results 
indicate that Srsf10 deletion causes a severe defect in meiosis initiation during spermatogenesis.

\section{Srsf10 depletion impairs the expansion and differentiation of the progenitor spermatogonia population}

152 Before meiosis, SSCs proliferate to self-renew or generate differentiation-committed progenitors. The progenitor spermatogonia respond to the RA signal and divide into $\mathrm{KIT}^{+}$differentiating spermatogonia (Figure

3A). Then type B differentiating spermatogonia further proliferate and differentiate into meiotic spermatocytes.

Therefore, the initiation of meiosis requires several rounds of mitotic divisions for full expansion and efficient differentiation of spermatogonia, ${ }^{43,34}$. Interestingly, we found that the expression of MVH and PLZF was development of spermatogonia, which may further lead to the failure of meiosis initiation.

Considering the loss of $\mathrm{PLZF}^{+}$cells in P12 Srsf $10^{\mathrm{cKO}}$ testes, we speculated that the proliferation and/or differentiation of spermatogonia may be disrupted when Srsf10 is depleted. Therefore, we analyzed the distribution and the number of spermatogonia in both control and $\operatorname{Srsf} 10^{\mathrm{cKO}}$ testes at P8 and P6, when only spermatogonia and Sertoli cells can be observed in the seminiferous tubules. At P8, co-staining for MVH and PLZF showed that numerous differentiating spermatogonia $\left(\mathrm{MVH}^{+} \mathrm{PLZF}^{-}\right)$could be detected at the basement of seminiferous tubules in control. However, MVH and PLZF were nearly co-localized in Srsf $10^{\mathrm{cKO}}$ testes, indicative of few differentiating spermatogonia $\left(\mathrm{MVH}^{+} \mathrm{PLZF}^{-}\right)$(Figure 3C). Statistical analysis showed that differentiating spermatogonia $\left(\mathrm{MVH}^{+} \mathrm{PLZF}^{-}\right)$were nearly absent and the number of undifferentiated spermatogonia $\left(\mathrm{MVH}^{+} \mathrm{PLZF}^{+}\right)$was significantly reduced in $\operatorname{Srsf} 10^{\mathrm{cKO}}$ testes compared to the control (Figure 
171 The result showed that the $\mathrm{KIT}^{+}$cells were obviously reduced in $\operatorname{Sr} f 10^{\mathrm{cKO}}$ testes compared to the control at P8

172 (Figure 3D), suggesting that deletion of Srsf10 leads to inefficient differentiation of the progenitor

173 spermatogonia. At P6, co-staining for MVH and PLZF showed that most of the germ cells were undifferentiated

174 spermatogonia $\left(\mathrm{MVH}^{+} \mathrm{PLZF}^{+}\right)$in both control and Srsf10 ${ }^{\mathrm{cKO}}$ testes (Figure 3E). However, the number of the

175 undifferentiated spermatogonia $\left(\mathrm{MVH}^{+} \mathrm{PLZF}^{+}\right)$was also significantly reduced in $\operatorname{Srsf} 10^{\mathrm{cKO}}$ testes compared to

176 the control (Figure 3E). PLZF is a broader marker of all undifferentiated spermatogonia including As, Apr and

177 Aal spermatogonia (Figure 3A). Thus, we performed whole-mount staining for GFR $\alpha 1$, which is specifically

178 expressed in As and Apr spermatogonia ${ }^{35,36}$, and showed that the GFR $\alpha 1^{+}$cells were also apparently reduced in

179 Srsf10 $10^{\mathrm{cKO}}$ testes compared to the control at P6 (Figure 3F). Altogether, these results suggest that fewer

180 undifferentiated spermatogonia (SSCs and progenitor cells) are produced in the absence of Srsf10 as early as

181 P6.

182 During male germ cell development, the pre-spermatogonia undergo a period of G1/G0 arrest from around

183 E15.5 to P3, when these germ cells migrate from the center of seminiferous tubules to the periphery, and then

184 restore mitosis proliferation, transforming into type A spermatogonia and some get stem cell properties around

$185 \mathrm{P} 3$ to $\mathrm{P} 6^{37,38}$. Because Vasa-Cre recombinase is expressed as early as E15.5, we asked whether depletion of

186 Srsf10 would affect the development of pre-spermatogonia at P3. There was no difference in germ cell numbers

187 between control and $\operatorname{Srsf1} 0^{\mathrm{cKO}}$ testes (Figure 3G), suggesting that $\operatorname{Srsf10}$ is dispensable for the development of

$188 \mathrm{G} 1 / \mathrm{G} 0$ arrested pre-spermatogonia. Interestingly, from P3 to P12, the number of undifferentiated spermatogonia

was gradually increased in both control and $\operatorname{Srsf} 10^{\mathrm{cKO}}$ testes. However, the kinetics in $\operatorname{Sr} s f 10^{\mathrm{cKO}}$ testes was much

190 slower, leading to a comparable number of $\mathrm{PLZF}^{+}$cells per tubule in P12 Srsf1 $0^{\text {cKO }}$ to that in P6 control testes

191 (Figure 3H). Western blot confirmed that the expression of PLZF in P3 testes was lower and no significant

192 difference was observed between control and $\operatorname{Srsf} 10^{\mathrm{cKO}}$ testes. With the resumption of mitosis, the expression 
of PLZF was apparently increased from P3 to P8 in control testes, but was only slightly increased in Srsf10 ${ }^{\mathrm{cKO}}$ testes (Figure 3-figure supplement 1C). It should be noted that we cannot exclude the possibility that the SSCs are also affected. However, the slower increase of $\mathrm{PLZF}^{+}$cells suggests that Srsf10 may be essential for the expansion and differentiation of the progenitor spermatogonia population.

\section{Srsf10 depletion disturbs the expression of genes involved in progenitor spermatogonia}

To systematically investigate the molecular effects of Srsf10 loss in germ cells, we compared the transcriptomes of control and Srsf $10^{c K O}$ testes at P3, P6 and P8. RNA-seq analyses identified only 10 upregulated and 9 downregulated genes in $\operatorname{Srsf} 10^{c K O}$ testes compared with the control at P3 (FPKM $>=5$, fold change $>=2, P<$ 0.01) (Figure 4A), suggesting that the transcriptome is largely normal at P3 in the Srsf10 depletion testes. This is consistent with the immunostaining result showing that the number of germ cells is comparable between control and $\operatorname{Srsf1} 0^{c K O}$ testes at P3. However, 139 genes were differentially expressed in the $\operatorname{Sr} s f 10^{c K O}$ testes at P6 and nearly all genes (135/139) were down-regulated in $\operatorname{Srsf10^{cKO}}$ testes (Figure 4A). 396 genes were differentially expressed in $\operatorname{SrSf} 10^{c K O}$ testes at P8, including 243 upregulated and 153 downregulated genes (Figure 4A). Surprisingly, only 57 genes were commonly downregulated in the $S r s f 10^{c K O}$ testes at both P6 and P8 (Figure 4B). Gene ontology (GO) analysis of the 57 genes showed that these genes are involved in the meiotic cell cycle, spermatogenesis, cell differentiation and germ cell development (Figure 4B). We then systematically analyzed the expression pattern of all downregulated genes in control and $\operatorname{Sr} f 10^{c K O}$ testes from P3 to P8. The vast majority of down-regulated genes were gradually increased from P3 to P8 (Figure 4- figure supplement 1A). Interestingly, P6 specific down-regulated genes (e.g., Pou5f1, GFR 1 1, Sohlh1, Egr4, Nanos3, Foxc2, and Sox3) are mainly involved in the expansion and early differentiation of progenitor spermatogonia (Figure 4B). In P6 Srsf10 $0^{c K O}$ testes, the expression level of these genes was very low, although they were upregulated afterward and reached a level comparable to the control P6 testes in P8 Srsf $10^{c K O}$ testes (Figure 4- 
215 figure supplement 1A). These results suggest that the expansion and early differentiation of progenitor

216 spermatogonia are presumably impaired as early as P6, consistent with the observation that the number of PLZF

217 and GFR $\alpha 1^{+}$undifferentiated spermatogonia was significantly reduced at P6 in the absence of Srsf10. Many

218 P8-specific downregulated genes (e.g., Kit, Sycp3, Sycp2, Atm and Rec8) were involved in spermatogonia

219 differentiation and meiosis and were barely up-regulated in $\operatorname{Srsf1} 10^{c K O}$ testes from P6 to P8 (Figure 4B and Figure

220 4- figure supplement 1A), echoing nearly no differentiating spermatogonia and meiotic spermatocytes in P8

$221 S r s f 10^{c K O}$ testes. Unsupervised cluster analysis of spermatogonia-specific genes (SPGs) ${ }^{12}$ showed that the gene

222 expression pattern of $\operatorname{Sr} S \mathrm{f} 10^{c K O}$ testes at P8 was much more similar to that of control testes at P6 (Figure 4C),

223 consistent with the compromised and slower expansion and differentiation of progenitor spermatogonia in the

$224 \operatorname{Srsf1} 0^{c K O}$ testes than control.

225 We then systematically analyzed several marker genes for stem cell maintenance, expansion and differentiation

226 of the spermatogonia population. Genes involved in SSC maintenance (Etv5, Bmil, Id4, Lhxl, Cd82 and T)

227 were hardly affected in the $\operatorname{Srsf} 10^{c K O}$ testes from P3 to P8. However, genes associated with progenitor

228 spermatogonia (Lin28a, Nanos3, Sox3, Neurog3, Pou5f1 and Sohlh1), undifferentiated spermatogonia (Plzf and

229 Sall4) and differentiating spermatogonia (Dmrtb1, Dnmt3b, Stra8, Kit and Prdm9) were down-regulated in

230 Srsf $10^{c K O}$ testes at P6 and P8 compared to control (Figure 4D and Figure 4- figure supplement 1B). The qRT-

231 PCR results confirmed that Srsf10 deficiency did not affect the expression of genes involved in SSCs, but

232 globally reduced the expression of genes that control expansion and differentiation of progenitor cells at P6

233 (Figure 4E). These results are consistent with previous staining results that the number of stem/progenitor cells

234 was significantly decreased at P6. Taken together, these data suggest that Srsf10 deficiency may not affect the

235 gene expression and formation of SSCs, but disturbs genes involved in progenitor spermatogonia and thus their

236 expansion and differentiation. 
To address the heterogeneity of spermatogonia after Srsf 10 depletion, we sought to enrich the undifferentiated and differentiating spermatogonia using their cell surface markers, THY1 (undifferentiated) and KIT (differentiating). We enriched $\mathrm{THY}^{+} \mathrm{KIT}^{-}$, $\mathrm{THY}^{-} \mathrm{KIT}^{+}$and $\mathrm{THY}^{+} \mathrm{KIT}^{+}$spermatogonia from control and Srsf $10^{c K O}$ testes using magnetic-activated cell sorting (MACS) with anti-THY1 and anti-KIT antibodies at P8 ${ }^{39}$. (Figure 5A). After filtering out low-quality cells and somatic cells, 1157 control and 766 Srsf1 ${ }^{c K O}$ (from two replicates) spermatogonial cells were used for further analysis. Uniform manifold approximation and projection

(UMAP) and cell type-specific marker gene analyses were then performed for cell-type identification ${ }^{40}$. UMAP analysis identified five distinct spermatogonial subtypes/states that we named USSC1, USSC2, DSSC1, DSSC2 and DSSC3 (Figure 5B), mainly comprising undifferentiated spermatogonia and differentiating spermatogonia. Analysis using marker genes indicates that USSC1 cells correspond to SSCs, as they highly express SSC marker genes, including Eomes, Id4, Lhxl, Etv5, Gfral and Smoc2 (Figure 5C and Figure 5- figure supplement 1A).

USSC2 cells are highly enriched for Nanos 3, Pou5f1 and Plzf(Zbtb16), with increased levels of Sox3 and Sohlh1, but lower levels of SSC-associated markers and differentiation markers (Figure 5C and Figure 5- figure supplement 1A), corresponding to early progenitor spermatogonia. By contrast, DSSC1 cells express high levels of early differentiation marker genes such as Stra8, Sox3, Sohlh1, Sohlh2 and Dmrt1 and low levels of Pou5f1,

Nanos3 and Plzf (Figure 5C and Figure 5- figure supplement 1A), indicating that this cell population is likely late progenitor/early differentiating spermatogonia. DSSC2 cells display lower Stra8 expression but mainly express differentiation marker genes including Kit, Dmrtb1, Cited1 and Dmrt1 (Figure 5C and Figure 5- figure 
the $\operatorname{Sr} f 10^{c K O}$ group. These cells express some differentiating markers such as Stra8, Dmrt1, Sohlh2 and Kit, but the expression level of Stra8 and Kit was lower than DSSC1 and DSSC2, respectively (Figure 5C), suggesting that DSSC3 cells might have differentiated but with abnormal development. The pseudo-time analysis provided a trajectory indicating the development of germline cells from USSC1 to DSSC2 (Figure 5D).

We then asked whether and how the subtypes of spermatogonia changed after Srsf 10 depletion. We found that (203 cells), $20.2 \%$ (234 cells), $23.6 \%$ (273 cells) and 38.6\% (447 cells) cells sorted into USSC1, USSC2, DSSC1 and DSSC2, respectively (Figure 5E). By contrast, the proportion in the $\operatorname{Srsf} 10^{c K O}$ group was severely slanted, which was resulted from the dramatic decrease of USSC2 (8.1\%, 62 cells), DSSC1 (11.6\%, 89 cells) and DSSC2

(20.3\%, 156 cells) subtypes, concomitant with the dominance of the USSC1 subtype ( $35.6 \%, 273$ cells). On the other hand, $24.3 \%$ (186 cells) of the cells were sorted into the DSSC3 subtype, which scattered in the other four spermatogonia. Analysis using SPG subtypes marker genes revealed that Oomes $^{+}, \mathrm{Id}^{+}$and $\mathrm{Gfral}^{+}$cells (SSCs)

272 were comparable in control and $\operatorname{Srsf} 10^{c K O}$ spermatogonia (Figure 5F and Figure 5- figure supplement 1B).

$273 \mathrm{Zbtbl6}^{+}$and $\mathrm{Sall}^{+}$cells (undifferentiated spermatogonia), and $\mathrm{Nanos}^{+}$and $\mathrm{Egr}^{+}$cells (progenitor 274 spermatogonia) were significantly reduced in the USSC2 subtype in the $\operatorname{Srsf} 10^{c K O}$ testes (Figure 5- figure

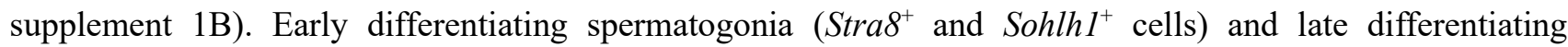
spermatogonia (Kit ${ }^{+}$and $\mathrm{Dmrtb}^{+}$cells) were also significantly reduced in the DSSC1 and DSSC2, respectively, 277 in the $\operatorname{Srsf1} 0^{c K O}$ testes (Figure 5F and Figure 5- figure supplement 1B). Taken together, single-cell transcriptional 278 analysis of spermatogonia shows that the progenitor and differentiating spermatogonia are largely lost in

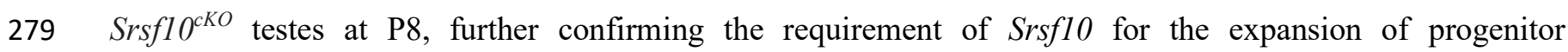
spermatogonia. 


\section{The cell cycle and proliferation of spermatogonia are impaired in $\operatorname{Srsf10^{cKO}}$ testes}

282 We then analyzed the differentially expressed genes in the aforementioned four subtypes of cells between the control and $\operatorname{Srsf} 10^{c K O}$ samples. In USSC1, 108 and 98 genes were down-regulated and up-regulated, respectively $(|\log 2 \mathrm{FC}|>0.25$, adjusted $P$-value $<0.01)$ (Figure 6A). The down-regulated genes were mainly enriched for 'Cell cycle', ‘Cell division', ‘Chromosome segregation', ‘Spermatogenesis' and 'Regulation of G2/M transition of mitotic cell cycle'. The up-regulated genes were enriched for 'G1/S transition of mitotic cell cycle', 'Regulation of apoptotic process', 'Regulation of cell proliferation' and 'Cellular response to growth factor stimulus' (Figure 6B). Consistently, Top2a, Mki67, Cdc20, Ccnb1, Ccna2, Cenpe, Rad50, Kif11, Nusap1 and Prcl, which are important for cell cycle and cell division, were significantly reduced in the USSC1 cells in the

DSSC2, the down-regulated genes were also enriched for 'cell cycle', 'cell division' and 'cell proliferation'

(Figure 6- figure supplement 2). These data indicate that depletion of Srsf10 in germ cells likely disrupts the normal cell cycle and proliferation of spermatogonia.

To test this idea, we first investigated the proliferation of spermatogonia in $\operatorname{Srsf1} 0^{c K O}$ testes by co-staining for

PLZF and KI67 (labeling mitotic cells that are not in the G0 phase) to analyze the mitotic status of

in both control and $\operatorname{Srsf} 10^{c K O}$ testes (Figure 6D). The number of $\mathrm{KI} 67^{+} \mathrm{PLZF}^{+}$cells was not significantly different between control and $\operatorname{Srsf} 10^{c K O}$ testes (Figure 6E), suggesting that all the $\mathrm{PLZF}^{+}$cells were in the mitotic status.

We further tested the EdU incorporation of spermatogonia $\left(\mathrm{PLZF}^{+}\right.$cells) in the control and $\operatorname{Srsf1} 0^{c K O}$ testes at 
$\operatorname{Srsf1} 0^{c K O}$ mice were intraperitoneally injected with $\mathrm{EdU}(5 \mathrm{mg} / \mathrm{kg})$, and testes were collected 4 hours later for fixation and paraffin section. Co-staining for EdU and PLZF showed that the EdU incorporation was significantly reduced in $S r s f 10^{c K O} \mathrm{PLZF}^{+}$spermatogonia at P6 (Figure 6F and 6G). These results suggest that the proliferation of spermatogonia in $\operatorname{Sr} f 10^{c K O}$ mice was significantly impaired. As apoptosis-related genes are up-regulated in the USSC1 and USSC2 cells, we also analyzed the apoptosis of spermatogonia. Double staining

for cleaved caspase 3 (CAP3) and PLZF showed that the number of $\mathrm{CAP}^{+} \mathrm{PLZF}^{+}$spermatogonia was significantly higher in $\operatorname{Srsf10^{cKO}}$ testes compared to the control (Figure 6H and 6I), implying that the survival of spermatogonia was also impaired when Srsf10 is depleted. In conclusion, Srsf10 depletion might lead to abnormal cell cycle and mitotic division, and further affect the proliferation and survival of spermatogonia.

\section{Srsf10 regulates alternative splicing of functional genes in spermatogonia}

313 We then sought to probe into how Srsf10 depletion affects spermatogenesis at the molecular level. To this end, 314 we collected the $\mathrm{THY}^{+}$spermatogonia using MACS from control and $\operatorname{Sr} s f 10^{c K O}$ testes at P6 to minimize the potential side effects ${ }^{39}$ (Figure 7A). Flow cytometry and immunostaining analyses showed that the proportion of undifferentiated spermatogonia (THY $1^{+}$cells or $\mathrm{PLZF}^{+}$cells) was significantly increased in the sorted group than that in the unsorted group (Figure 7- figure supplement 1A and 1B). We confirmed the dramatic decrease of $\operatorname{Srsf10}$ in the enriched spermatogonia of $\operatorname{Srsf1} 10^{c K O}$ testes at both RNA and protein levels (Figure 7- figure supplement $1 \mathrm{C}$ and 1D). Then, we performed next-generation sequencing of the enriched spermatogonia of control and $\operatorname{SrSf} 10^{c K O}$ and compared the transcriptome between them. A total of 507 genes were differentially expressed in P6 Srsf1 $0^{c K O}$ spermatogonia $(P<0.01$, fold change $>=2$ and FPKM $>=2)$, including 200 downregulated genes that were significantly enriched for genes involved in spermatogenesis, meiotic cell cycle, cell differentiation, male germline stem cell asymmetric division and germ cell development (Figure 7- figure 
Nanos3, Sox3, Lin28a and Neurog3 (Figure 7- figure supplement 2), presumably due to the absence of the

progenitor spermatogonia, as observed in the scRNA-seq data.

Srsf10 is an SR protein and is involved in constitutive and alternative splicing. We asked whether depletion of

Srsf 10 would affect the splicing and alternative splicing in spermatogonia. THY $1^{+}$spermatogonia at P6 were

collected and subjected to PacBio Isoform Sequencing (Iso-seq) (Figure 7A), which can generate and capture

the full-length cDNAs and present more accurate information about isoforms, alternatively spliced exons and

fused transcripts. We then analyzed the Iso-seq data for identification of the differential alternative splicing events between control and $\operatorname{SrSf} 10^{c K O}$ spermatogonia using SUPPA2 software ${ }^{41} .522$ differentially spliced events

(DSEs) were identified ( $\mathrm{P}<0.05$ and $|\Delta \mathrm{PSI}|>0.1)$, the majority of which were exon skipping (191) (Figure 7B).

Among the 522 DSE, 266 AS events had negative $\triangle$ PSI values and 256 had positive $\triangle$ PSI values, indicating

that Srsf10 has no bias in the regulation of AS (Figure 7C). The 522 DSEs involve 419 genes. Gene ontology

(GO) analysis revealed that these genes participate in cell cycle (30 genes), cell-cell adhesion (14 genes),

response to DNA damage stimulus (22 genes) and germ cell development ( 5 genes) (Figure 7D). We then asked

what would be resulted from these DSEs. Taking exon skipping as an example, 132 of the 191 differentially

spliced exons (excluded or included) happens in the gene coding regions (Figure 7- figure supplement 3A).

While $59.8 \%(n=79)$ of them produces another protein-coding isoform of potential regulatory functions (such

as, Dazl, Nasp and Cdc7) (Figure 7- figure supplement 3B), about 40\% of them generates frame-shifted

transcripts ( $\mathrm{n}=53$ ) (Figure 7- figure supplement 3A). Notably, the latter can potentially give rise to the premature

termination codon (PTC), such as in Bora, Kat7 and Clk1 (Figure 7- figure supplement 3C). The presence of

PTCs probably further results in nonsense-mediated mRNA decay (NMD). Moreover, the next-generation 
involved in 317 genes were identified $(P<0.05)$ and the majority of which were exon skipping (229) (Figure 7-

figure supplement 4A). 59 genes were commonly detected in the NGS data for CASH analysis and Iso-seq data

for SUPPA2 analysis (Figure 7- figure supplement 4B). Gene ontology (GO) analysis of the 59 genes showed

that these genes are involved in DNA replication (Kat7, Mcm4, Nasp and Ssrp1), cell cycle (Bora, Cdc7, Stag3,

Mcm4 and Uhrf1) and spermatid development (Xlr5a, Xlr5b and Xlr5c) (Figure 7- figure supplement 4B). In

addition to these overlapped genes, we also focused on the functional splicing changes involved in spermatogenesis and cell cycle. for example, Ret, Sycp 1, Exo1, Zfp207, Ccna2 and Ola1 in CASH analysis data and Ccne2, Kit, Ist1, Mapk7, Pttgl and Clk1 in SUPPA2 analysis data (Figure 7- figure supplement 4B).

We first confirmed the aberrant splicing of Bclafl (skipped exon), Acly (skipped exon) and Zfp207 (skipped exon) (Figure 7E and Figure 7- figure supplement 4C), which are known targets of $S r s f 10^{27,43}$. Importantly, the differential splicing of individual events in genes involved in important spermatogonia-related processes, including cell cycle and germ cell development were also successfully verified. For example, loss of $\operatorname{Srsf10}$ resulted in differential splicing of exon 8 in $\mathrm{Dazl}$ (increased exon inclusion), alternative last exon of Ret, alternative 5' splice sites of exon 9 in Kit (absence of four amino acids), exon 6 in Sycpl (increased exon

skipping), exon 8 in $C d c 7$ (increased exon inclusion), exon 7 in Nasp (increased exon skipping), exon 4 in Bora

(increased exon skipping), exon 14 in Kat7 (increased exon skipping), exon 7 in Ccna (increased exon skipping), exon 9 in Ist 1 (increased exon skipping), alternative 5' splice sites of exon 10 in Exol and alternative first exon

of Ccne2 (Figure 7E and Figure 7- figure supplement 4C). These data suggest that SRSF10 is required for the correct splicing of functional genes, thus maintaining the homeostasis of alternative splicing during spermatogenesis.

\section{Discussion}


368 Spermatogenesis is a very complex process in which germ cells undergo mitosis division of spermatogonia,

369 genomic rearrangement in meiosis, and morphological changes in spermiogenesis to give rise to millions of mature spermatozoa per day ${ }^{44}$. The foundation of this process is spermatogonial stem cells (SSCs) which can

371 self-renew to maintain the stem cell pool or undergo differentiation into spermatogonial progenitors that expand

372 and further differentiate. Therefore, fully understanding the regulation of proliferation and differentiation of

373 SSCs is of great importance. Recently, the importance of alternative splicing as a post-transcriptional regulatory mechanism involved in spermatogonia development is just beginning to be unraveled ${ }^{13,45}$. However, the

knowledge is still very limited regarding how the splicing machinery, including specific splicing factors that are involved in this process. By illustrating the function and mechanism of Srsf10 in mouse spermatogenesis (Figure

8), our study highlights the complexity and requirements of alternative splicing regulation in spermatogonia expansion and meiosis initiation.

Srsf 10 depletion mediated by Vasa-Cre leads to absence of differentiating spermatogonia, with existence of only

a few undifferentiated spermatogonia in adult testes, and thus male infertility. In the first wave of spermatogenesis, the number of $\mathrm{PLZF}^{+}$undifferentiated spermatogonia increases but with a much slower pace from P6 to P12, and differentiating spermatogonia and spermatocytes can barely be observed. This phenotype is very different from that of the depletion of genes that are important for the maintenance of SSCs $(E t v 5, B c l 6 b$, Id4 and Taf $4 b)^{39,46,47,48}$ or differentiation of spermatogonia (Sohlh1 and Sohlh2) $)^{49,50}$. The former does not lead to infertility until adulthood but exhibits an age-dependent progressive loss of germ cells, while the latter leads to loss of differentiating spermatogonia but with limited effect on undifferentiated spermatogonia. So, it is likely that the defects of $\operatorname{Sr} S f 10^{c K O}$ testes might mainly be due to failed expansion of the progenitor spermatogonia population, and thus their efficient differentiation. This is further supported by the RNA-seq data of P3, P6 and 
reduced. So Srsf10 is possibly critical for the formation and expansion of progenitor spermatogonia, but not the formation or maintenance of SSCs.

scRNA-seq data showed that the gene expression associated cell cycle of SSCs and progenitor cells was abnormal in $\operatorname{Sr} f f 10^{c K O}$ testes. This is further supported by the reduced EdU incorporation in PLZF spermatogonia in the $\operatorname{Sr} f 10^{c K O}$ testes as early as P6. The $\mathrm{PLZF}^{+}$spermatogonia include SSCs and progenitor cells and the proliferation of progenitor spermatogonia is reportedly at a higher rate than SSCs which are normally quiescent and exhibit a very slow cell cycle ${ }^{51}$. The scRNA-seq data show that the subtypes of SSCs can form and the number of SSCs is comparable to control. Thus, the phenotype of significantly decreased undifferentiated spermatogonia is most likely due to the abnormal cell cycle or proliferation of progenitor cells. Interestingly, alternative splicing shows that 'cell cycle' sits atop the Srsf10 affected gene GO terms and contains the most genes (30, including Prr5, Ccnk, Anapc15, Uhrf1, Syce2, Stk11, Mapk7, Pttg1, Check1, Pim2, Nae1,

Bora, Ist1, Cdc7, Cdc25c, Ccne2, Nasp, Stag3, Cdk4 and Mcm4, etc), many of which have been successfully

verified. Therefore, the negative effects on cell proliferation of spermatogonia of Srsf10 depletion might be due

to abnormal alternative splicing of abundant functional genes (Figure 8). However, how the aberrant splicing of

these genes affects their functions and further leads to the phenotype needs to be further clarified.

Interestingly, besides the above factors that are involved in general cellular events, we found and verified the aberrant splicing of many important germ cell genes, including Dazl, Kit, Ret and Sycp1 in Srsf10 deficient

spermatogonia (Fig. 8). Dazl encodes an RNA-binding protein essential for germ cell development and meiotic

initiation $^{52}$. DAZL has been proved to promote the expansion and differentiation of progenitor spermatogonia ${ }^{53,}$

${ }^{54}$. In our previous study, we found that Bcas 2 depletion in spermatogonia leads to dramatic skipping of exon 8 
414 isoforms were identified in ESCs, implying the potential functional divergence of these two isoforms in 415 spermatogenesis ${ }^{55}$. Although how the increased inclusion of exon 8 in Dazl affects its function and 416 spermatogenesis remains to be further clarified, we speculate that the splicing of Dazl should be precisely 417 regulated to keep the balance of its two isoforms and exert the normal functions. KIT is the marker of 418 differentiating spermatogonia and is critical for the survival and proliferation of differentiating type A 419 spermatogonia ${ }^{56}$. Several isoforms of $c$-Kit are produced by alternative mRNA splicing, of which two are the 420 presence or absence of four amino acids (GNNK+ and GNNK-, respectively) in the extracellular domain ${ }^{57}$. In the $\operatorname{Sr} f 10^{c K O}$ testes, the GNNK+ isoform was more decreased than GNNK-. Thus, the ratio of GNNK-/GNNK+ 422 displayed a significantly elevated in the $\operatorname{Sr} f f 10^{c K O}$ testes. Previous studies showed that the two KIT isoforms 423 share a similar affinity to ligand SCF, but the expression of GNNK- isoform was stronger transformation activity 424 in NIH3T3 cells and more tumorigenic in nude mice ${ }^{58,59}$. Thus, the abnormal ratio of Kit isoforms may play a 425 role in the development of spermatogonia. Glial cell-line-derived neurotrophic factor (GDNF) is critical for 426 SSCs self-renewal in mice by binding to the GFRA1/RET receptor ${ }^{60}$. GDNF-mediated RET signaling is required 427 the fate of undifferentiated spermatogonia and Ret mutant testis shows severe SSC depletion by P7 during the 428 first wave of spermatogenesis ${ }^{61}$. What's more, the numbers of progenitor spermatogonia decrease more severely 429 than the numbers of SSCs when GDNF/RET signaling is inhibited ${ }^{62}$. Thus, we suggest the AS change of Ret 430 regulated by Srsf10 may also play important role in the spermatogonia development.

431 While it is widely accepted that alternative splicing is an important post-transcriptional regulation, its function 432 in the specific context and biological processes has just begun to be illustrated. Our results demonstrate that 433 SRSF10 is essential for the expansion and differentiation of progenitor spermatogonia by regulating alternative 
bioRxiv preprint doi: https://doi.org/10.1101/2022.03.06.483179; this version posted March 6, 2022. The copyright holder for this preprint (which was not certified by peer review) is the author/funder, who has granted bioRxiv a license to display the preprint in perpetuity. It is made available under aCC-BY 4.0 International license.

434 splicing (Figure 8), providing new insights into the regulation of spermatogenesis regarding how alternative 435 splicing is involved by specific splicing factor.

436 
440 All mice were maintained under specific-pathogen-free (SPF) conditions and the illumination time, temperature and humidity were all in accord with the guidelines of the Animal Care and Use Committee of the Institute of

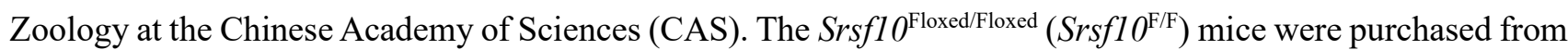
Shanghai Model Organisms Center, Inc. The $S r s f 10^{\mathrm{F} / \mathrm{F}}$ male mice were mated with Vasa-Cre transgenic females to obtain the mouse model with Srsf10 specific deletion in the germ cell lines. All the mice had C57BL/6J genomic background. Genotyping of Srsf 10 was performed by PCR of mice tail genomic DNA. Forward primer: 5-AACATTTAGCACATTTGAGGAT-3, and reverse primer: 5-AACAGCCATATTAACCCGTCTTG-3 were used to detect the wild-type allele $(615 \mathrm{bp})$ and the floxed allele (467 bp). Forward primer: 5AGCATGCCTATCTTGTGT-3, and reverse primer: 5-TAACCCGTCTTGTAGTAAATCT-3 were used to detect the mutant allele (300 bp). The Vasa-Cre was genotyped with forward primer (5including $\operatorname{Srsf} 10^{\mathrm{F} /+}$, Srsf $10^{\mathrm{F} /}$, Srsf $10^{F /+}$;Vasa-Cre and Srsf $10^{F /}$;Vasa-Cre were identified. The genotype of Srsf $10^{F /-}$; Vasa-Cre was used as mutants and was referred to as $S r s f 10^{\mathrm{cKO}}$. The genotypes of $\operatorname{Srsf} 10^{\mathrm{Fl}}$; $\mathrm{Vasa}-\mathrm{Cre}$ were used as control.

\section{Histological analysis, immunostaining and imaging}

456 For histological analysis, testes from control and $\operatorname{Srsf1} 0^{\mathrm{cKO}}$ were isolated and fixed in Bouin's solution 457 (Saturated picric acid: 37\% Formaldehyde: Glacial acetic acid=15:5:1) overnight at room temperature. These 
459 in paraffin. Then, paraffin-embedded samples were cut into sections of 5- $\mu \mathrm{m}$ thickness. After dewaxing and 460 hydration, the sections were stained with hematoxylin and 1\% eosin and imaged with a Nikon ECLIPSE Ti microscope.

462 For immunostaining, testes from control and $S r s f 10^{\mathrm{cKO}}$ mice were isolated and fixed in 4\% PFA overnight at

$4{ }^{\circ} \mathrm{C}$. Following dehydration, the testes were embedded in paraffin and cut into sections of $5 \mu \mathrm{m}$ thickness. After dewaxing and hydration, the sections were boiled in citrate antigen retrieval solution $(0.01 \mathrm{M}$ citric acid/sodium citrate, $\mathrm{pH}$ 6.0) for 20 mins in the microwave oven. After free cooling, the sections were washed with PBS 3 times and blocked with 5\% BSA in PBS for $1 \mathrm{~h}$ at room temperature. Then, the sections were incubated with primary antibody overnight at $4{ }^{\circ} \mathrm{C}$. On the second day, we washed the sections with PBS 3 times and incubated them with secondary antibody for $1 \mathrm{~h}$ at room temperature.

469 After washing in PBS 3 times, the sections were incubated with $2 \mathrm{mg} / \mathrm{ml}$ of Hoechst 33342 (Sigma, B2261) for $47015 \mathrm{~min}$ at room temperature. Finally, the sections were washed with PBS 2 times and mounted with 471 Fluoromount-G medium (Southern Biotech, 0100-01). The immunofluorescence staining was imaged with a 472 laser scanning confocal microscope LSM880 (Carl Zeiss, Germany).

473 The primary antibodies used were listed as follows, rabbit anti-SRSF10 polyclonal antibody (ab254935, Abcam, 474 1:200); goat anti-PLZF antibody (AF2944, R\&D, 1:200); goat anti-KIT antibody (AF1356, R\&D, 1:200); goat 475 anti-GFR $\alpha 1$ antibody (AF560, R\&D , 1:200); rabbit anti-DDX4/MVH polyclonal antibody (ab13840, Abcam, 476 1:200); rabbit anti- phospho-Histone H2A.X (Ser139/Tyr142) Antibody (\#5438, Cell Signaling Technology, 477 1:200); mouse anti-SCP3 antibody (ab97672, Abcam, 1:200); rabbit anti-Cleaved Caspase-3 (Asp175) antibody 478 (\#9661, Cell Signaling Technology, 1:200); and rabbit anti-Ki67 antibody (ab15580, Abcam, 1:200).

479 The secondary antibodies used were listed as follows: Alexa Fluor 488 donkey anti-rabbit (Jackson, 1:500); 
bioRxiv preprint doi: https://doi org/10.1101/2022 03 06.483179- this version posted March 6.2022 . The copyright holder for this preprint (which was not certified by peer review) is the author/funder, who has granted bioRxiv a license to display the preprint in perpetuity. It is made available under aCC-BY 4.0 International license.

Alexa Fluor 549 donkey anti-rabbit (Jackson, 1:500); Alexa Fluor 488 donkey Anti-Mouse (Jackson, 1:500);

Alexa Fluor 549 donkey anti-Mouse (Jackson, 1:500); and Alexa Fluor 488 donkey Anti-goat (Jackson, 1:500).

\section{RNA extraction and qRT-PCR}

Total RNA was extracted from whole testes or enriched cells using RNAzol ${ }^{\circledR}$ RT (Molecular Research Center. Inc, RN 190) following the manufacturer's instructions. After removing the residual genomic DNA with the DNase I Kit (Promega, M6101), 500 ng of total RNA was reverse-transcribed into cDNAs using the PrimeScript RT Reagent Kit (TaKaRa, RR037A) according to the manufacturer's protocol. qRT-PCR was performed using an Eva Green 2X qPCR MasterMix-No Dye kit (Abm, MasterMix-S) on a LightCycler 480 instrument (Roche). Relative gene expression was analyzed based on the $2^{-\Delta \Delta C t}$ method with $\beta$-actin as internal controls. At least three independent experiments were analyzed. All primers were listed in the Supplementary file 1.

\section{Western blot}

The protein from testes or enriched cells were extracted using RIPA lysis buffer (50 mM Tris- $\mathrm{HCl}$ (pH 7.5), $150 \mathrm{mM} \mathrm{NaCl}, 1 \%$ Sodium deoxycholate, 1\% Triton X-100, 0.1\% SDS, 5 mM EDTA, 1 mM Na3VO4, 5-10 $\mathrm{mM} \mathrm{NaF}$ ) containing a protease inhibitor cocktail (Roche, 04693132001) and the protein lysis buffers were incubated on ice for $20 \mathrm{~min}$. After the ultrasound, the protein lysis buffers were centrifuged at $4{ }^{\circ} \mathrm{C}, 12,000 \mathrm{rpm}$ for $20 \mathrm{~min}$ and quantified using a BCA reagent kit (Beyotime, P0012-1). After being boiled at $95{ }^{\circ} \mathrm{C}$ for $6 \mathrm{~min}$, equal amounts of total protein lysates were used for immunoblotting analysis. Different molecular weight proteins were separated in a 10\% SDS-PAGE gel and transferred onto PVDF membranes. After blocking with $5 \%$ non-fat milk for $1 \mathrm{~h}$ at room temperature, the membranes were incubated with diluted primary antibodies at $4{ }^{\circ} \mathrm{C}$ overnight. After three washes with TBST, the membranes were incubated with secondary antibodies conjugated with horseradish peroxidase (1:3,000, Jackson ImmunoResearch) at room temperature for $1 \mathrm{~h}$. The 
signals were developed with Pierce ECL Substrate (Thermo Fisher Scientific, \#34080), detected with Bio-RAD

goat anti-PLZF antibody (AF2944, R\&D, 1:1,000); rabbit anti-DDX4/MVH polyclonal antibody (ab13840,

Abcam, 1:1,000); rabbit anti- phospho-Histone H2A.X (Ser139/Tyr142) Antibody (\#5438, Cell Signaling

Technology, 1:1,000).

\section{Whole-mount immunostaining}

508 The testes were collected and dissected to remove the tunica albuginea. Seminiferous tubules were dispersed

with tweezers and fixed at $4 \%$ PFA overnight at $4{ }^{\circ} \mathrm{C}$. The tubules were washed three times with PBST for 10

min each and permeated with $0.1 \%$ TritonX-100 for $4 \mathrm{~h}$ at room temperature. Then, the tubules were washed three times with PBST and blocked with 5\% BSA in PBS for $2 \mathrm{~h}$ at room temperature. Primary antibodies were incubated overnight at $4{ }^{\circ} \mathrm{C}$. After washing with PBST and the tubules were incubated with secondary antibodies

for $4 \mathrm{~h}$ at room temperature. With the washing of PBST, the tubules were stained with Hoechst for 30min at room temperature. After simply washing, the tubules were mounted with Fluoromount-G medium (Southern Biotech, 0100-01). The imaging of whole-mount staining followed the protocol described above.

\section{RNA sequencing}

517 Testes samples were collected from P3, P6 and P8 control and $S r f 10^{\mathrm{cKO}}$ mice. THY $1^{+}$spermatogonia were 518 isolated from P6 control and Srf10 ${ }^{\mathrm{cKO}}$ mice. Total RNA was isolated using the RNAzol ${ }^{\circledR}$ RT (Molecular 519 Research Center. Inc, RN 190) according to the manufacturer's protocol and treated with DNase I to remove residual genomic DNA. A total amount of $1 \mu \mathrm{g}$ of RNA per sample was used to prepare cDNA libraries generated 
recommendations. 6G base pairs (raw data) were generated by Illumina Novaseq 6000 for each cDNA library.

523 The adaptor sequence and sequences with a high content of unknown bases or low-quality reads were removed 524 to produce the clean reads used for bioinformatic analysis.

\section{RNA-seq bioinformatic analyses}

526 After initial quality control, the clean reads were aligned to the mouse reference genome ( $\mathrm{mm} 9$ ) using Tophat 527 v2.1.1 (TopHat: discovering splice junctions with RNA-Seq). Next, the gene expression was calculated by 528 Cufflinks v2.2.1. And the normalization of the gene expression values was based on the fragments per kilobase of exon per million reads mapped (FPKM).

\section{EdU incorporation assay}

EdU (RiboBio, C00053) dissolved in PBS was injected intraperitoneally at $5 \mathrm{mg} / \mathrm{kg}$ of body weight. Testes were collected from control and Srsf10 $0^{\mathrm{cKO}}$ mice at $4 \mathrm{~h}$ following EdU incorporation and fixed in 4\% PFA overnight at $4{ }^{\circ} \mathrm{C}$, and then embedded in paraffin. EdU and PLZF co-staining was performed according to the protocol of

Cell-Light $^{\mathrm{TM}}$ Apollo567 Stain Kit (100T) (RiboBio, C10310-1).

\section{Testes digestion and generation of cell suspensions}

536 Testes from P6 mice were used to generate single-cell suspensions following enzymatic digestion as described previously $^{2}$. In brief, testes were collected from P6 or P8 control and Srsf10 $0^{\mathrm{cKO}}$ mice in Hanks' balanced salt solution (HBSS) and the tunica albuginea was removed. Then, the testes were digested with $4.5 \mathrm{ml} 0.25 \%$ trypsin/EDTA and $0.5 \mathrm{ml} 7 \mathrm{mg} / \mathrm{ml}$ DNase I solution (Sigma, d5025) for 6 min at $37^{\circ} \mathrm{C}$. After gently pipetting, another $0.5 \mathrm{ml}$ DNase I solution was added to the cell suspension to digest for another $2-3 \mathrm{~min}$ at $37{ }^{\circ} \mathrm{C}$ and

541 followed by the addition of $1 \mathrm{ml} \mathrm{10 \%} \mathrm{FBS.} \mathrm{Single-cell} \mathrm{suspensions} \mathrm{were} \mathrm{made} \mathrm{by} \mathrm{gently} \mathrm{repeated} \mathrm{pipetting} \mathrm{and}$

542 passed through a $40 \mu \mathrm{m}$ pore size cell strainer. The cells are centrifugated at $600 \mathrm{~g}$ for $7 \mathrm{~min}$ at $4{ }^{\circ} \mathrm{C}$ and 26 
resuspended with $180 \mu$ running buffer (Miltenyi Biotec, 130-091-221) for MACS selection.

\section{THY1 $^{+}$spermatogonia isolation}

545 We added $20 \mu \mathrm{THY}$ THtibody-conjugated microbeads [anti-mouse CD90.2 (Thy1.2) MicroBeads; Miltenyi 546 Biotech, 130-121-278] to the single-cell suspensions and mixed well, then incubated for $20 \mathrm{~min}$ at $4{ }^{\circ} \mathrm{C}$. After 547 incubation, $2 \mathrm{ml}$ running buffer was added to the cells and centrifugated at $600 \mathrm{~g}$ for $7 \mathrm{~min}$ at $4{ }^{\circ} \mathrm{C}$. The pellet 548 was then resuspended in $500 \mu$ l of running buffer for magnetic cell separation. The LS columns (Miltenyi Biotec, 549 130-042-401) were placed in the magnetic field of the MACS Separator and prewashed with $0.5 \mathrm{ml}$ of running buffer followed by the addition of the THY1-labeled cell suspension. Wash the LS columns 3 times with $3 \mathrm{ml}$ running buffer and the unlabeled THY1- cells were eluted. Then, the LS columns were removed from the separator and placed on new $15 \mathrm{ml}$ centrifuge tubes. The THY $1^{+}$cells were eluted from the LS columns in a 5 $\mathrm{ml}$ running buffer and centrifuged at $600 \mathrm{~g}$ for $7 \mathrm{~min}$ at $4{ }^{\circ} \mathrm{C}$. After centrifugation, the supernatant is removed and the pellet of $\mathrm{THY} 1^{+}$cells was stored at $-80{ }^{\circ} \mathrm{C}$ for subsequent sequencing analysis and validation.

\section{Droplet-based single-cell RNA-sequencing}

$\mathrm{THY}^{+} \mathrm{KIT}^{-}, \mathrm{KIT}^{+} \mathrm{THY}^{-}$and $\mathrm{THY}^{+} \mathrm{KIT}^{+}$spermatogonia collection: Testes collected from $\mathrm{P} 8$ control and $\operatorname{Srsf} 10^{\mathrm{cKO}}$ mice were digested and the single cell suspensions were generated following the protocol described above. We added $20 \mu 1$ THY1 antibody-conjugated microbeads [anti-mouse CD90 (Thy1.2) MicroBeads; Miltenyi Biotech, 130-121-278] and $40 \mu \mathrm{l}$ KIT antibody-conjugated microbeads [anti-mouse CD117 MicroBeads; Miltenyi Biotech, 130-091-224] to the single-cell suspensions for 20 min at $4{ }^{\circ} \mathrm{C}$, and followed the protocol described above to get the $\mathrm{THY}^{+}{ }^{+} \mathrm{KIT}^{-}, \mathrm{KIT}^{+} \mathrm{THY}^{-}$and $\mathrm{THY} 1^{+} \mathrm{KIT}^{+}$spermatogonia.

562 Single cells were suspended in PBS containing 0.04\% BSA and loaded onto the Chromium 3' v3 platform (10x 563 Genomics) to generate single cell libraries according to the manufacturer's protocol. Briefly, single cells were 
564 partitioned into Gel Bead-In-EMulsions (GEMs) in the 10X Chromium Controller instrument followed by cell

565 lysis and barcoded reverse transcription using a unique molecular identifier (UMI). The cDNA was generated

566 and then amplified, and the libraries were finally sequenced using an Illumina Novaseq 6000 sequencer with a 567 sequencing depth of at least 100,000 reads per cell with a pair-end $150 \mathrm{bp}$ (PE150) reading strategy (performed 568 by CapitalBio Technology, Beijing).

\section{Data processing of scRNA-seq}

570 Raw data were processed using the Cell Ranger Software (version 4.0.0). Briefly, the raw files were converted 571 to demultiplexed fastq files through the Cell Ranger mkfastq pipeline. The fastq files were then aligned to the 572 mouse reference genome (mm10) using the STAR aligner. Next, the reads were further filtered for valid cell 573 barcodes and UMIs to produce a count matrix. Finally, the count matrix was imported into the R package Seurat 574 and quality control was performed to remove outlier cells and genes. Cells with 200-4000 detected genes were 575 retained. Genes were retained in the data if they were expressed in $\geqslant 3$ cells. After applying these quality 576 control criteria, 1923 cells and 23310 genes remained for further analysis. Additional normalization was 577 performed in Seurat on the filtered matrix to obtain the normalized count. Highly variable genes across single 578 cells were identified and PCA was performed to reduce the dimensionality on the top 16 principal components. 579 Then, cells were clustered and visualized in two dimensions using UMAP (Uniform Manifold Approximation and Projection).

\section{Pseudotime analysis of single-cell transcriptomes}

582 Germ cell lineage trajectories were constructed according to the procedure recommended in the Monocle3 documentation (https://cole-trapnell-lab.github.io/monocle3/docs/starting/). Cluster 1 (USSC1) was used as start, cluster 2 and 3 (USSC2 and DSSC1) as middle, and cluster 5 (DSSC3) as the end of pseudotime. Briefly, 
the top differentially expressed genes were selected as "ordering genes" to recover lineage trajectories in

Monocle3 using default parameters. After pseudotime time was determined, differentially expressed genes were

clustered to verify the fidelity of lineage trajectories.

\section{PacBio Isoform Sequencing (Iso-seq)}

$\mathrm{THY}^{+}$spermatogonia were isolated from P6 control and $S r f 10^{\mathrm{cKO}}$ mice. Total RNA was isolated using the

RNAzol ${ }^{\circledR}$ RT (Molecular Research Center. Inc, RN 190) according to the manufacturer's protocol and treated

with DNase I to remove residual genomic DNA. $5 \mu \mathrm{g}$ of total RNA per sample was used to prepare the Iso-Seq

library using the Clontech SMARTer cDNA synthesis kit and the BluePippin Size Selection System protocol as

described by Pacific Biosciences (PN 100-092-800-03).

After running the Iso-Seq pipeline, sequence data were processed using the SMRTlink 5.0 software. A circular consensus sequence (CCS) was generated from subread BAM files. Additional nucleotide errors in consensus reads were corrected using the Illumina RNAseq data with the software LoRDEC. Then all the consensus reads were aligned to the mouse reference genome ( $\mathrm{mm}$ 9) using Hisat2.

\section{Differential splicing analysis and validation}

Differential splicing events of Iso-seq data were analyzed using SUPPA2 software with the standard protocol.

The SUPPA2 software can identify the seven common modes of AS events and obtain accurate splicing change quantification between control and $\operatorname{Srsf} 10^{\mathrm{cKO}}$ samples. We used $P$-value $<0.05$ and $|\Delta \mathrm{PSI}|>0.1$ as the threshold to filter for significantly differential splicing events. Differential splicing events of NGS data were analyzed using CASH software with the standard protocol using $P$-value $<0.05$ as the threshold for filtering. For 
spliced sites between control and $\operatorname{Srsf} 10^{\mathrm{cKO}}$ samples. The primers for differentially spliced exons were designed

using Primer5. Primers were designed within constitutive exons flanking the differentially spliced exons.

Standard PCR for analysis by gel electrophoresis was performed according to the manufacturers' instructions and visualized by running on a $\%$ agarose gel. All primers were listed in the Supplementary file 2.

\section{Statistical analysis}

All experiments were performed at least three independent times. At least three independent biological samples were collected for the quantitative experiments. Quantification of positively stained cells was counted from at least three independent fields of view. Paired two-tailed Student's t-test was used for statistical analysis and data were presented as mean \pm SEM. $P$-value $<0.05$ was considered with a significant difference level. Equal variances were not formally tested. No statistical method was used to predetermine sample sizes.

\section{Data availability}

All RNA-sequencing data have been deposited to GEO with the accession number GSE190646. The following secure token has been created to allow review of record GSE190646 while it remains in private status: gbuvgeiqxjclbgf. Our work did not generate any datasets or use any previously published datasets. Source data for Figures 1, 2, 3, 4, 6, 7 and figure supplement of Figures 1, 3, 7 have been provided.

\section{Author contributions}

622 W.L. designed and performed the major experiments and wrote the manuscript. K.L. performed the data analysis of RNA-seq, AS analysis and the drawing of a pattern diagram. Z.Z. contributed to the data analysis of singlecell RNA sequencing. Q.L., Z.G., Y.X. S.S. and W.L. contributed to mouse maintenance and performed some experiments. L.L., A.G. and H.L. contributed to some statistics and analysis. Z.H., Y.H., and Y. O. contributed 
627 approved the final manuscript.

\section{Funding}

629 This study was funded by the National R \& D Program (2018YFA0107701), National Natural Science

630 Foundation of China $(31801241,31801240,81971452,81871211)$, the Natural Science Foundation of

631 Guangdong Province, China (Grant No. 2018A030313665), and the Medical Key Discipline of Guangzhou

$632(2021-2023)$.

\section{Acknowledgments}

634 We thank Shiwen Li and Xili Zhu for their technical assistance. Jian Chen and all members in Sun lab for their 635 helpful advice. We thank Mingming Fan for her guidance of MACS of spermatogonia.

\section{Competing interests}

637 The authors declare no competing or financial interests. 


\section{References}

640 1. de Rooij DG. Proliferation and differentiation of spermatogonial stem cells. Reproduction 2001, 121(3): $347-354$.

641

2. Oatley JM, Brinster RL. Spermatogonial stem cells. Methods Enzymol 2006, 419: 259-282.

3. de Rooij DG. The nature and dynamics of spermatogonial stem cells. Development 2017, 144(17): 3022-3030.

4. Song HW, Wilkinson MF. Transcriptional control of spermatogonial maintenance and differentiation. Semin Cell

9. Yeo G, Holste D, Kreiman G, Burge CB. Variation in alternative splicing across human tissues. Genome Biol 2004, 5(10): R74.

10. Soumillon M, Necsulea A, Weier M, Brawand D, Zhang X, Gu H, et al. Cellular source and mechanisms of high transcriptome complexity in the mammalian testis. Cell Rep 2013, 3(6): 2179-2190.

11. Ramskold D, Wang ET, Burge CB, Sandberg R. An abundance of ubiquitously expressed genes revealed by tissue transcriptome sequence data. PLoS Comput Biol 2009, 5(12): e1000598.

12. Green CD, Ma Q, Manske GL, Shami AN, Zheng X, Marini S, et al. A Comprehensive Roadmap of Murine Spermatogenesis Defined by Single-Cell RNA-Seq. Dev Cell 2018, 46(5): 651-667 e610.

13. Schmid R, Grellscheid SN, Ehrmann I, Dalgliesh C, Danilenko M, Paronetto MP, et al. The splicing landscape is globally reprogrammed during male meiosis. Nucleic Acids Res 2013, 41(22): 10170-10184.

14. Gan H, Cai T, Lin X, Wu Y, Wang X, Yang F, et al. Integrative proteomic and transcriptomic analyses reveal multiple post-transcriptional regulatory mechanisms of mouse spermatogenesis. Mol Cell Proteomics 2013, 12(5): 11441157.

15. Hannigan MM, Zagore LL, Licatalosi DD. Ptbp2 Controls an Alternative Splicing Network Required for Cell Communication during Spermatogenesis. Cell Rep 2017, 19(12): 2598-2612. 
bioRxiv preprint doi: https://doi org/10.1101/2022 03 06 483179; this version posted March 6,2022 . The copyright holder for this preprint (which was not certified by peer review) is the author/funder, who has granted bioRxiv a license to display the preprint in perpetuity. It is made available under aCC-BY 4.0 International license.

682

16. Legrand JMD, Chan AL, La HM, Rossello FJ, Anko ML, Fuller-Pace FV, et al. DDX5 plays essential transcriptional and post-transcriptional roles in the maintenance and function of spermatogonia. Nat Commun 2019, 10(1): 2278.

17. Xu K, Yang $\mathrm{Y}$, Feng GH, Sun BF, Chen JQ, Li YF, et al. Mettl3-mediated $m(6) A$ regulates spermatogonial differentiation and meiosis initiation. Cell Res 2017, 27(9): 1100-1114.

18. Liu W, Wang F, Xu Q, Shi J, Zhang X, Lu X, et al. BCAS2 is involved in alternative mRNA splicing in spermatogonia and the transition to meiosis. Nat Commun 2017, 8: 14182.

19. Ule J, Blencowe BJ. Alternative Splicing Regulatory Networks: Functions, Mechanisms, and Evolution. Mol Cell 2019, 76(2): 329-345.

20. Fu XD, Ares M, Jr. Context-dependent control of alternative splicing by RNA-binding proteins. Nat Rev Genet 2014, 15(10): 689-701.

21. Jeong S. SR Proteins: Binders, Regulators, and Connectors of RNA. Mol Cells 2017, 40(1): 1-9.

22. Zhou Z, Fu XD. Regulation of splicing by SR proteins and SR protein-specific kinases. Chromosoma 2013, 122(3): 191-207.

23. Shin C, Kleiman FE, Manley JL. Multiple properties of the splicing repressor SRp38 distinguish it from typical SR proteins. Mol Cell Biol 2005, 25(18): 8334-8343.

24. Shin C, Feng Y, Manley JL. Dephosphorylated SRp38 acts as a splicing repressor in response to heat shock. Nature 2004, 427(6974): 553-558.

25. Shin C, Manley JL. The SR protein SRp38 represses splicing in M phase cells. Cell 2002, 111(3): 407-417.

26. Feng $\mathrm{Y}$, Valley MT, Lazar J, Yang AL, Bronson RT, Firestein S, et al. SRp38 regulates alternative splicing and is required for $\mathrm{Ca}(2+)$ handling in the embryonic heart. Dev Cell 2009, 16(4): 528-538.

27. Li H, Cheng Y, Wu W, Liu Y, Wei N, Feng X, et al. SRSF10 regulates alternative splicing and is required for adipocyte differentiation. Mol Cell Biol 2014, 34(12): 2198-2207.

28. Zhou X, Wu W, Li H, Cheng Y, Wei N, Zong J, et al. Transcriptome analysis of alternative splicing events regulated by SRSF10 reveals position-dependent splicing modulation. Nucleic Acids Res 2014, 42(6): 4019-4030.

29. Wei N, Cheng Y, Wang Z, Liu Y, Luo C, Liu L, et al. SRSF10 Plays a Role in Myoblast Differentiation and Glucose Production via Regulation of Alternative Splicing. Cell Rep 2015, 13(8): 1647-1657.

30. Gallardo T, Shirley L, John GB, Castrillon DH. Generation of a germ cell-specific mouse transgenic Cre line, VasaCre. Genesis 2007, 45(6): 413-417. 
bioRxiv preprint doi: https://doi.org/10.1101/2022.03 06 483179; this version posted March 6 , 2022. The copyright holder for this preprint (which was not certified by peer review) is the author/funder, who has granted bioRxiv a license to display the preprint in perpetuity. It is made available under aCC-BY 4.0 International license.

31. Buaas FW, Kirsh AL, Sharma M, McLean DJ, Morris JL, Griswold MD, et al. Plzf is required in adult male germ cells for stem cell self-renewal. Nat Genet 2004, 36(6): 647-652.

32. Ahmed EA, de Rooij DG. Staging of mouse seminiferous tubule cross-sections. Methods Mol Biol 2009, 558: 263277.

33. Niedenberger BA, Busada JT, Geyer CB. Marker expression reveals heterogeneity of spermatogonia in the neonatal mouse testis. Reproduction 2015, 149(4): 329-338.

34. Busada JT, Chappell VA, Niedenberger BA, Kaye EP, Keiper BD, Hogarth CA, et al. Retinoic acid regulates Kit translation during spermatogonial differentiation in the mouse. Dev Biol 2015, 397(1): 140-149.

35. Sada A, Suzuki A, Suzuki H, Saga Y. The RNA-binding protein NANOS2 is required to maintain murine spermatogonial stem cells. Science 2009, 325(5946): 1394-1398.

36. Grasso M, Fuso A, Dovere L, de Rooij DG, Stefanini M, Boitani C, et al. Distribution of GFRA1-expressing spermatogonia in adult mouse testis. Reproduction 2012, 143(3): 325-332.

37. de Rooij DG, Grootegoed JA. Spermatogonial stem cells. Curr Opin Cell Biol 1998, 10(6): 694-701.

38. Nagano R, Tabata S, Nakanishi Y, Ohsako S, Kurohmaru M, Hayashi Y. Reproliferation and relocation of mouse male germ cells (gonocytes) during prespermatogenesis. Anat Rec 2000, 258(2): 210-220.

39. Oatley JM, Avarbock MR, Telaranta Al, Fearon DT, Brinster RL. Identifying genes important for spermatogonial stem cell self-renewal and survival. Proc Natl Acad Sci U S A 2006, 103(25): 9524-9529.

40. Becht E, Mclnnes L, Healy J, Dutertre CA, Kwok IWH, Ng LG, et al. Dimensionality reduction for visualizing singlecell data using UMAP. Nat Biotechnol 2018.

41. Trincado JL, Entizne JC, Hysenaj G, Singh B, Skalic M, Elliott DJ, et al. SUPPA2: fast, accurate, and uncertaintyaware differential splicing analysis across multiple conditions. Genome Biol 2018, 19(1): 40.

42. Wu W, Zong J, Wei N, Cheng J, Zhou X, Cheng Y, et al. CASH: a constructing comprehensive splice site method for detecting alternative splicing events. Brief Bioinform 2018, 19(5): 905-917.

43. Zhou X, Li X, Cheng Y, Wu W, Xie Z, Xi Q, et al. BCLAF1 and its splicing regulator SRSF10 regulate the tumorigenic potential of colon cancer cells. Nat Commun 2014, 5: 4581.

44. Griswold MD. Spermatogenesis: The Commitment to Meiosis. Physiol Rev 2016, 96(1): 1-17.

45. Elliott DJ, Grellscheid SN. Alternative RNA splicing regulation in the testis. Reproduction 2006, 132(6): 811-819.

46. Oatley MJ, Kaucher AV, Racicot KE, Oatley JM. Inhibitor of DNA binding 4 is expressed selectively by single 
bioRxiv preprint doi: https://doi.org/10.1101/2022.03 06 483179; this version posted March 6,2022 . The copyright holder for this preprint (which was not certified by peer review) is the author/funder, who has granted bioRxiv a license to display the preprint in perpetuity. It is made available under aCC-BY 4.0 International license.

spermatogonia in the male germline and regulates the self-renewal of spermatogonial stem cells in mice. Biol Reprod 2011, 85(2): 347-356.

47. Chen C, Ouyang W, Grigura V, Zhou Q, Carnes K, Lim H, et al. ERM is required for transcriptional control of the spermatogonial stem cell niche. Nature 2005, 436(7053): 1030-1034.

48. Falender AE, Freiman RN, Geles KG, Lo KC, Hwang K, Lamb DJ, et al. Maintenance of spermatogenesis requires TAF4b, a gonad-specific subunit of TFIID. Genes Dev 2005, 19(7): 794-803.

49. Hao J, Yamamoto M, Richardson TE, Chapman KM, Denard BS, Hammer RE, et al. Sohlh2 knockout mice are malesterile because of degeneration of differentiating type A spermatogonia. Stem Cells 2008, 26(6): 1587-1597.

50. Ballow D, Meistrich ML, Matzuk M, Rajkovic A. Sohlh1 is essential for spermatogonial differentiation. Dev Biol 2006, 294(1): 161-167.

51. de Rooij DG, Russell LD. All you wanted to know about spermatogonia but were afraid to ask. J Androl 2000, 21(6): 776-798.

52. Zagore LL, Sweet TJ, Hannigan MM, Weyn-Vanhentenryck SM, Jobava R, Hatzoglou M, et al. DAZL Regulates Germ Cell Survival through a Network of PolyA-Proximal mRNA Interactions. Cell Rep 2018, 25(5): 1225-1240 e1226.

53. Mikedis MM, Fan Y, Nicholls PK, Endo T, Jackson EK, Cobb SA, et al. DAZL mediates a broad translational program regulating expansion and differentiation of spermatogonial progenitors. Elife 2020, 9.

54. Lin Y, Gill ME, Koubova J, Page DC. Germ cell-intrinsic and -extrinsic factors govern meiotic initiation in mouse embryos. Science 2008, 322(5908): 1685-1687.

55. Xu X, Tan X, Lin Q, Schmidt B, Engel W, Pantakani DV. Mouse Dazl and its novel splice variant functions in translational repression of target mRNAs in embryonic stem cells. Biochim Biophys Acta 2013, 1829(5): 425-435.

56. Yoshinaga K, Nishikawa S, Ogawa M, Hayashi S, Kunisada T, Fujimoto T, et al. Role of c-kit in mouse spermatogenesis: identification of spermatogonia as a specific site of c-kit expression and function. Development 1991, 113(2): 689-699.

57. Crosier PS, Ricciardi ST, Hall LR, Vitas MR, Clark SC, Crosier KE. Expression of isoforms of the human receptor tyrosine kinase c-kit in leukemic cell lines and acute myeloid leukemia. Blood 1993, 82(4): 1151-1158.

58. Caruana G, Cambareri AC, Ashman LK. Isoforms of C-KIT differ in activation of signalling pathways and transformation of NIH3T3 fibroblasts. Oncogene 1999, 18(40): 5573-5581.

59. Sakuma Y, Sakurai S, Oguni S, Hironaka M, Saito K. Alterations of the c-kit gene in testicular germ cell tumors. Cancer Sci 2003, 94(6): 486-491.

60. Hofmann MC. Gdnf signaling pathways within the mammalian spermatogonial stem cell niche. Mol Cell 
bioRxiv preprint doi: https://doi.org/10.1101/2022.03 06.483179. this version posted March 6.2022 The copyriaht holder for this preprint (which was not certified by peer review) is the author/funder, who has granted bioRxiv a license to display the preprint in perpetuity. It is made available under aCC-BY 4.0 International license. 


\section{Figure Legends}

Figure $1 \mathrm{Srsf10}$ is required for spermatogenesis and male fertility. A. Schematic diagram showing the deletion of $\operatorname{Srsf10}$ exon 3 and generation of $\operatorname{Srsf} 10^{\mathrm{cKO}}$ by Vasa-Cre mediated recombination in male germ cells as early as E15. B. IF staining for SRSF10 in the control and Srsf1 $0^{\mathrm{cKO}}$ testes of P8 mice. White circles denote the SRSF10 null germ cells. MVH (a germ cell marker) was co-stained to indicate the location of germ cells. The DNA was stained with Hoechst 33342. Scale bar, $20 \mu \mathrm{m}$. C. Morphological analysis of the adult testes of control and Srsf1 $0^{\mathrm{cKO}}$ mice. D. Testis weight of adult control and Srsf $10^{\mathrm{cKO}}$ mice $(* * * P<0.001, \mathrm{n}=6)$. Error bars represent s.e.m. E. The ratio of testes to body weight in adult control and $\operatorname{Srsf} 10^{\mathrm{cKO}}$ mice $(* * * P<0.001, \mathrm{n}$ =4). Error bars represent s.e.m. F. Hematoxylin and eosin (H\&E) staining of testes in adult control and Srsf $10^{\text {cKO }}$ mice. Scale bar, $50 \mu \mathrm{m}$. G. H\&E staining of the cauda epididymis in adult control and $S r s f 10^{\mathrm{cKO}}$ mice. Scale bar, $50 \mu \mathrm{m}$. H. Co-staining for MVH and PLZF (undifferentiated spermatogonia marker) in adult testes in control

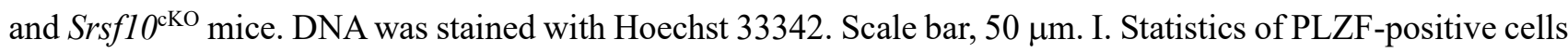
per tubule of adult testes in control and $\operatorname{Srsf} 10^{\mathrm{cKO}}$ mice. At least 200 tubules were counted from at least three different mice. $* * * P<0.001$. Error bars represent s.e.m.

Figure 1- figure supplement $1 \mathrm{Srsf10}$ is required for the first wave of spermatogenesis. A. Morphological analysis of the control and $\operatorname{Srsf1} 10^{\mathrm{cKO}}$ testes at P35. B. Testes weight of P35 control and $\operatorname{Srsf} 10^{\mathrm{cKO}}$ mice $(* * * P<$ $0.001, \mathrm{n}=3)$. Error bars represent s.e.m. C. Hematoxylin and eosin $(\mathrm{H} \& \mathrm{E})$ staining of P35 testes in control and

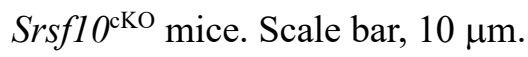

Figure 1-source data 1 The testis weight and the number of $\mathrm{PLZF}^{+}$cells of adult male mice.

Figure 1- figure supplement 1-source data 1 The testis weight of one-month-old male mice.

Fig. 2 Srsf10 deficient germ cells fail to initiate meiosis. A. H\&E staining of control and $\operatorname{Srsf} 10^{\mathrm{cKO}}$ testes at 
P8, P10, P12 and P15. Spermatogenic cells were shown in cross-sections of seminiferous tubules from control

and $\operatorname{Srsf} 10^{\mathrm{cKO}}$ testes. Scale bar, $10 \mu \mathrm{m}$. Red arrows indicate the representative stages of the spermatocytes. A,

type A spermatogonia; In, intermediate spermatogonia; B, type B spermatogonia; L, leptotene spermatocytes;

Z, zygotene spermatocytes; P, pachytene spermatocytes. Black arrows indicate apoptotic cells. Scale bar, $10 \mu \mathrm{m}$.

$\mu \mathrm{m}$. C. Statistics of the ratio of SCP3-positive tubules in control and $\operatorname{Srsf} 10^{\mathrm{cKO}}$ testes at P12. At least 500 tubules were counted from at least three different mice. ${ }^{* * *} P<0.001$. Error bars represent s.e.m. D.

Immunofluorescence staining for $\gamma \mathrm{H} 2 \mathrm{AX}$ in control and $\operatorname{Srsf} 10^{\mathrm{cKO}}$ testes at P12. Scale bar, $20 \mu \mathrm{m}$. E. Western

blot analyses of $\gamma \mathrm{H} 2 \mathrm{AX}$ in control and $\operatorname{Srsf} 10^{\mathrm{cKO}}$ testes at P8, P10 and P12. $\beta$-actin was used as the loading

control.

Figure 2-source data 1 The ratio of $\mathrm{SCP} 3^{+}$tubules in $\mathrm{P} 12$ testes.

Fig. 3 Srsf10 depletion impairs the expansion and differentiation of progenitor spermatogonia. A.

870 Schematic diagram showing the progression of mitosis phase of spermatogonia from spermatogonial stem cells

871 (SSCs) to differentiating spermatogonia. The expression of representative markers at each stage is also shown.

872 B. Western blot analyses of PLZF and MVH in control and Srsf $10^{\text {cKO }}$ testes at P8, P10 and P12. $\beta$-actin was

used as the loading control. C. Left, immunofluorescence co-staining for PLZF and MVH in control and

$874 S r s f 10^{\mathrm{cKO}}$ testes at P8. Scale bar, $50 \mu \mathrm{m}$. Right, quantification of MVH-positive and PLZF-positive cells

$875\left(\mathrm{MVH}^{+} \mathrm{PLZF}^{+}\right)$per tubule or MVH-positive but PLZF-negative $\left(\mathrm{MVH}^{+} \mathrm{PLZF}^{+}\right)$cells per tubule in control and

876 Srsf $10^{\mathrm{cKO}}$ testes at P8. At least 1000 tubules were counted from 6 different mice. ${ }^{* * *} P<0.001 . * P<0.05$. Error

877 bars represent s.e.m. D. Whole-mount staining for KIT in control and Srsf10 ${ }^{\text {cKO }}$ testes at P8. Scale bar, $20 \mu \mathrm{m}$.

878 E. Left, immunofluorescence co-staining for PLZF and MVH in control and Srsf $10^{\text {cKO }}$ testes at P6. Scale bar,

$87950 \mu \mathrm{m}$. Right, quantification of $\mathrm{MVH}^{+} \mathrm{PLZF}^{-}$cells or $\mathrm{MVH}^{+} \mathrm{PLZF}^{+}$cells per tubule in control and $\operatorname{Srsf} 10^{\mathrm{cKO}}$ 
testes at P6. At least 1000 tubules were counted from at least 3 different mice. $* P<0.05$. ns represents no

significance. Error bars represent s.e.m. F. Whole-mount staining for GFR $\alpha 1$ in control and $\operatorname{Srsf} 10^{\text {cKO }}$ testes at

P6. Scale bar, $20 \mu \mathrm{m}$. G. Left, immunofluorescence staining for MVH in control and $\operatorname{Srsf1} 10^{\mathrm{cKO}}$ testes at P3.

Scale bar, $50 \mu \mathrm{m}$. Right, quantification of MVH-positive cells per tubule in control and $\operatorname{Srsf10^{\mathrm {cKO}}}$ testes at P3.

At least 1000 tubules were counted from at least 4 mice. ns represents no significance. Error bars represent

s.e.m. H. Quantification of PLZF-positive cells per tubule in control and control and Srsf $10^{\text {cKO }}$ testes at P3, P6,

P8 and P12. P3 are counted with MVH-positive cells. $* P<0.05 . * * * P<0.001$. ns represents no significance.

Error bars represent s.e.m.

Figure 3-figure supplement 1 Spermatogonia development is impaired in $S r s f 10^{\text {cKo }}$ testes. A.

Immunofluorescence co-staining for PLZF and MVH in control and Srsf $10^{\text {cKO }}$ testes at P12. Scale bar, $20 \mu \mathrm{m}$.

B. Quantification of PLZF-positive cells per tubule in control and $S r s f 10^{\text {cKO }}$ testes at P12. At least 300 tubules

were counted from at least 3 different mice. ${ }^{* * *} P<0.001$, Error bars represent s.e.m. C. Western blot analyses

of MVH and PLZF in control and Srsf $10^{\text {cKO }}$ testes at P3, P6 and P8. $\beta$-actin was used as the loading control.

Figure 3-source data 1 Quantification of MVH/PLZF-positive cells per tubule in control and $S r s f 10^{\mathrm{cKO}}$ testes at P3, P6, P8 and P12.

Figure 3- figure supplement 1-source data 1 Quantification of PLZF-positive cells per tubule in P12 control and $\operatorname{Srsf1} 10^{\mathrm{cKO}}$ testes.

Fig. 4 Srsf10 deficiency alters expression patterns of genes involved in progenitor spermatogonia. A.

Scatter plots showing the expression of genes in control and $S r s f 10^{\text {cKO }}$ testes at P3, P6 and P8. Blue dots 9005 , fold change $>=2, P<0.01)$. Grey dots represent unchanged genes. B. Venn diagram depicting the overlap of 
P6 and P8 Srsf10 ${ }^{\mathrm{cKO}}$ testes and genes involved in specific GO terms were shown on the right. C. Hierarchical

clustering of two replicates of control and Srsf10 $0^{\mathrm{cKO}}$ testes at P3, P6 and P8 based on the expression of

spermatogonia specific genes ${ }^{12}$. Note the closer relationship between P8 Srsf10 ${ }^{\mathrm{cKO}}$ and P6 control testes. D.

Heatmap showing the mRNA abundance of genes functioning in SSCs (Bcl6b, Etv5, Lhx 1, Cd82, Bmi1, T, Id4

and Gfra1), progenitors (Lin28a, Nanos3, Neurog3, Pou5f1, Sohlh1 and Sox3), undifferentiated spermatogonia

(Sall4 and Zbtb16) and differentiating spermatogonia (Dmrtb1, Dnmt3b, Kit, Stra8 and Prdm9). E. Quantitative

RT-PCR validation of the expression of genes involved in SSC, progenitors, undifferentiated spermatogonia and

differentiating spermatogonia in control and $\operatorname{Srsf} 10^{\mathrm{cKO}}$ testes at P6. $\beta$-actin was used as the internal control. *P

$<0.05, * * P<0.01, * * * P<0.001$; ns, no significance. Error bars represent s.e.m.

Figure 4-figure supplement 1 Systematical analysis of the down-regulated genes from P3 to P8. A.

Heatmap shows the mRNA abundance of all the down-regulated genes from P3 to P8. B. RNA-seq results of

the expression level of selected marker genes related to spermatogonial stem cells, progenitor cells and

undifferentiated spermatogonia from P3 to P8.

Figure 4-source data 1 The expression of marker genes in control and Srsf $10^{\mathrm{cKO}}$ testes at P6.

Fig. 5 scRNA-seq defines the transcriptome-wide signatures of spermatogonia development in $\operatorname{Srsf10}$ cKo

testes at P8. A. Schematic illustration of the workflow for scRNA-seq analysis. B. UMAP clustering analysis 
922 in combined, control and $S r s f 10^{\mathrm{cKO}}$ groups. F. The expression of selected marker genes in each subtype in control 923 and $\operatorname{Sr}$ f $10^{\mathrm{cKO}}$ samples.

Figure 5-figure supplement 1 The expression pattern of spermatogonial maker genes in the subtypes of

control and $\operatorname{Srsf10^{\mathrm {cKO}}}$ samples. A. Gene expression patterns of marker genes corresponding to each cellular state on the UMAP plots. B. UMAP plots of the expression patterns of selected marker genes in each subtype in control and $\operatorname{Sr} s f 0^{\mathrm{cKO}}$ samples.

Fig. 6 Srsf10 depletion impairs the cell cycle and proliferation of undifferentiated spermatogonia. A.

Volcano plot showing the significantly differentially expressed transcripts in the USSC1 subtype in $\operatorname{Sr} f 10^{\text {cKO }}$ compared with the control samples. Blue dots represent significantly down-regulated transcripts, while red dots show significantly up-regulated transcripts ( $\log 2$ fold change $>=0.25, P<0.01)$. Grey dots represent unchanged transcripts. B. Gene ontology of up-regulated and down-regulated genes in $\operatorname{Srsf} 10^{\mathrm{cKO}}$ USSC1 subtype and representative genes in up- and down-regulated groups are shown. C. Violin plots showing the expression of functional genes involved in cell cycle and spermatogenesis in the USSC1 subtype in control and Srsf $10^{\text {cKO }}$ groups. D. Immunofluorescence co-staining for the mitosis marker KI67 and PLZF in control and Srsf10 $0^{\text {cKO }}$ testes at P6. The DNA was stained with Hoechst 33342. Double-positive cells $\left(\mathrm{KI} 7^{+} \mathrm{PLZF}^{+}\right)$are indicated by the white arrowhead. Scale bar, $50 \mu \mathrm{m}$. E. Quantification of the ratio of $\mathrm{KI}^{+} 7^{+} \mathrm{PLZF}^{+}$cells in $\mathrm{PLZF}^{+}$cells in control and Srsf $10^{\mathrm{cKO}}$ testes at P6. ns, no significance. Error bars represent s.e.m. F. Immunofluorescence costaining for the EdU and PLZF in control and $\operatorname{Srsf} 10^{\mathrm{cKO}}$ testes at P6. Control and $\operatorname{Srsf} 10^{\mathrm{cKO}}$ mice were treated with EdU for 4 hours. The DNA was stained with Hoechst 33342. White arrowheads indicate the representative EdU $^{+}$PLZF ${ }^{+}$cells. Scale bar, $20 \mu \mathrm{m}$. G. Quantification of the ratio of EdU'PLZF ${ }^{+}$cells in $\mathrm{PLZF}^{+}$cells of control and $\operatorname{Srsf} 10^{\text {cKO }}$ testes at P6. At least 500 tubules were counted from at least 7 different mice. ${ }^{*} P<0.05$, Error 
and PLZF in control and Srsf10 ${ }^{\mathrm{cKO}}$ testes at P8. The DNA was stained with Hoechst 33342. Scale bar, $50 \mu \mathrm{m}$. I.

Quantification of the number of $\mathrm{CAP3}^{+} \mathrm{PLZF}^{+}$cells per tubule in control and $\operatorname{Srsf} 10^{\mathrm{cKO}}$ testes at P8. At least 300

tubules were counted from at least 5 different mice. ${ }^{* *} P<0.01$, Error bars represent s.e.m.

Figure 6-figure supplement 1 The expression pattern of key genes of the USSC1 subtype in control and

Srsf10 ${ }^{\text {cko }}$ groups. The violin plots show the expression level of cell cycle key genes and spermatogenesis-

related genes of the USSC1 subtype in control and $\operatorname{Srsf} 10^{\mathrm{cKO}}$ groups.

Figure 6-figure supplement 2 Identification of the differential expression genes in USSC2, DSSC1 and

DSSC2 subtypes between control and $S r s f 10^{\text {cko }}$ samples. A, C and E. Volcano plot of significantly differentially expressed transcripts of the USSC2, DSSC1 and DSSC2 subtype, respectively, in Srsf $10^{\text {cKO }}$ sample compared with the control. Blue dots represent significantly down-regulated transcripts, while red dots show

significantly up-regulated transcripts ( $\log 2$ fold change $>=0.25, \quad<0.01)$. Grey dots illustrated unchanged transcripts. B, D and F. Gene ontology of up-regulated and down-regulated genes in Srsf $10^{\text {cKO }}$ USSC2, DSSC1 and DSSC2 subtype, respectively.

Figure 6-source data 1 Quantification of the ratio of $\mathrm{KI}_{6} 7^{+} \mathrm{PLZF}^{+}$cells, $\mathrm{EdU}^{+} \mathrm{PLZF}^{+}$cells and $\mathrm{CAP} 3^{+} \mathrm{PLZF}^{+}$ cells in $\mathrm{PLZF}^{+}$cells in control and $\operatorname{Srsf10^{\mathrm {cKO}}}$ testes.

Fig. 7 SrsflO is required for normal splicing of key genes involved in the cell cycle and germ cell

development. A. Schematic illustration of the workflow for the enrichment of $\mathrm{THY} 1^{+}$spermatogonia for transcriptome analysis and alternative splicing analysis using Iso-seq. B. Seven AS events were significantly affected by depletion of Srsf10 in the spermatogonia at P6. Splicing events affected by depletion of Srsf10 were analyzed using SUPPA2 software $(P<0.05$ and $\mid \Delta$ PSI $\mid>=0.1)$. C. Scatter plot showing the significantly 
AS events $(\triangle \mathrm{PSI}<=-0.1)$, while red dots show significantly up-regulated AS events ( $\Delta$ PSI $>=0.1)$. D. Gene

ontology terms for genes with significantly affected AS events and representative genes involved in cell cycle

and spermatogenesis are shown. E. Visualization and validation of the differentially spliced genes in control and

Srsf10 depleted spermatogonia. Tracks from IGV are shown for selected candidate genes (left). Differentially

spliced exons are shaded. Schematics of alternative splicing events are shown (blue and yellow rectangles)

(right). Changes in "percent spliced in (PSI)" between control and Srsf $10^{\mathrm{cKO}}$ spermatogonia are shown below

splicing schematics ( $\triangle \mathrm{PSI})$. SE, Skipped exon, A5SS, Alternative 5' splice sites, AL, Alternative last exon, A3SS,

972 Alternative 3' splice sites.

Figure 7-figure supplement 1 Sorting strategies for $\mathrm{THY}^{+}$spermatogonia in control and $S r s f 10^{\text {cKO }}$ testes

at P6. A. Gating strategy for identifying $\mathrm{THY} 1^{+}$spermatogonia from P6 testes. FSC vs SSC gating was used to

clean up the debris and dead cells. The percentage of THY $1^{+}$cells in the unsorted and sorted groups corresponds

to 21.9 and $66.0 \%$, respectively. B. Immunofluorescence staining for PLZF in the unsorted and sorted groups.

Scale bar, $20 \mu \mathrm{m}$. C. Quantitative RT-PCR analysis of Srsf10 expression in the sorted THY1 ${ }^{+}$spermatogonia from control and Srsf10 $0^{\mathrm{cKO}}$ testes at P6. -actin was used as the internal control. *** $\quad<0.001$, Error bars represent s.e.m. D. Western blot analyses of SRSF10 expression in the sorted THY1 $1^{+}$spermatogonia from control and $\operatorname{Sr} f 10^{\text {cKO }}$ testes at P6. -actin was used as the loading control.

Figure 7-figure supplement 2 Analysis of the transcriptome of $\mathrm{THY1}^{+}$spermatogonia enriched from

control and $\operatorname{Srsf10^{\mathrm {cKO}}}$ testes at P6. A. Scatter plots showing the expression of genes in $\mathrm{THY}^{+}$spermatogonia

enriched from control and $\operatorname{Sr} s \mathrm{f} 10^{\mathrm{cKO}}$ testes at P6. Blue dots represent significantly down-regulated genes, while red dots show significantly up-regulated genes (FPKM $>=2$, fold change $>=1.5, \quad<0.01$ ). Grey dots represent unchanged genes. B. Gene ontology of up-regulated and down-regulated genes in $\operatorname{Srsf} 10^{\mathrm{cKO}} \mathrm{THY} 1^{+}$ spermatogonia. 
spermatogonia. A. Statistically analysis of the base number of the excluded or included exons (multiple of 3,

$=3 \mathrm{n}$ and not multiple of $3, \neq 3 \mathrm{n})$. B. Take Dazl, Nasp and $C d c 7$ for example to show the outcomes of abnormal

skipped 3n base number exons. C. Take Bora, Kat7 and Clk1 for example to analyze the outcomes of abnormal

skipped $\neq 3$ n base number exons.

Figure 7-figure supplement 4 Visualization and validation of some differentially spliced functional genes

in control and $S r s f 10$ depleted spermatogonia. A. Seven AS events were significantly affected by depletion

of Srsf10 in the NGS data using CASH software analysis. $(\quad<0.05)$. B. Venn diagram depicting the overlap

of significantly affected AS genes between NGS data using CASH and Iso-seq data using SUPPA2. Gene

ontology (GO) terms of the 59 shared genes involved in specific functional terms which were shown on the

right. C. Tracks from IGV are shown for selected candidate genes (left). Differentially spliced exons are shaded.

Schematics of alternative splicing events are shown (blue and yellow rectangles) (right). Changes in "percent spliced in (PSI)" between control and Srsf10 $0^{\mathrm{cKO}}$ spermatogonia are shown below splicing schematics ( $\left.\Delta \mathrm{PSI}\right)$.

$\mathrm{AL}$, Alternative last exon.

Figure 7-source data 1 Differential alternative splicing events in the Iso-seq data using SUPPA2 analysis.

1003 Figure 7-source data 2 Relative expression of Kit in control and $\operatorname{srsf} 10^{\mathrm{cKO}}$ spermatogonia.

1004 Figure 7-figure supplement 1-source data 1 Relative mRNA expression of Srsf10 in enriched cells.

1005 Figure 7-figure supplement 3-source data 1 Analysis the skipped exon events.

1006 Figure 7-figure supplement 4-source data 1 Differential alternative splicing events in the NGS-seq data using 
bioRxiv preprint doi: https://doi.org/10.1101/2022.03 06.483179. this version posted March 6 , 2022. The copyright holder for this preprint (which was not certified by peer review) is the author/funder, who has granted bioRxiv a license to display the preprint in perpetuity. It is made available under aCC-BY 4.0 International license.

1008 Fig. 8 Model of SRSF10-mediated AS regulation in the development of undifferentiated spermatogonia.

1009 In the control testes, SRSF10 promotes the expansion of progenitor spermatogonia and subsequent 1010 differentiation of spermatogonia. In the absence of SRSF10, the alternative splicing (AS) defects of key genes 1011 involved in spermatogenesis and cell cycle impair the expansion of progenitor spermatogonia, leading to the 1012 decreased number of undifferentiated spermatogonia and nearly absence of differentiating spermatogonia.

1013 Table 1-source data 1: The fertility of Srsf10cKO male mice. 
bioRxiv preprint doi: https://doi.org/10.1101/2022.03.06.483179; this version posted March 6, 2022. The copyright holder for this preprint (which was not certified by peer review) is the author/funder, who has granted bioRxiv a license to display the preprint in perpetuity. It is Figure 1 made available under aCC-BY 4.0 International license.

A

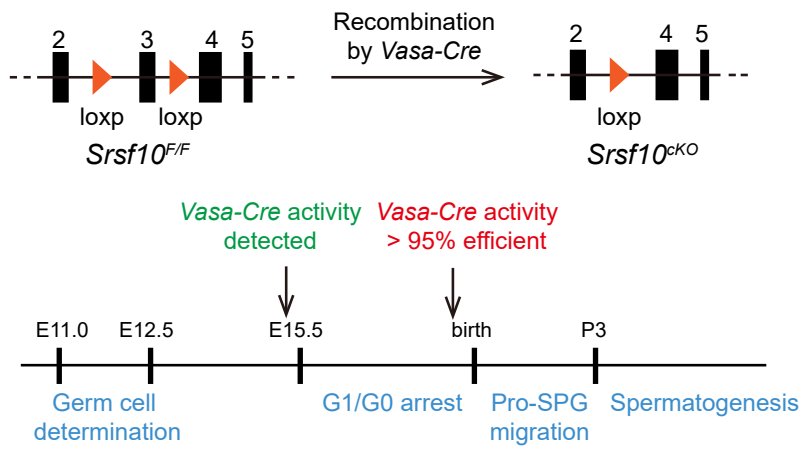

B

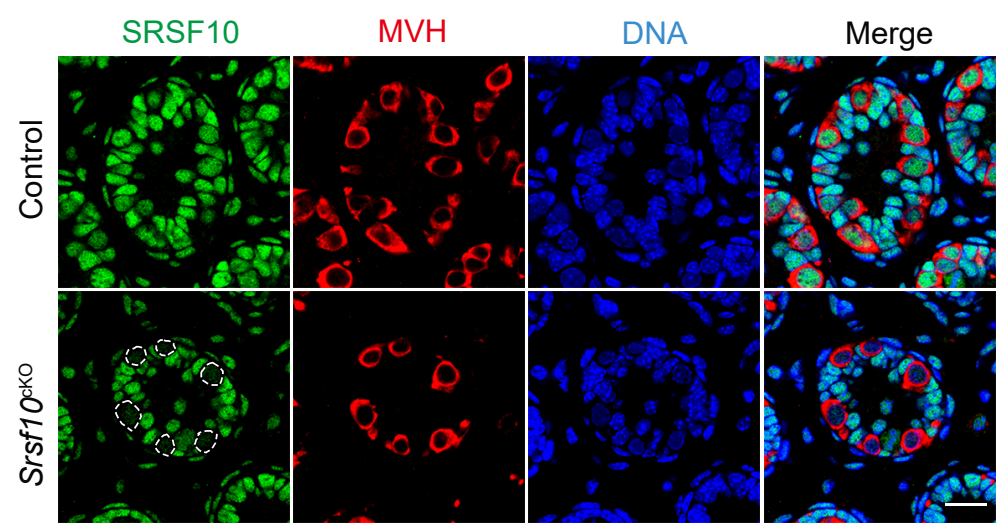

C

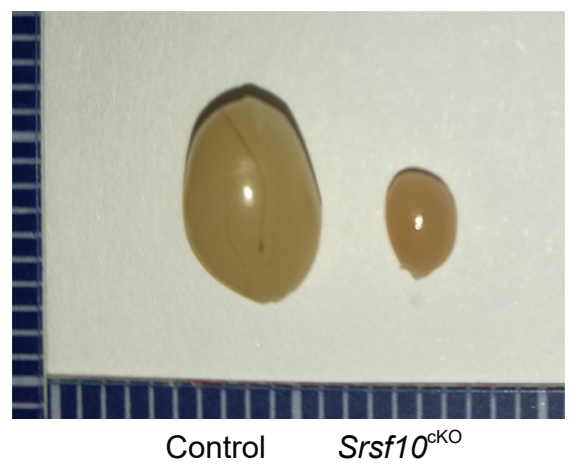

$\mathrm{F}$
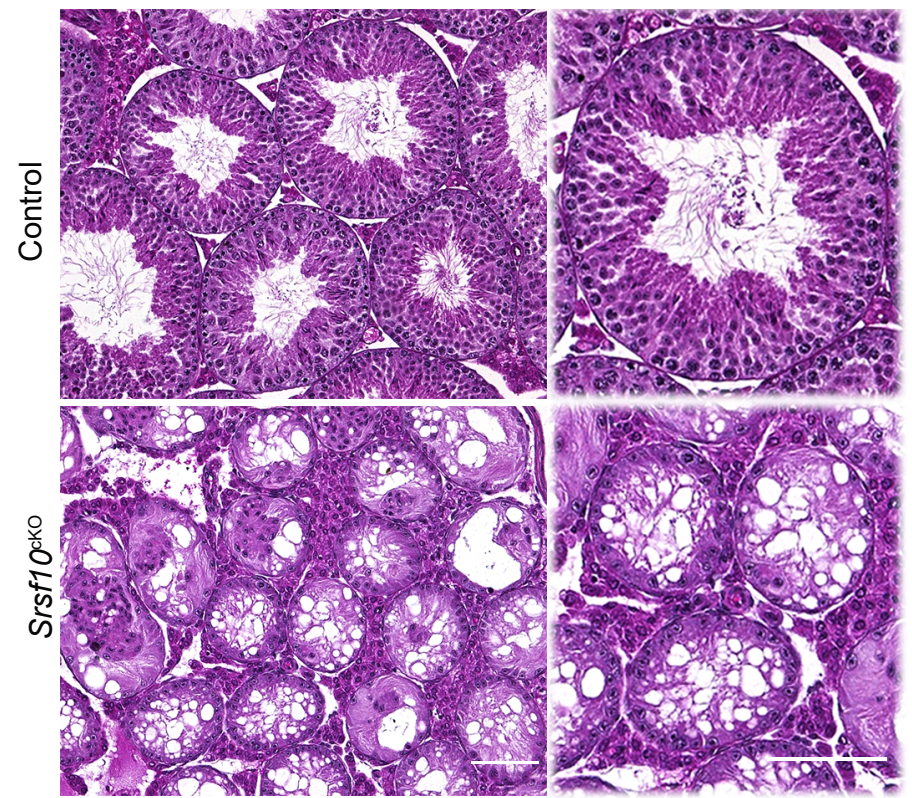

$\mathrm{D}$

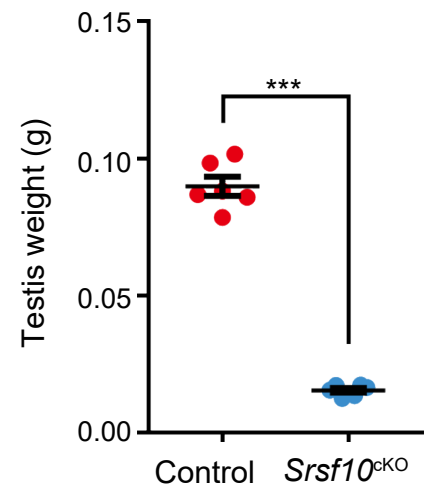

$E$

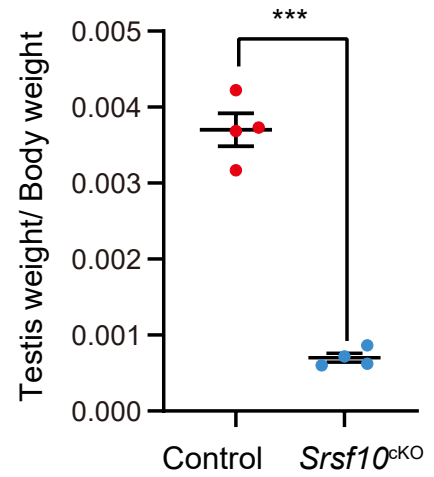

G

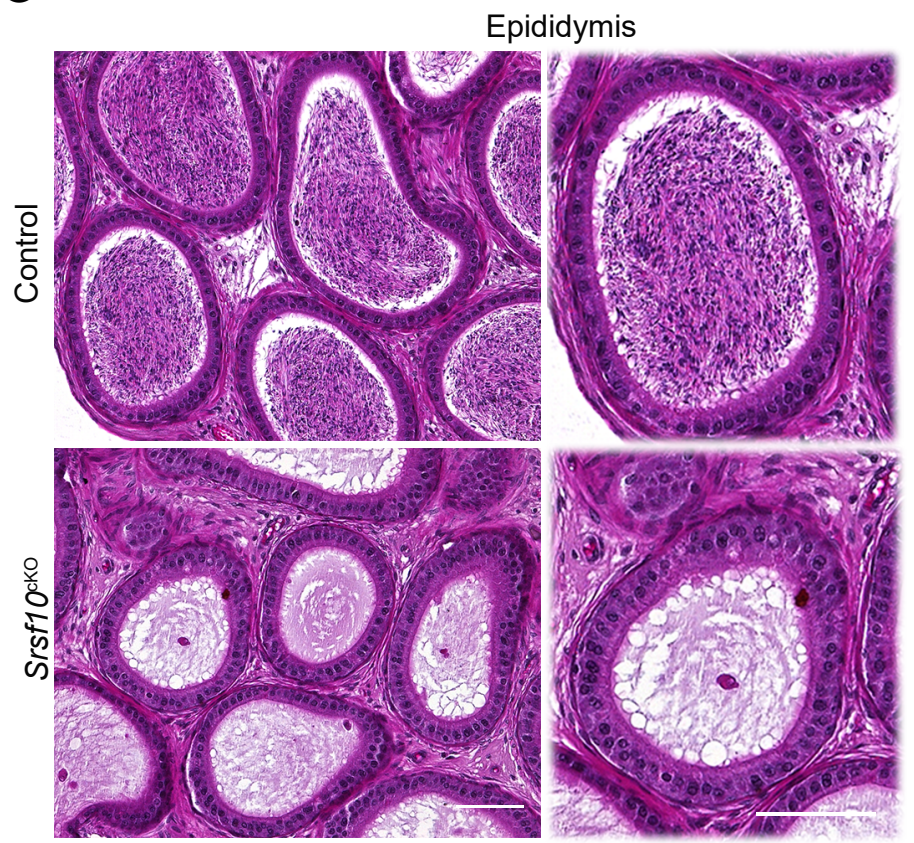

$\mathrm{H}$

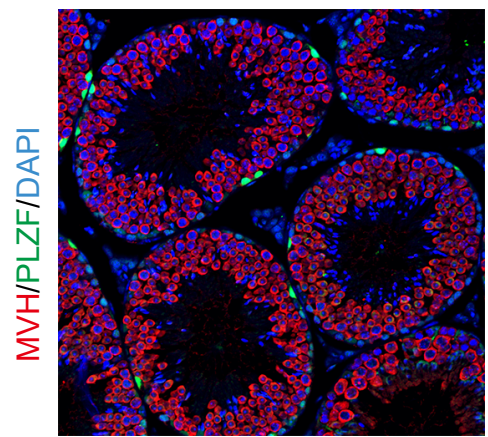

Control

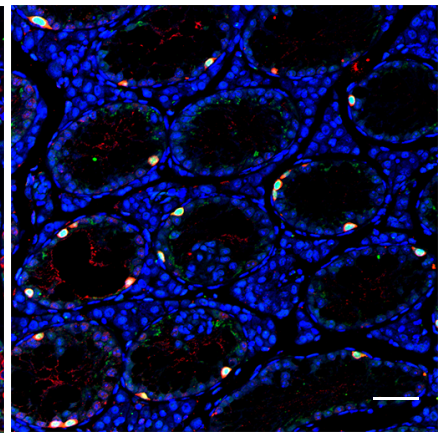

Srsf10 cko
I

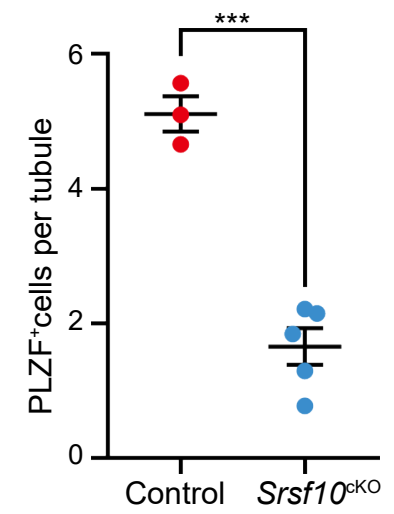


Figure 2

A

P8

P10

P12

P15
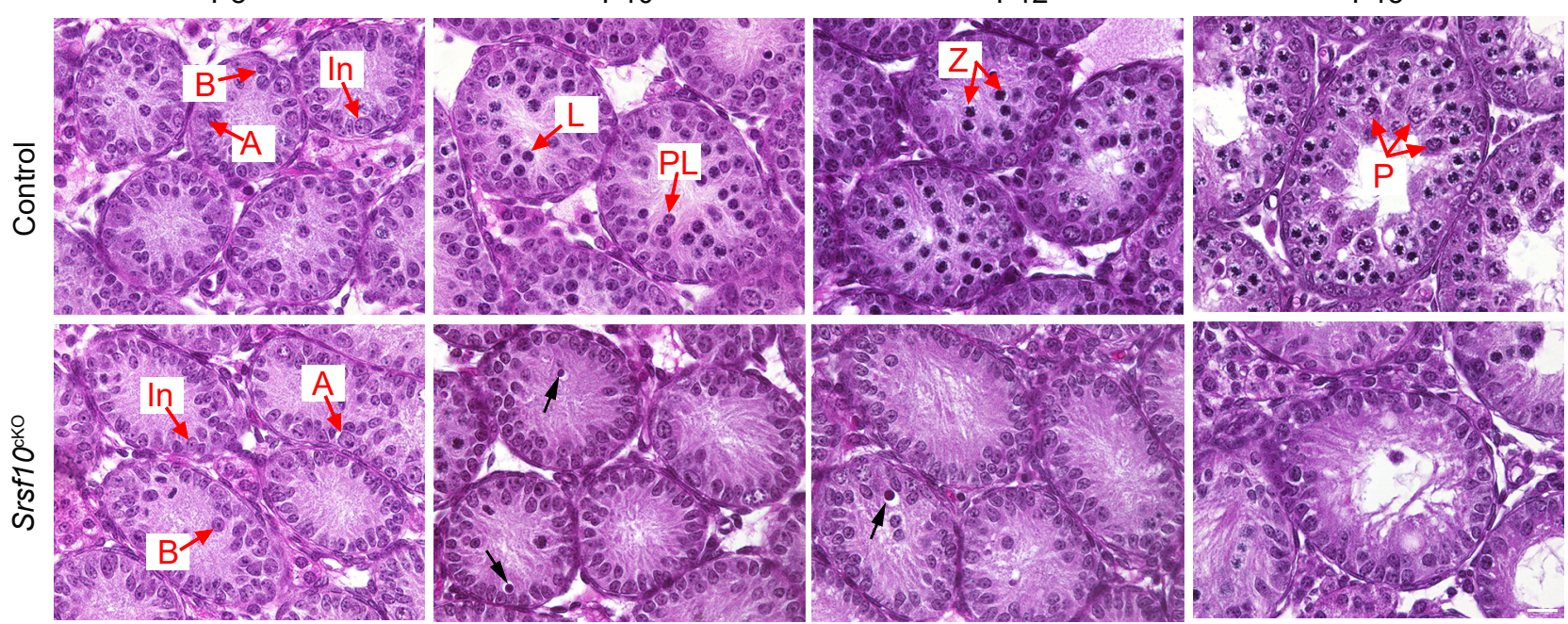

B
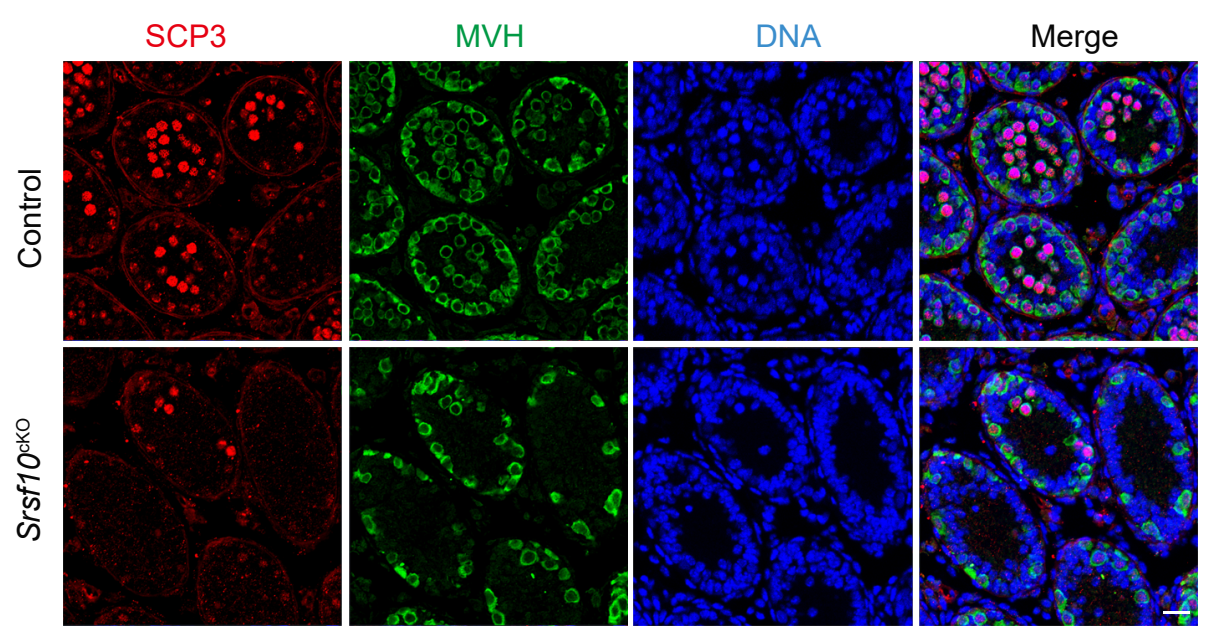

C

D

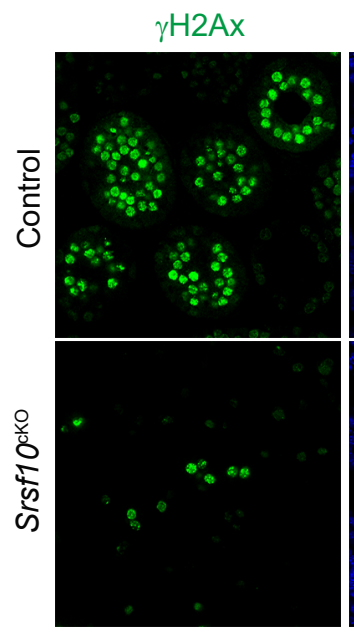

DNA

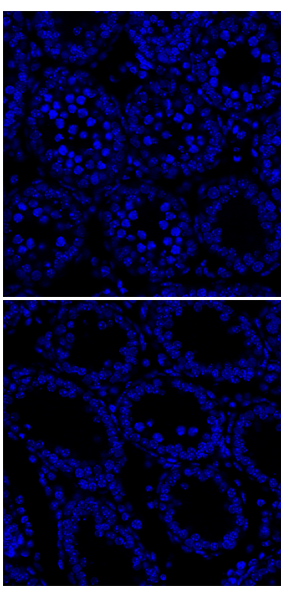

Merge

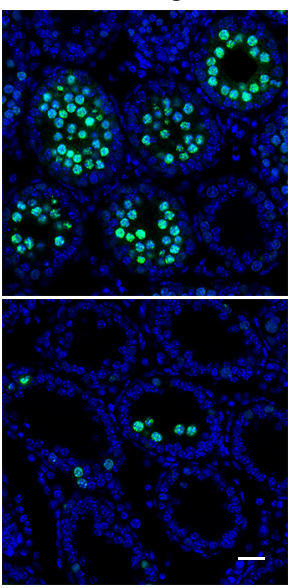

E

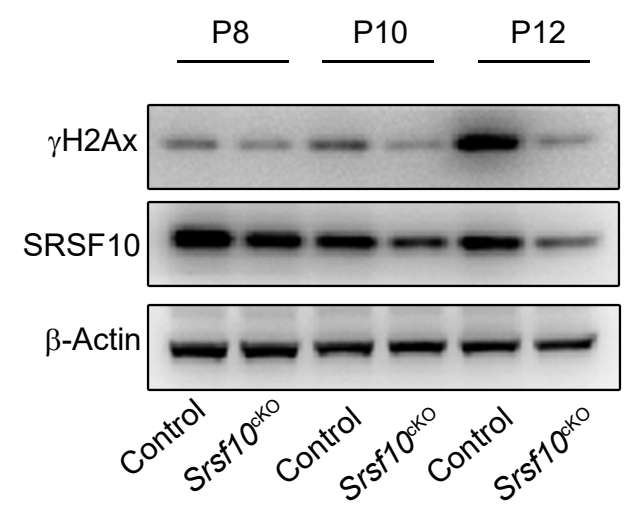


bioRxiv preprint doi: https://doi.org/10.1101/2022.03.06.483179; this version posted March 6, 2022. The copyright holder for this preprint (which was not certified by peer review) is the author/funder, who has granted bioRxiv a license to display the preprint in perpetuity. It is Figure 3 made available under aCC-BY 4.0 International license.

A

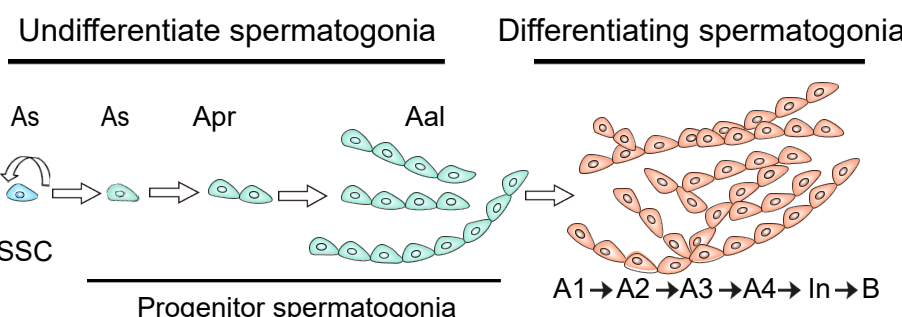

\section{GFR $\alpha 1$}

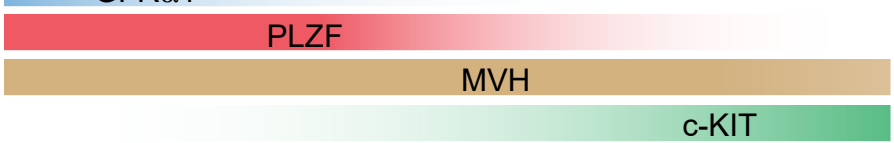

C

P8

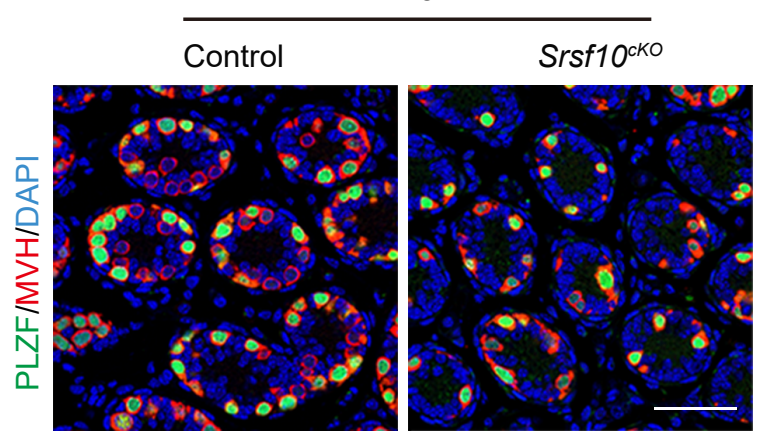

$E$

P6

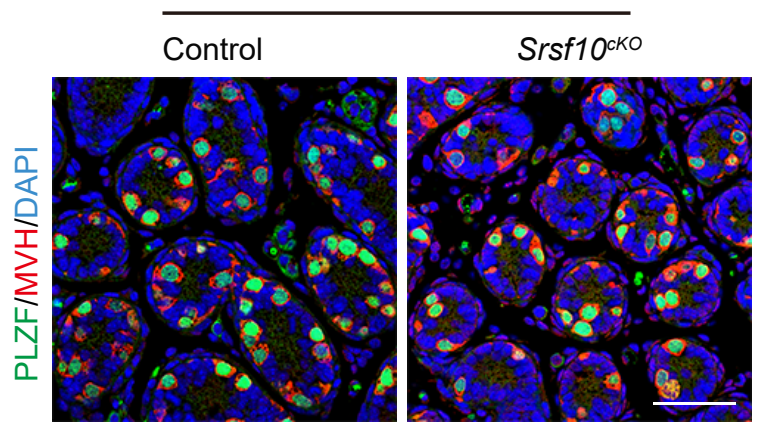

G

P3

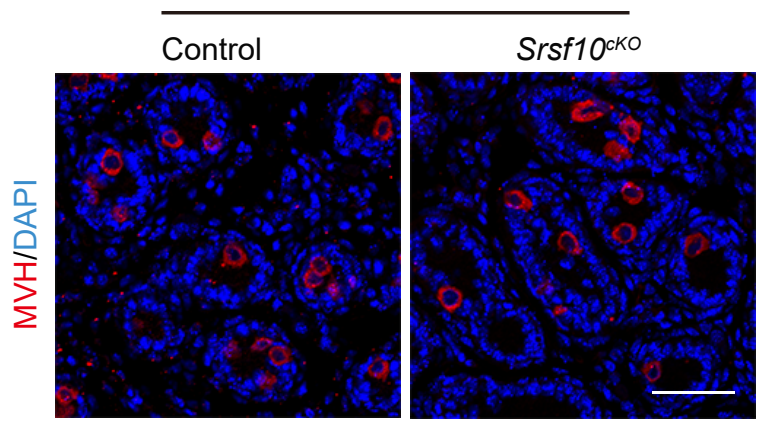

B
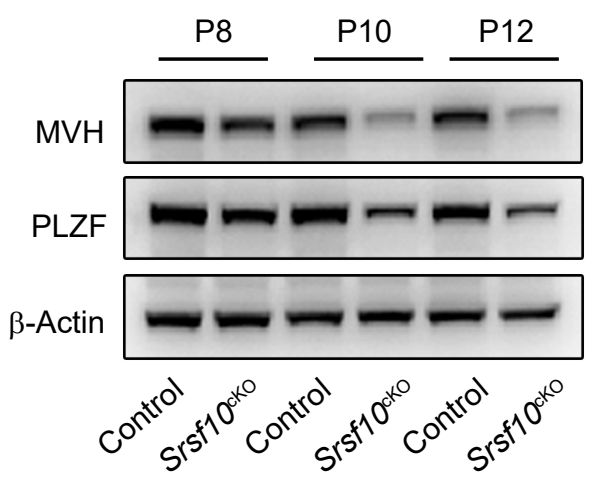

D

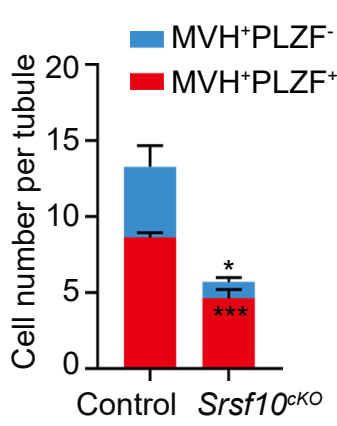

$\mathrm{F}$

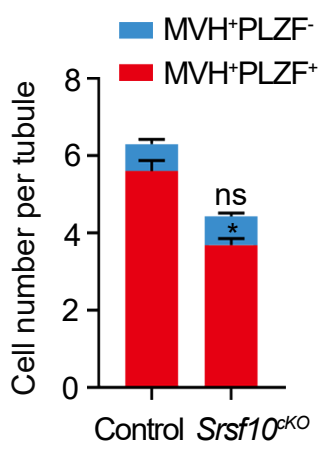

$\mathrm{H}$

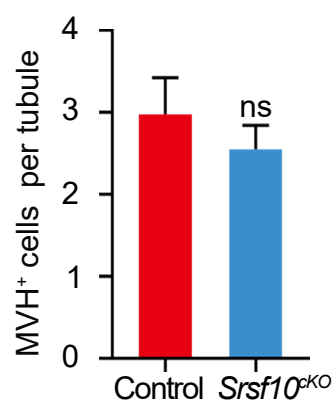

P8

Control Srsf10
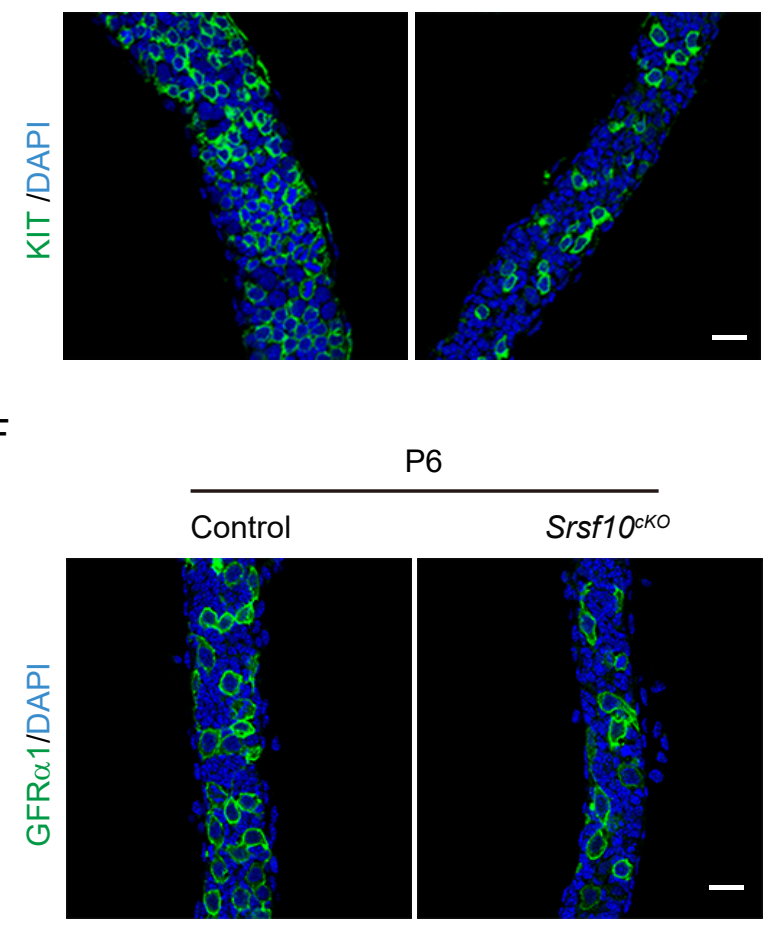

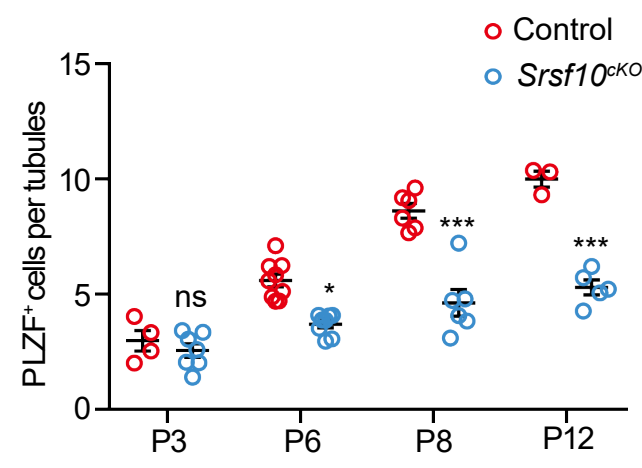


bioRxiv preprint doi: https://doi org/10.1101/2022.03.06 483179; this version posted March 6 , 2022. The copyright holder for this preprint (which was not certified by peer review) is the author/funder, who has granted bioRxiv a license to display the preprint in perpetuity. It is Figure 4 made available under aCC-BY 4.0 International license.

A

P3

P6

P8

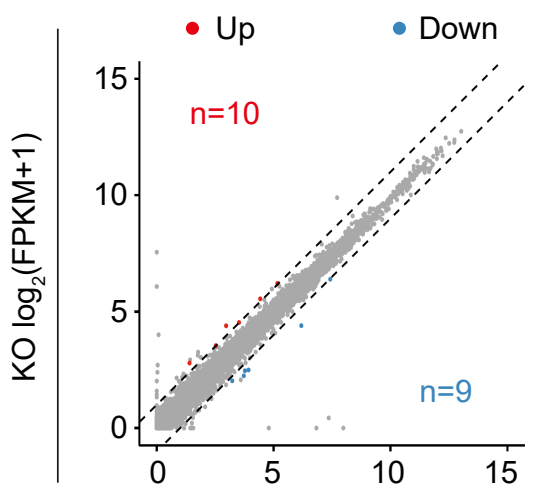

- Unchanged
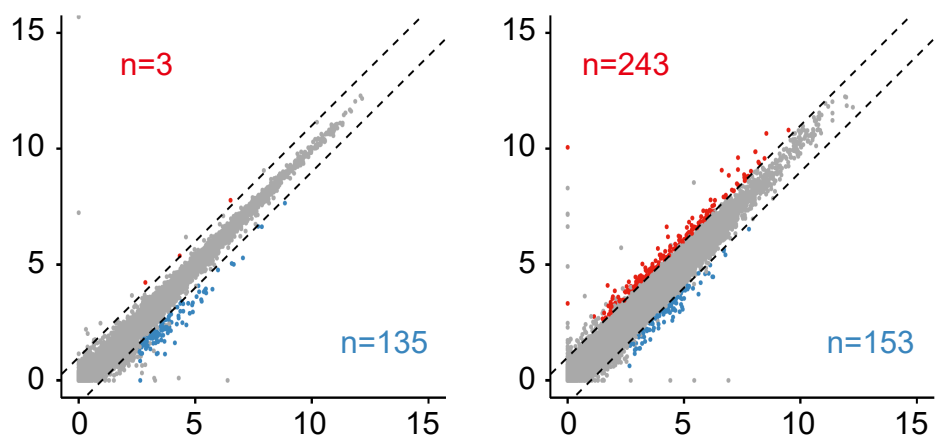

Ctrl $\log _{2}(\mathrm{FPKM}+1)$

B

P6

P8
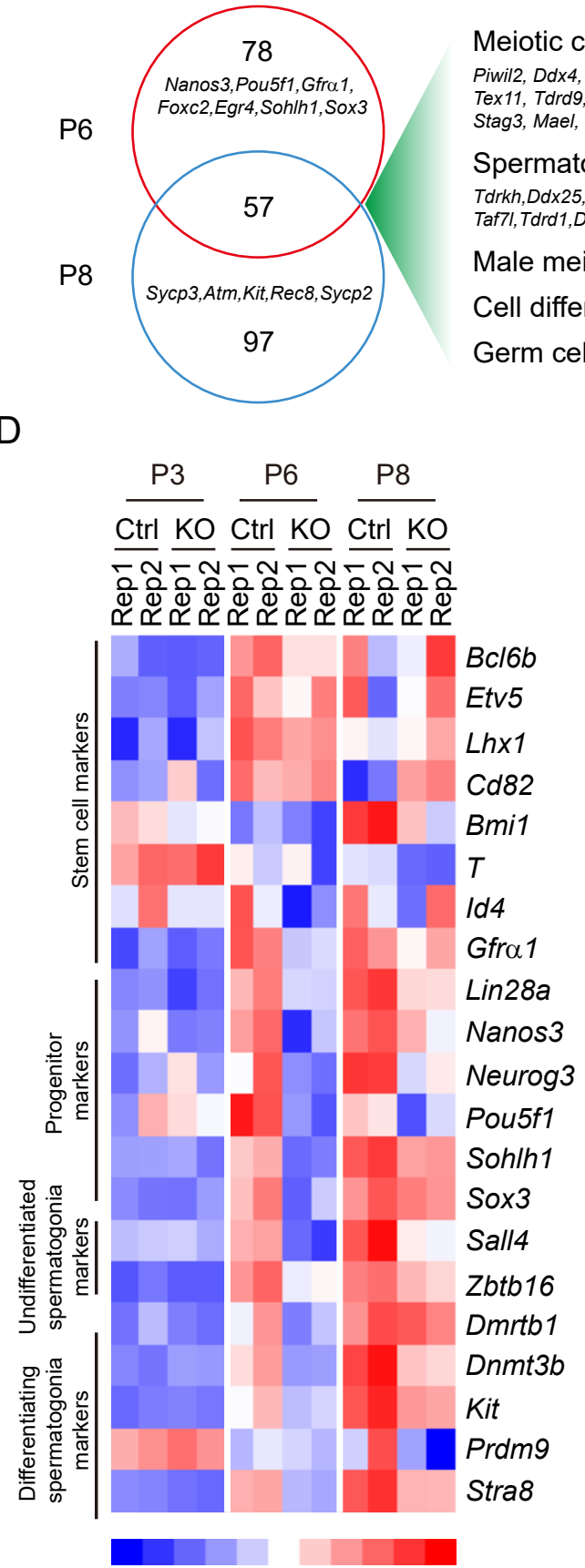

E

C

Meiotic cell cycle:

Piwil2, Ddx4, Sycp1,

Stag3, Mael, Mov10l1, Hormad1

Spermatogenesis:

Tdrkh,Ddx25, Tdrd5,

(tra8, Rnf17

Male meiosis

Cell differentiation

Germ cell development

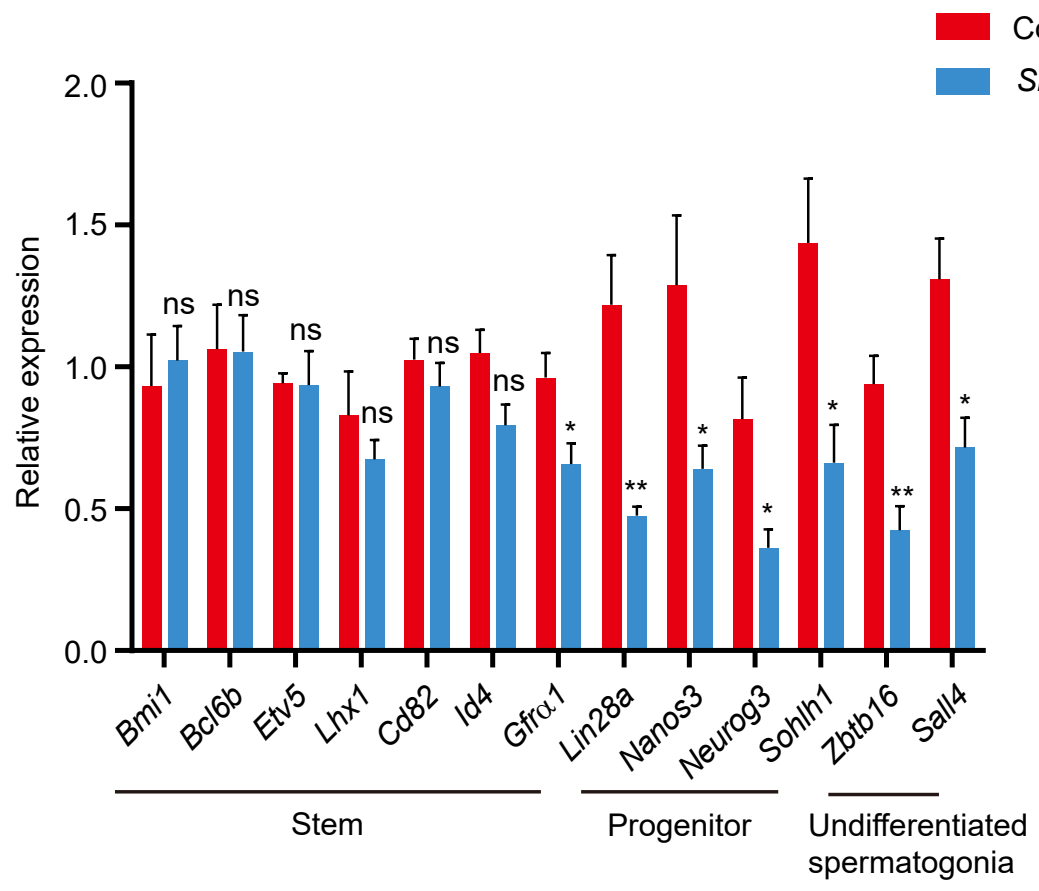

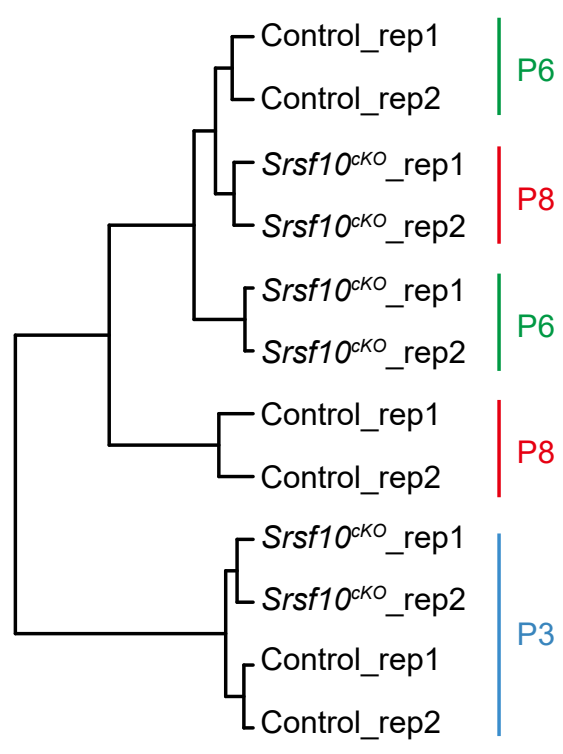

Control

Srsf10 cko 
bioRxiv preprint doi: https://doi.org/10.1101/2022.03.06.483179; this version posted March 6, 2022. The copyright holder for this preprint (which was not certified by peer review) is the author/funder, who has granted bioRxiv a license to display the preprint in perpetuity. It is Figure 5 made available under aCC-BY 4.0 International license.

A

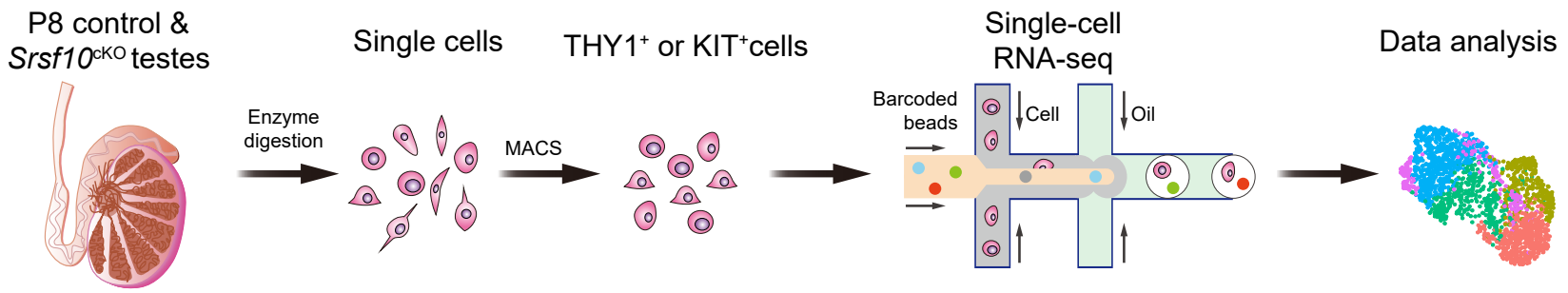

B
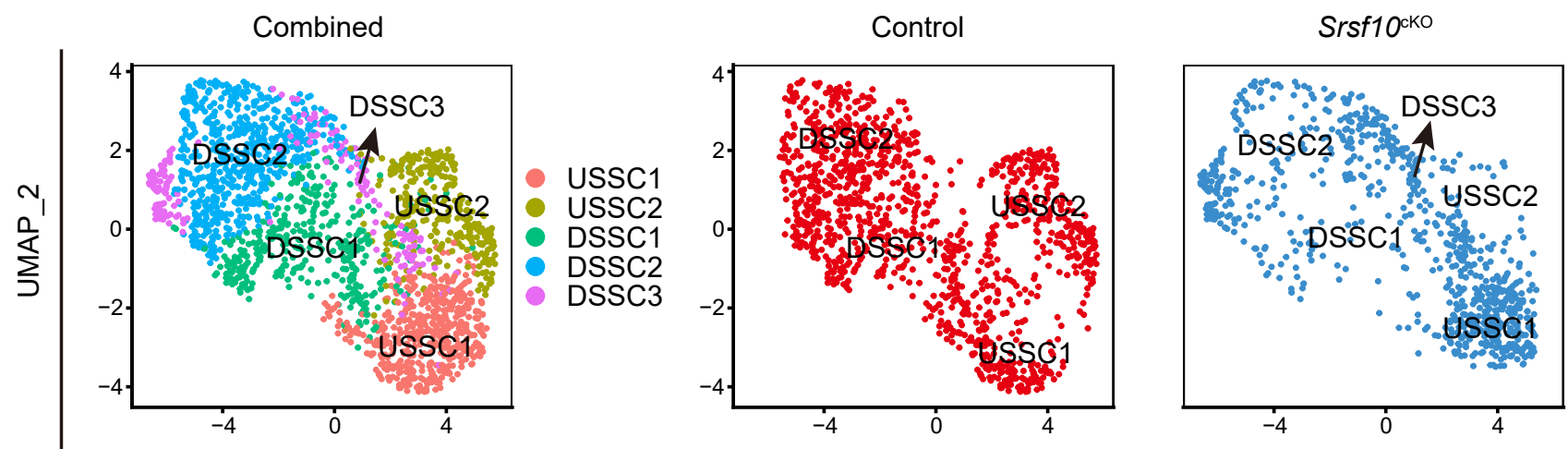

C

UMAP_1

D

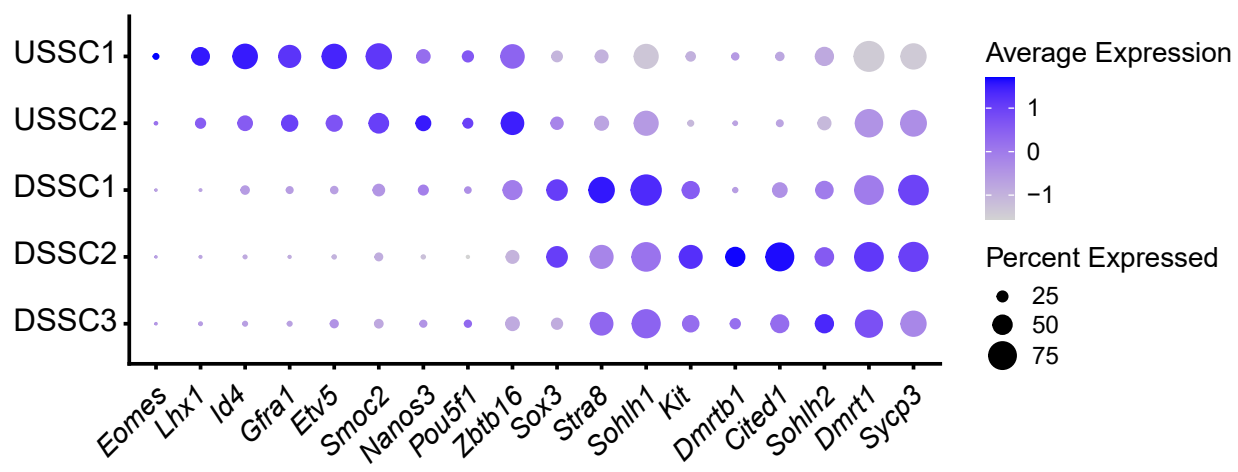

E

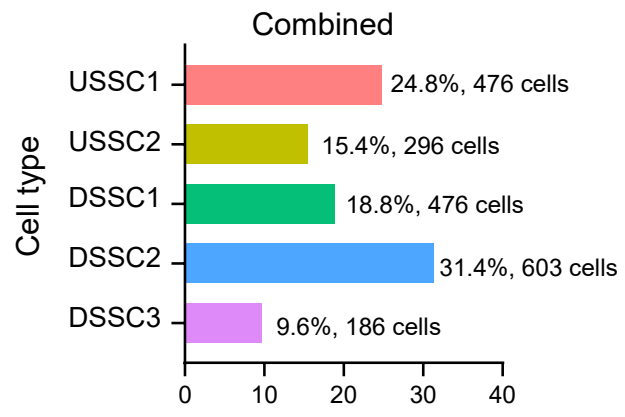

F
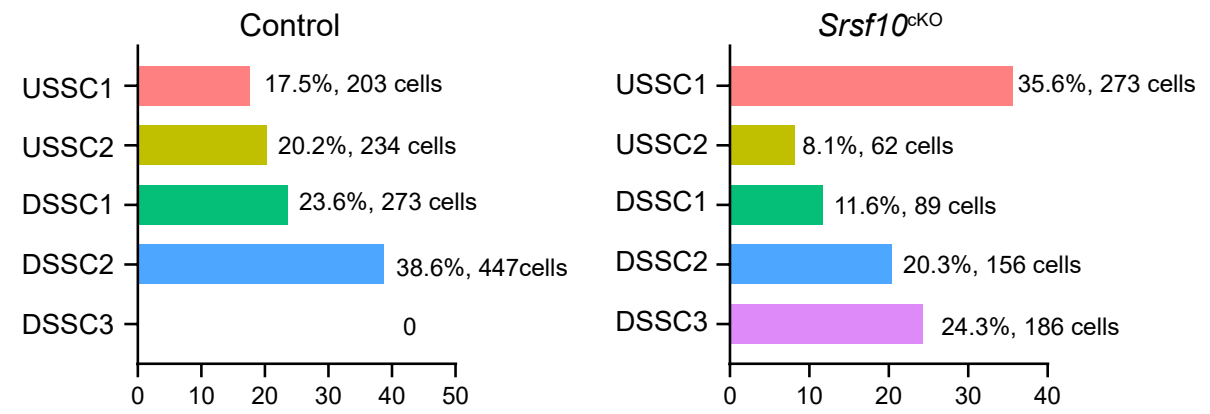

The ratio of cells
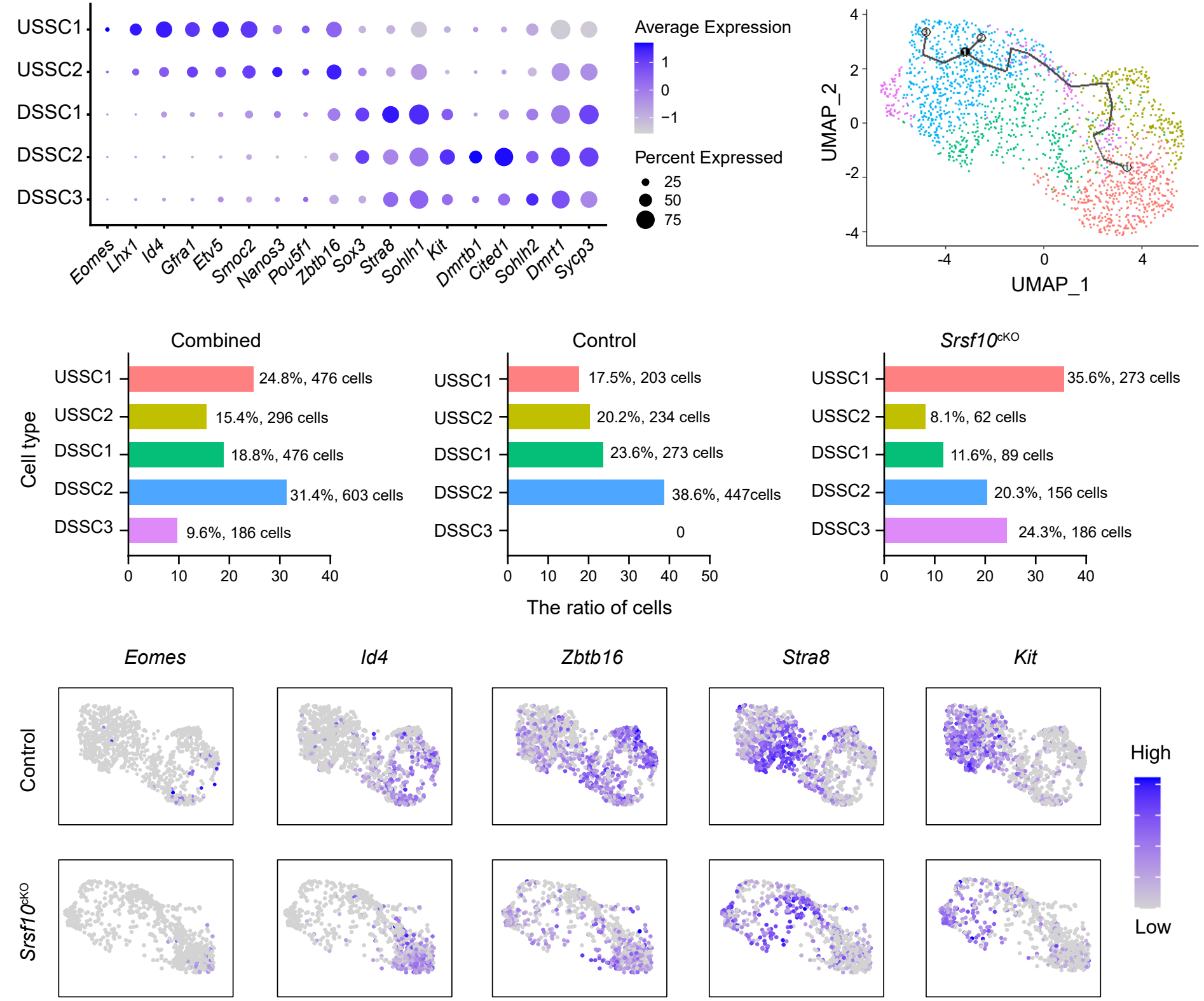

High

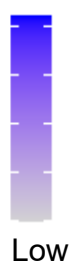




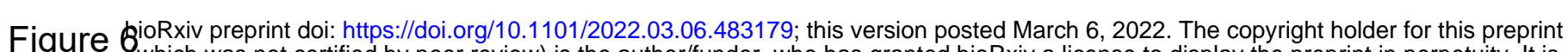

made available under aCC-BY 4.0 International license. A

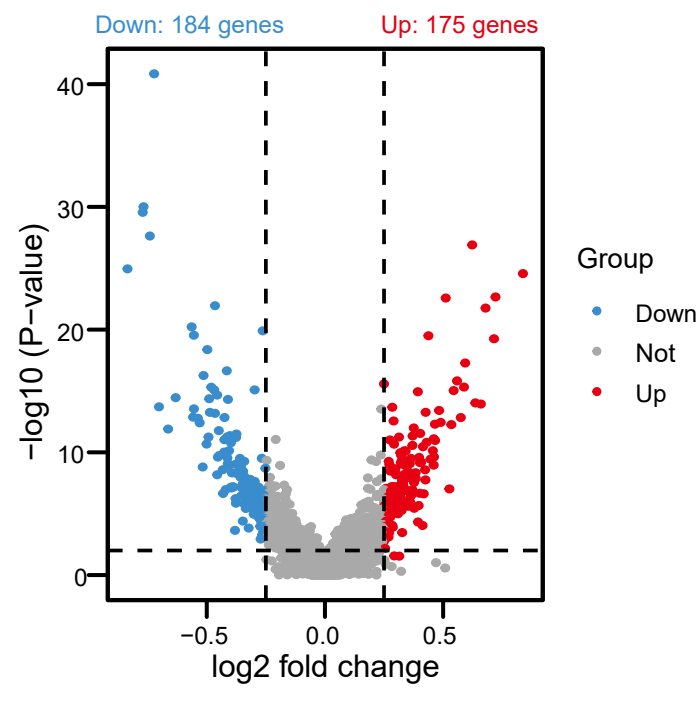

C
Up:

Regulation of apoptotic process

Negative regulation of cell proliferation

G1/S transition of mitotic cell cycle

Tmsb10, Txn1, Bax, Pfn1, Ftl1, Tgfb1, Fth1, Chchd10,Dph3, Eno1, Sox4, Bin1, Cdk4,Egr1, Mt3, Gclm, Mdk, Crlf1, Mt1, Tle5, Cond2

Down:

Cell cycle

Chromosome segregation

Mitotic spindle organization

Spermatogenesis

Cell proliferation

Top2a, Mki67, Cenpe, Cenpf, Sycp3, Prc1, Rcc2, Nusap1, Ccnb1, Smc4, Cdc20, Ndc80, Sycp1, Csnk2a2, Kif23, Cul3, Kif20b, Ndc80, Cdkn1c, Kif11
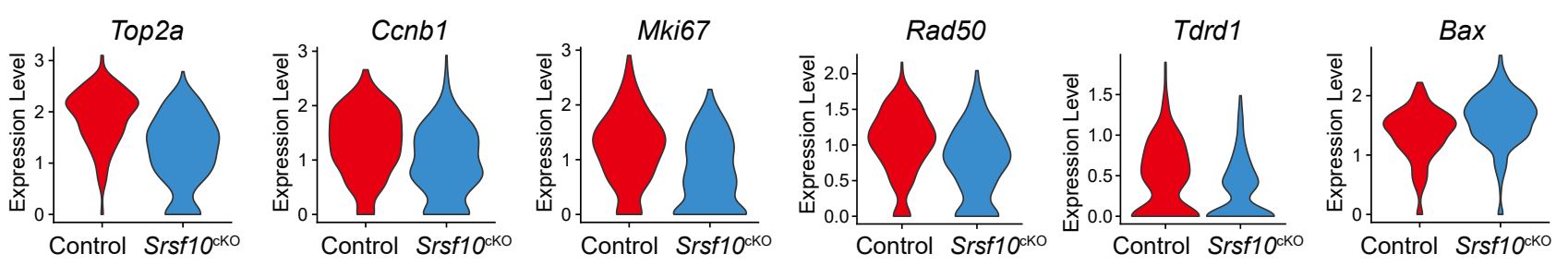

D
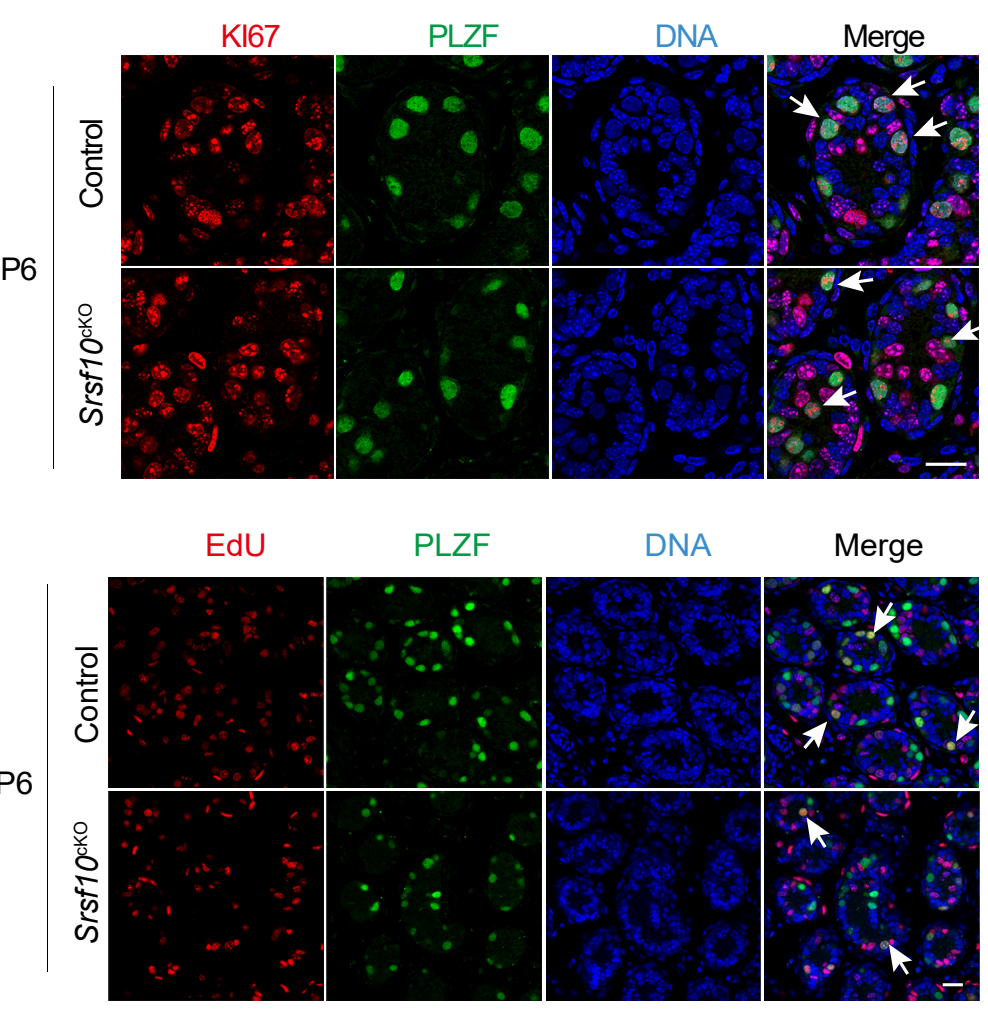

$\mathrm{H}$

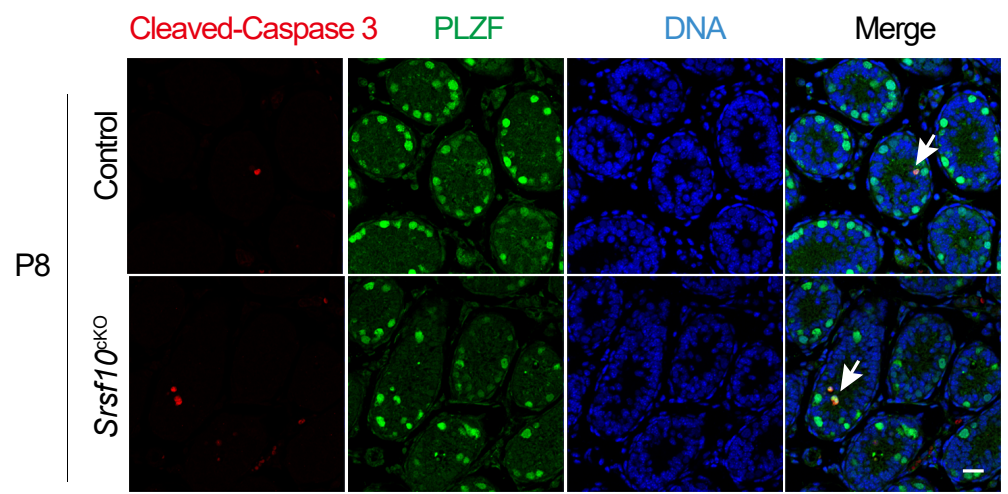

E

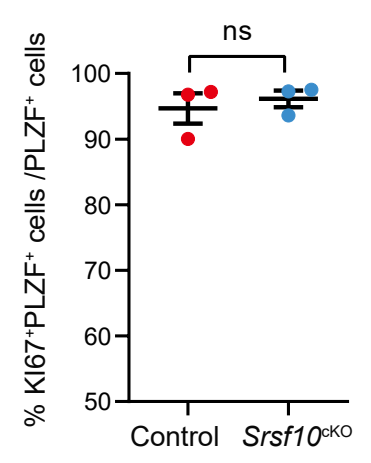

G

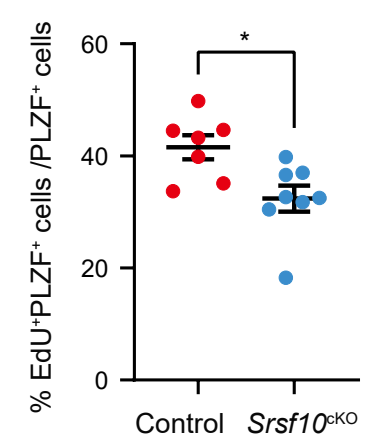

I

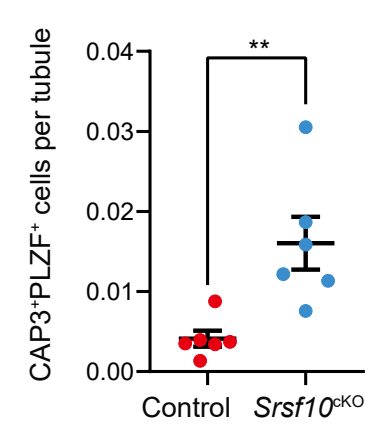


bioRxiv preprint doi: https://doi.org/10.1101/2022.03.06.483179; this version posted March 6, 2022. The copyright holder for this preprint

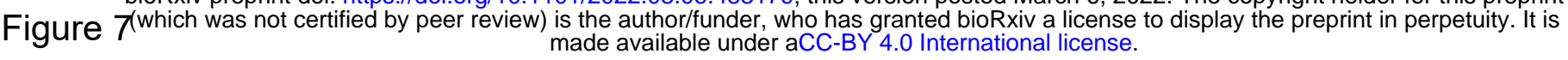

A

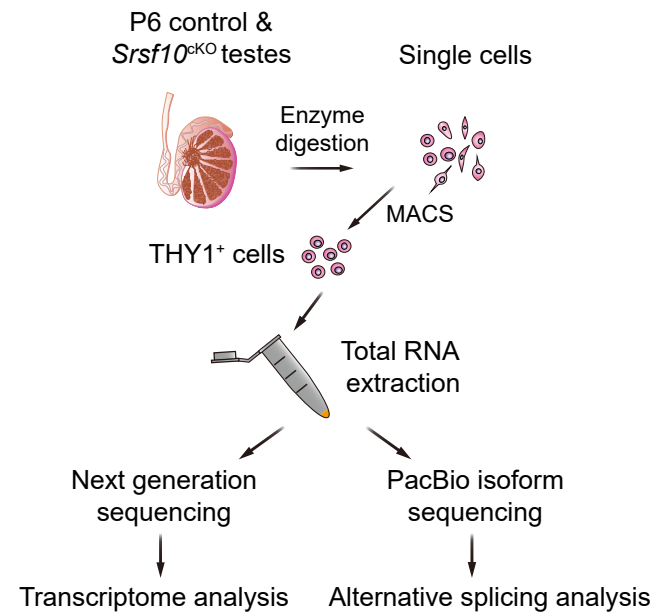

C

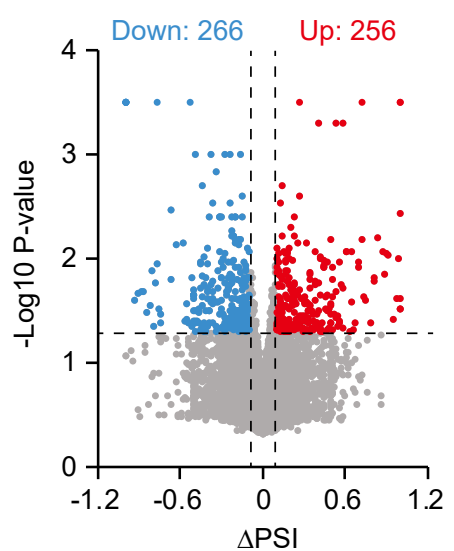

$E$

Dazl

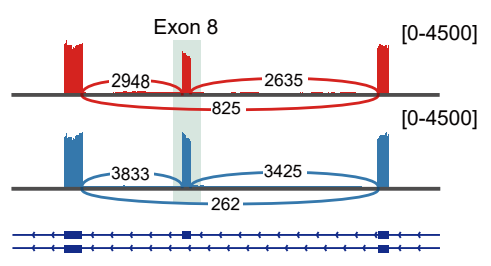

Ret
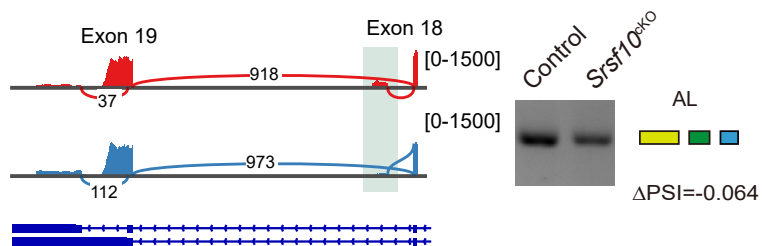

Nasp
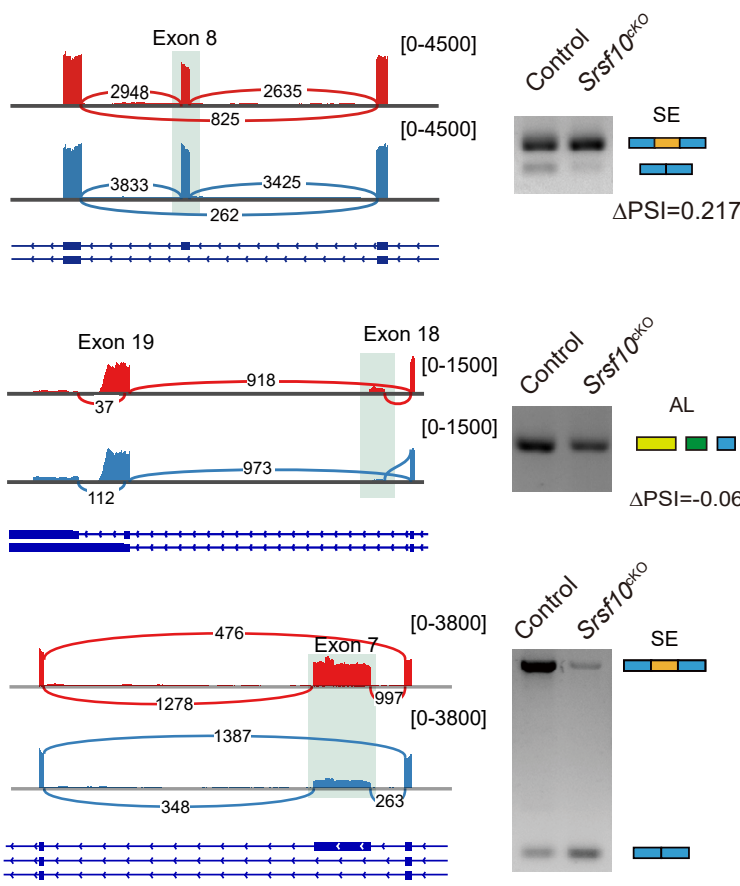

$\Delta P S \mid=0.217$

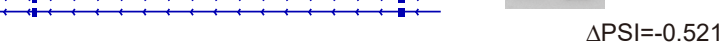

Bclaf1
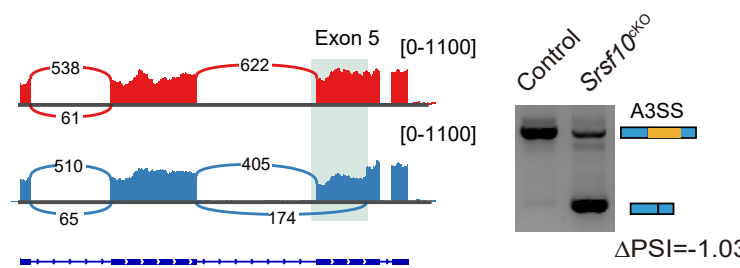

$\mathrm{B}$

\begin{tabular}{|c|c|c|}
\hline \multicolumn{2}{|c|}{ Types of AS } & \# of affected \\
\hline Skipped exon & & 191 \\
\hline Alternative $3^{\prime}$ splice sites & $\sqsubset$ & 0 \\
\hline Alternative $5^{\prime}$ splice sites & صر & 95 \\
\hline Mutually exclusive exon & ص & 13 \\
\hline Retained intron & صد & 65 \\
\hline Alternative first exon & & 115 \\
\hline Alternative last exon & בे & 43 \\
\hline Total & & 522 \\
\hline
\end{tabular}

\section{GO}

Cell cycle (30)

Cell-cell adhesion (14)

Response to DNA damage stimulus (22)

Protein ubiquitination (10)

Phosphorylation (24)

Translation (17)

Germ cell development (5)

\section{Gene}

Cell cycle: Prr5, Ccnk, Anapc15, Uhrf1, Syce2 Stk11, Mapk7, Pttg1, Chek1, Pim2, Nae1, Bora, Ist1, Nek6, Nsmce2, Haus4, Cdc7, Lig3, Cdc25c Chfr, Sirt2, Mau2, Cdc34, Ccne2, Nasp, Stag3, Cdk4, Incenp, Mcm4, Rhno1 Germ cell development: Tdrd1, Dazl, Kit, Tdrd7, Bc/2/1

Kit
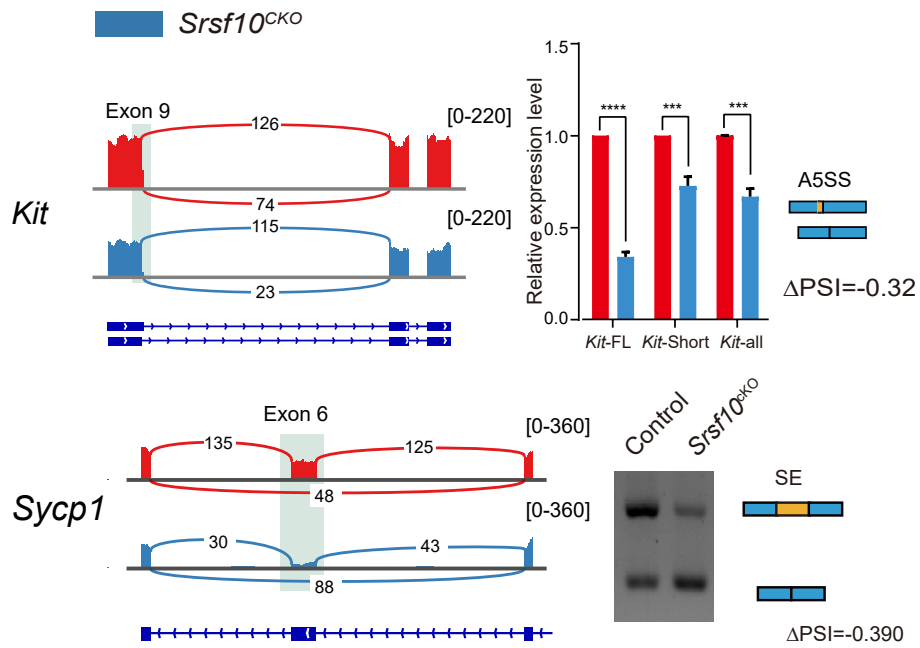

Bora
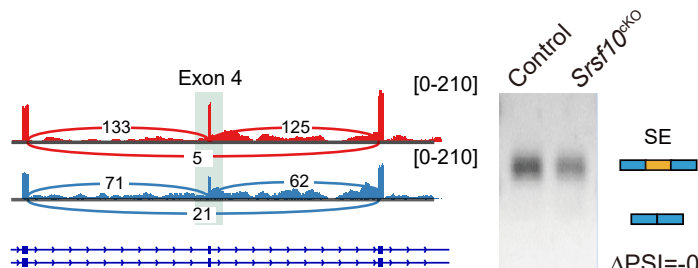

$\Delta \mathrm{PSI}=-0.248$
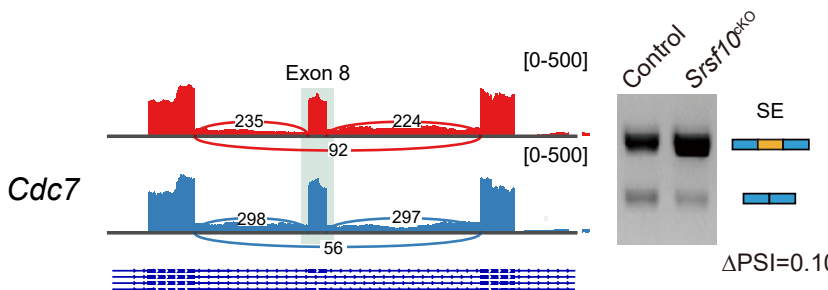

$\Delta \mathrm{PSI}=0.106$ 
bioRxiv preprint doi: https:/doi.org/10.1101/2022 03 06 483179. this version posted March 6, 2022. The copyright holder for this preprint (which was not certified by peer review) is the author/funder, who has granted bioRxiv a license to display the preprint in perpetuity. It is Figure 8 made available under aCC-BY 4.0 International license.

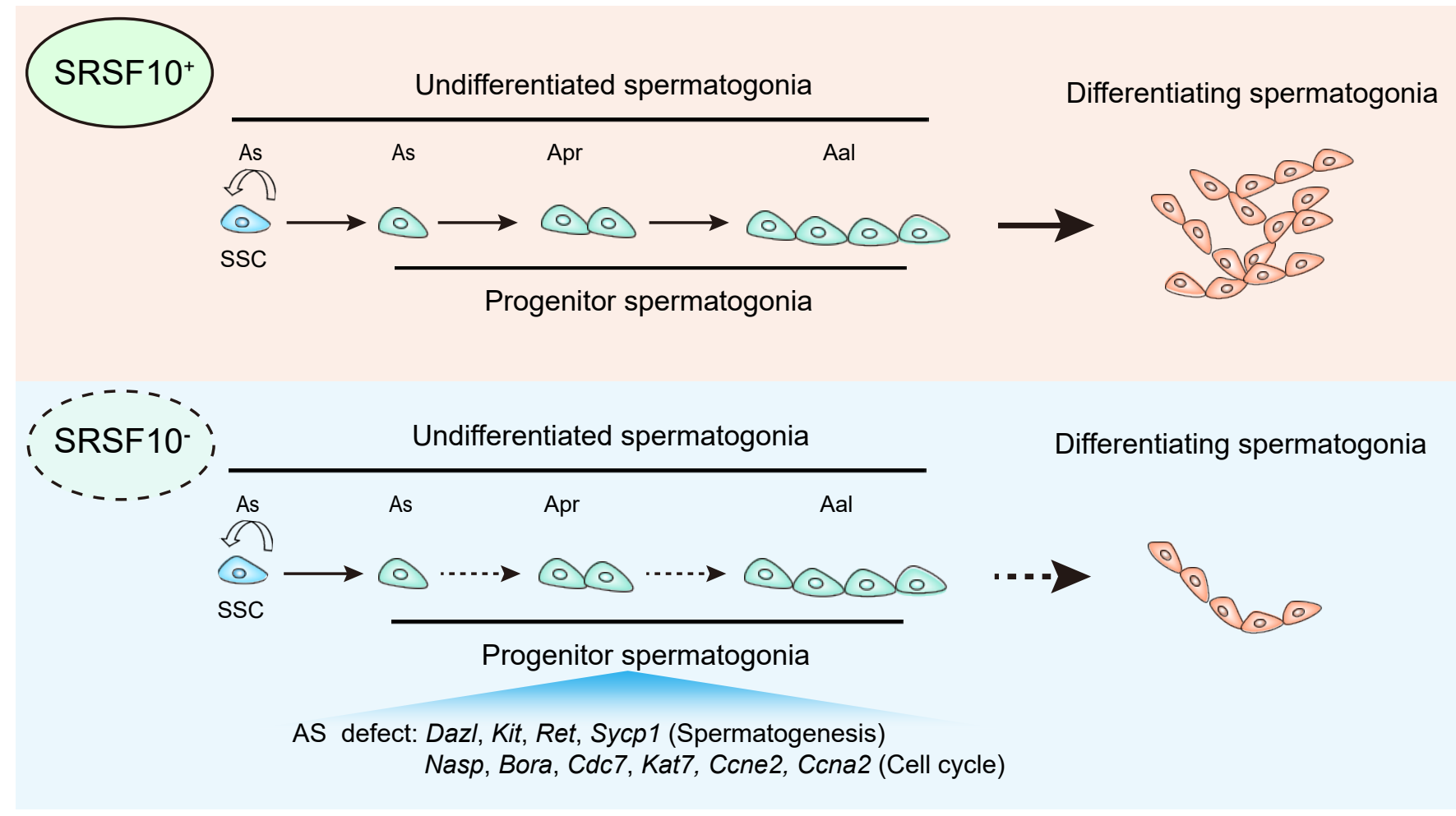


bioRxiv preprint doi: https://doi.org/10.1101/2022.03.06.483179; this version posted March 6, 2022. The copyright holder for this preprint (which was not certified by peer review) is the author/funder, who has granted bioRxiv a license to display the preprint in perpetuity. It is made available under aCC-BY 4.0 International license.

Table 1 The fertility of Srsf10 ${ }^{\text {cKO }}$ males.

\begin{tabular}{cccccc}
\hline \multicolumn{2}{c}{ Genotype } & No. of male mice & $\begin{array}{c}\text { No. of plugged } \\
\text { female mice }\end{array}$ & No. of litters & $\begin{array}{c}\text { No. of pups per } \\
\text { litter }\end{array}$ \\
\hline Male & Female & 8 & 17 & 14 & $13.43 \pm 3.78$ \\
Control & $\mathrm{Wt}$ & 8 & 16 & 0 & 0 \\
\hline
\end{tabular}


bioRxiv preprint doi: https://doi org/10.1101/2022.03 06 483179. this version posted March 6, 2022. The copyright holder for this preprint (which was not certified by peer review) is the author/funder, who has granted bioRxiv a license to display the preprint in perpetuity. It is Figure 1-figure supplement 1 made available under aCC-BY 4.0 International license.

A

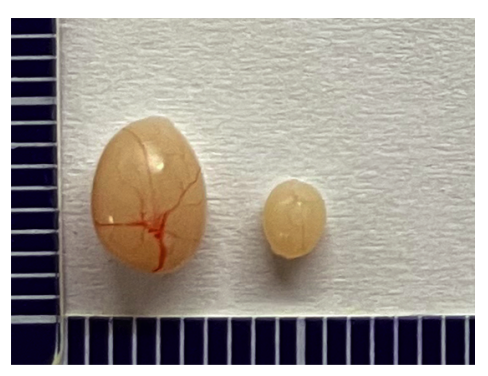

Control

C
B

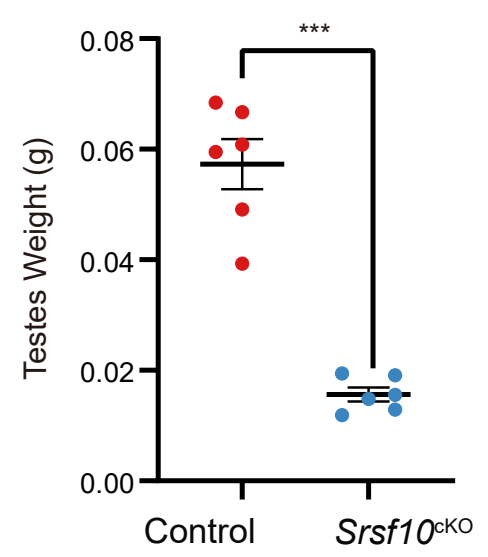

Control

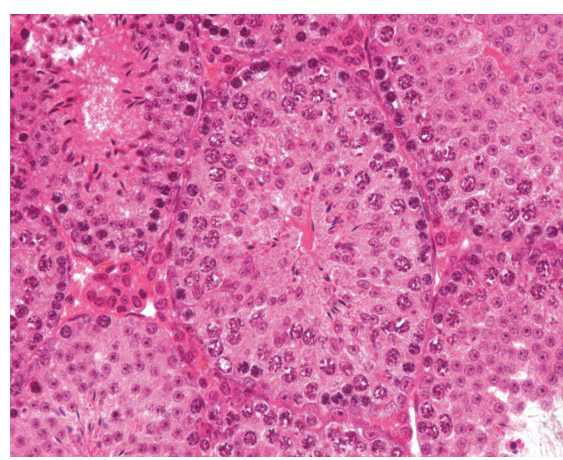

Srsf10 cko

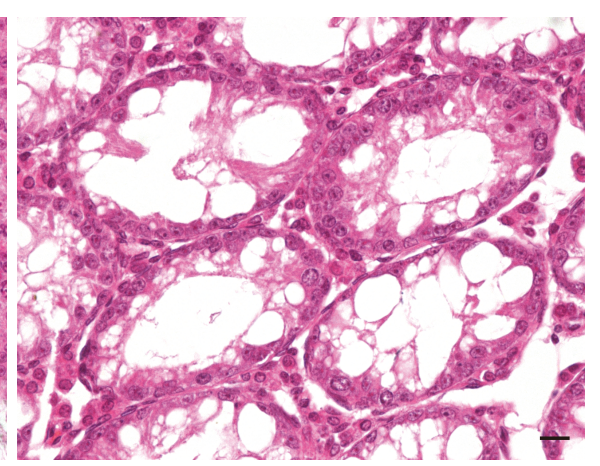


Figure 3- figure supplement 1

A

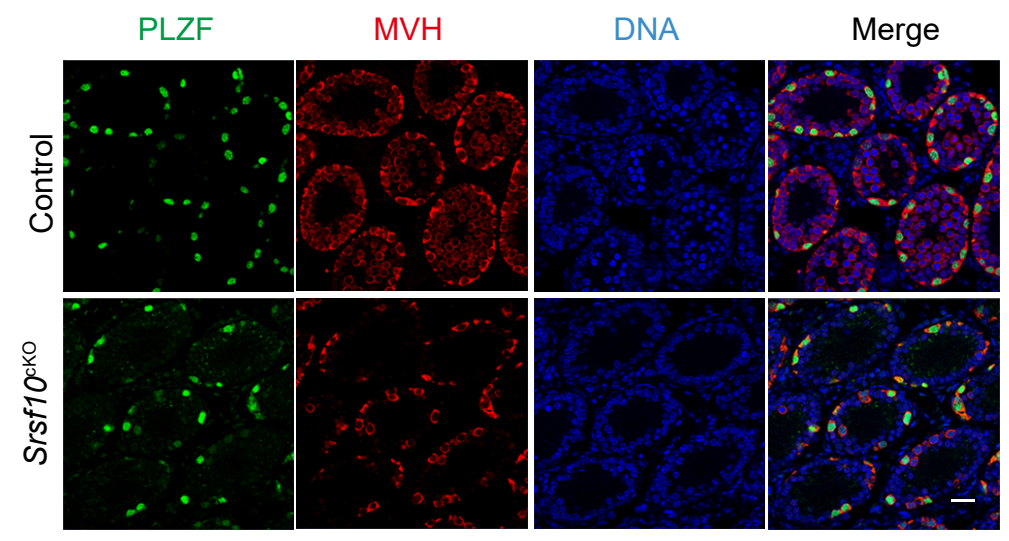

C

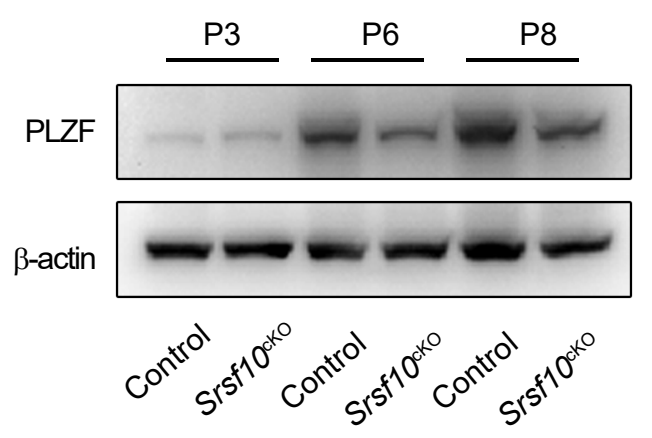

B

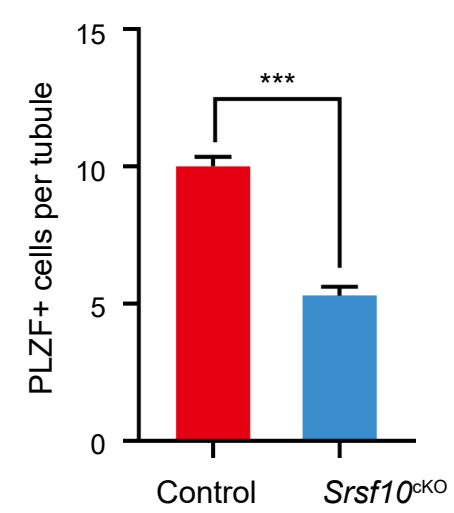


bioRxiv preprint doi: https://doi.org/10.1101/2022 03 06.483179. this version posted March 6, 2022. The copyright holder for this preprint (which was not certified by peer review) is the author/funder, who has granted bioRxiv a license to display the preprint in perpetuity. It is made available under aCC-BY 4.0 International license.

Figure 4- figure supplement 1

A

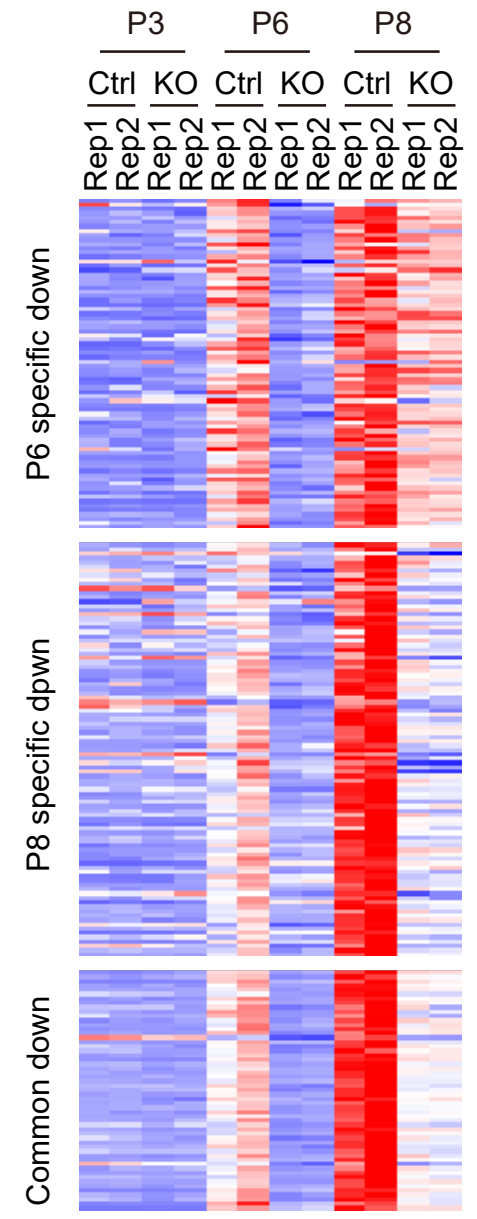

B

Spermatogonial stem cells
$B c / 6 b$

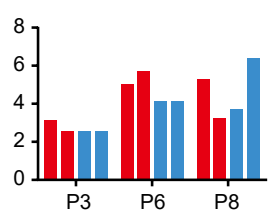

Progenitor cells

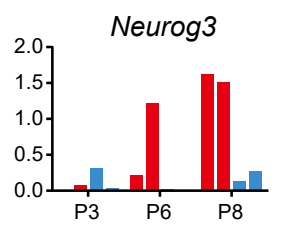

Bmi1
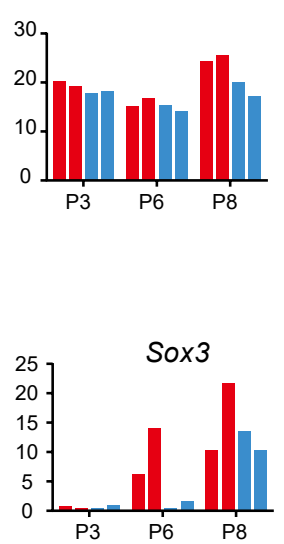

Etv5

- Control-rep1

- Control-rep2

- Srsf10 cko-rep1

- Srsf10 cko-rep2

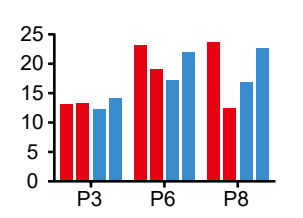

Undifferentiated spermatogonia
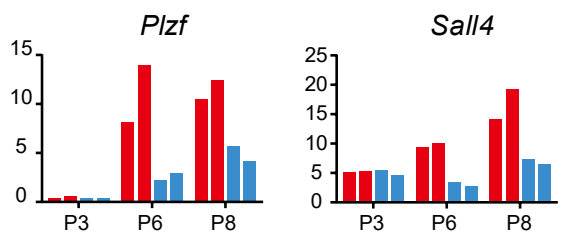
Figure 5- figure suppplement 1

A

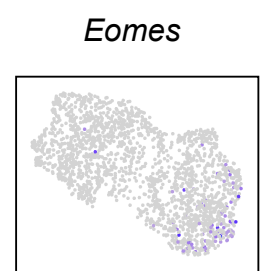

Sdc4

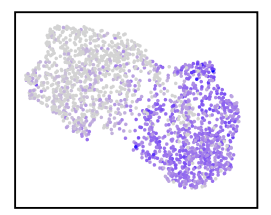

B
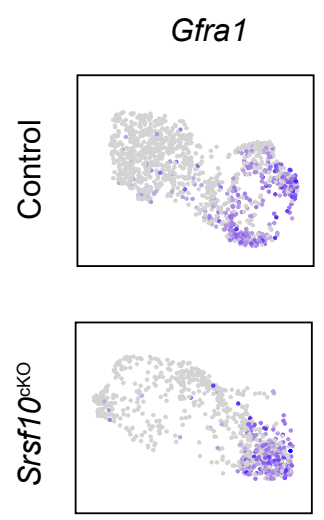

Lhx1

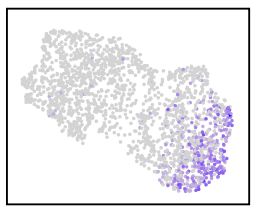

Utf1

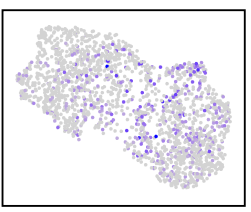

Sall4
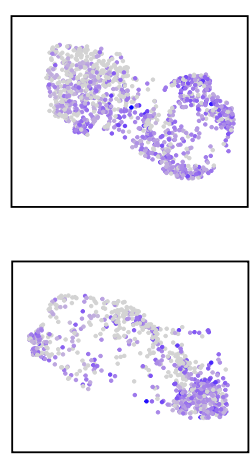

Id4

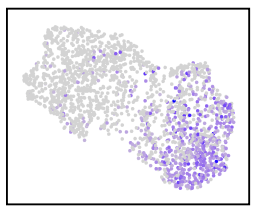

Sohlh2

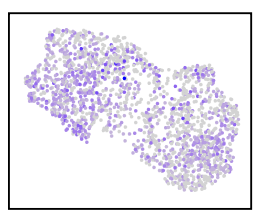

Nanos3
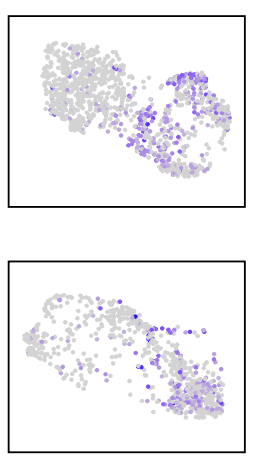

Gra1

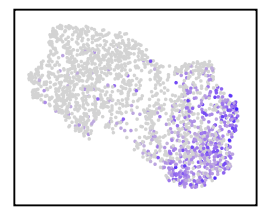

Stra8

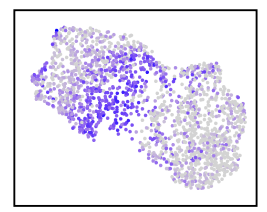

Egr4
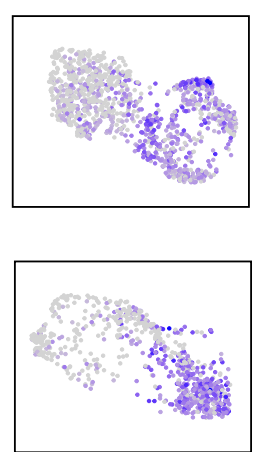

Zbtb16

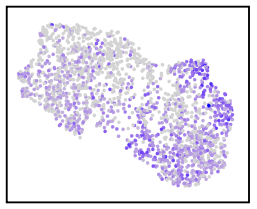

Kit
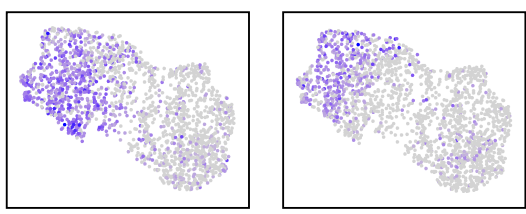

Low
High

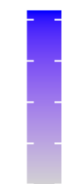

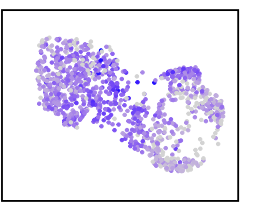

Dnmt3b

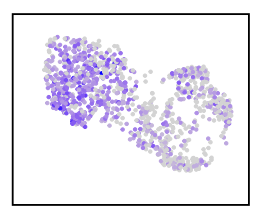

High
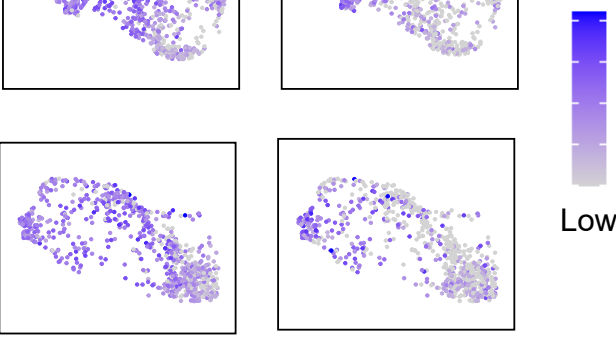
bioRxiv preprint doi: https://doi.org/10.1101/2022.03.06.483179; this version posted March 6, 2022. The copyright holder for this preprint (which was not certified by peer review) is the author/funder, who has granted bioRxiv a license to display the preprint in perpetuity. It is Figure 6- figure suppplement 1 made available under aCC-BY 4.0 International license.
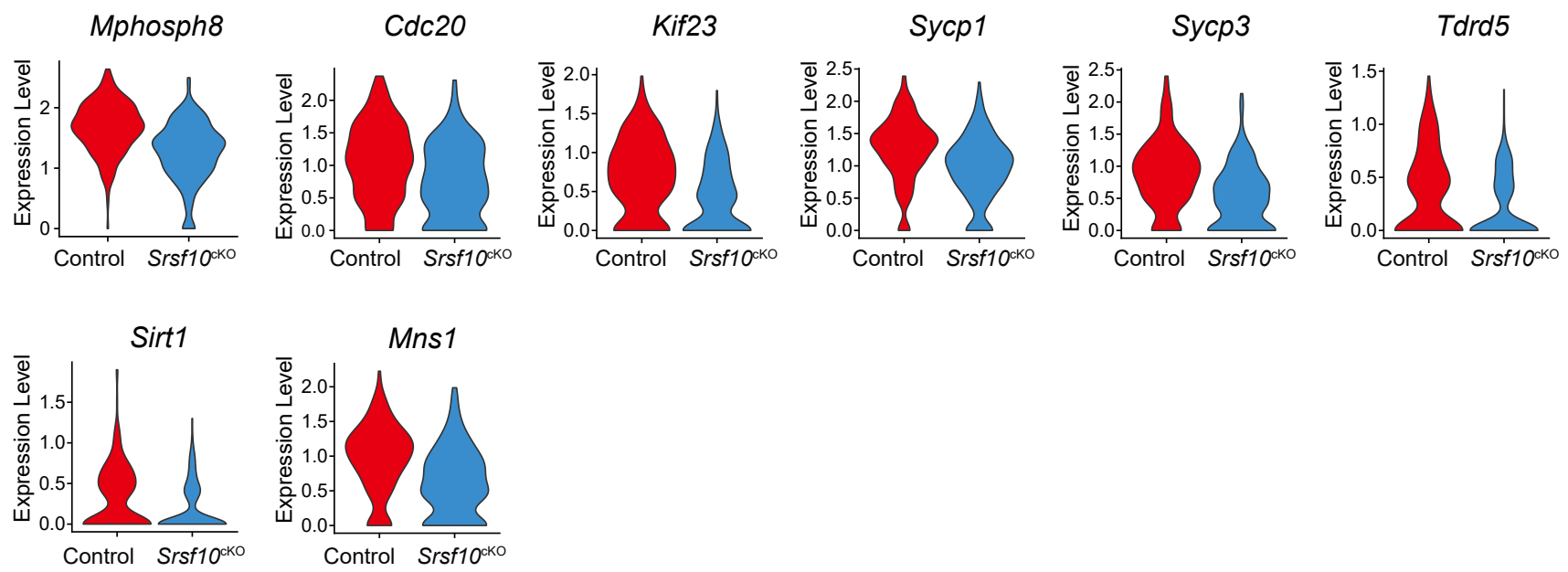
bioRxiv preprint doi: https://doi.org/10.1101/2022.03.06.483179; this version posted March 6, 2022. The copyright holder for this preprint (which was not certified by peer review) is the author/funder, who has granted bioRxiv a license to display the preprint in perpetuity. It is Figure 6- figure suppplement 2 made available under aCC-BY 4.0 International license.

A

USSC2

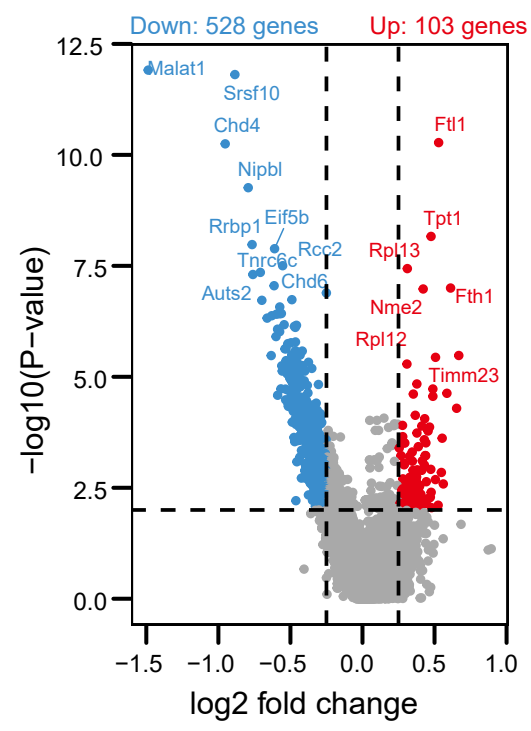

DSSC1

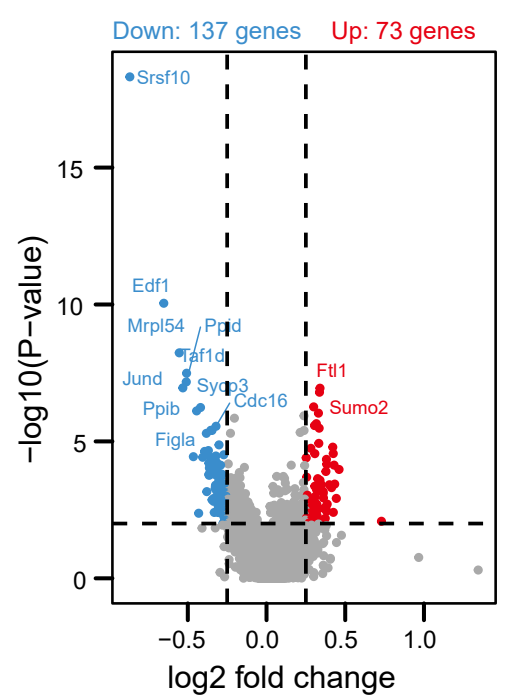

$E$

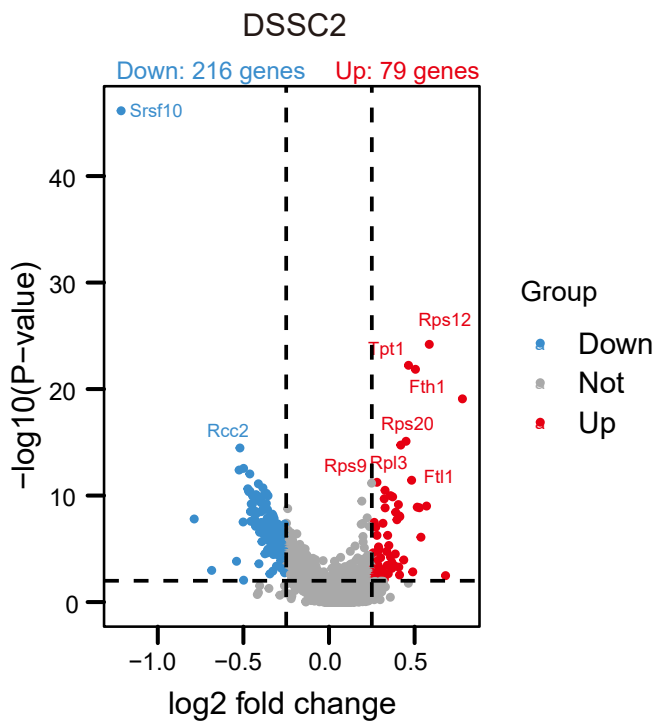

Group

- Down

Not

Up
B

Up:

Cellular iron ion homeostasis

Response to oxidative stress

RNA splicing

Ube2v2, Bax, Mt1, Rps9, Atg3, Rpl10, Eif2s2, Eif1, Rp/36al, Rpl13, Rps12

Down:

RNA splicing

Cell cycle

DNA repair

Stem cell population maintenance

Cdkn1c, Usp37, Usp16, Rif1, Sycp1, Ccnf, Smc5, Cdc73, Tpr, Tlk2, Rbbp8, Smc1a, Aspm, Rad50, Son, Msh2, Cencp1, Mcm3, Lin28a, Apc, Sall4, Ctnnb1, Dicer1

Up:

Cellular iron ion homeostasis

Response to oxidative stress

mRNA processing

Ft11, Fth1, Homx1, Prdx1, Txnrd1, Gclm

Down:

RNA splicing

Spermatogenesis

Cell cycle

Mitotic nuclear division

Prpf38b, Sf3b3, Esrp1, Gemin5, Cdk12, Hnrnpa1, Bcap31, Tdrd1, Tdrkh, Stra8, Plekha1, Akap9, Sycp3, Calr, Rad50, Zfp830, Cdc16, Mcm3, Bub1b, Knl1, Kif20b

\section{$\mathrm{F}$}

Up:

Translation

Cellular iron ion homeostasis

Response to oxidative stress

Sumo2, Rps12, Tpt1, Fth1, Sumo1, Mt3

Down:

DNA replication

Cell differentiation

Spermatogenesis

Cell cycle

Kit, Rad50, Hnrnpl, Bub1b, Kif20, Sox3, Rif1, Cdc34, Kif2a, Mcm5, Sycp3, Mcm6, Top2a, Stra8, Ppid, Srpk1, Mea1, Cadm1, Alkbh5, Nr6a1 
bioRxiv preprint doi: https://doi.org/10.1101/2022.03 06 483179. this version posted March 6, 2022. The copyright holder for this preprint (which was not certified by peer review) is the author/funder, who has granted bioRxiv a license to display the preprint in perpetuity. It is made available under aCC-BY 4.0 International license.

Figure 7- figure supplement 1

A
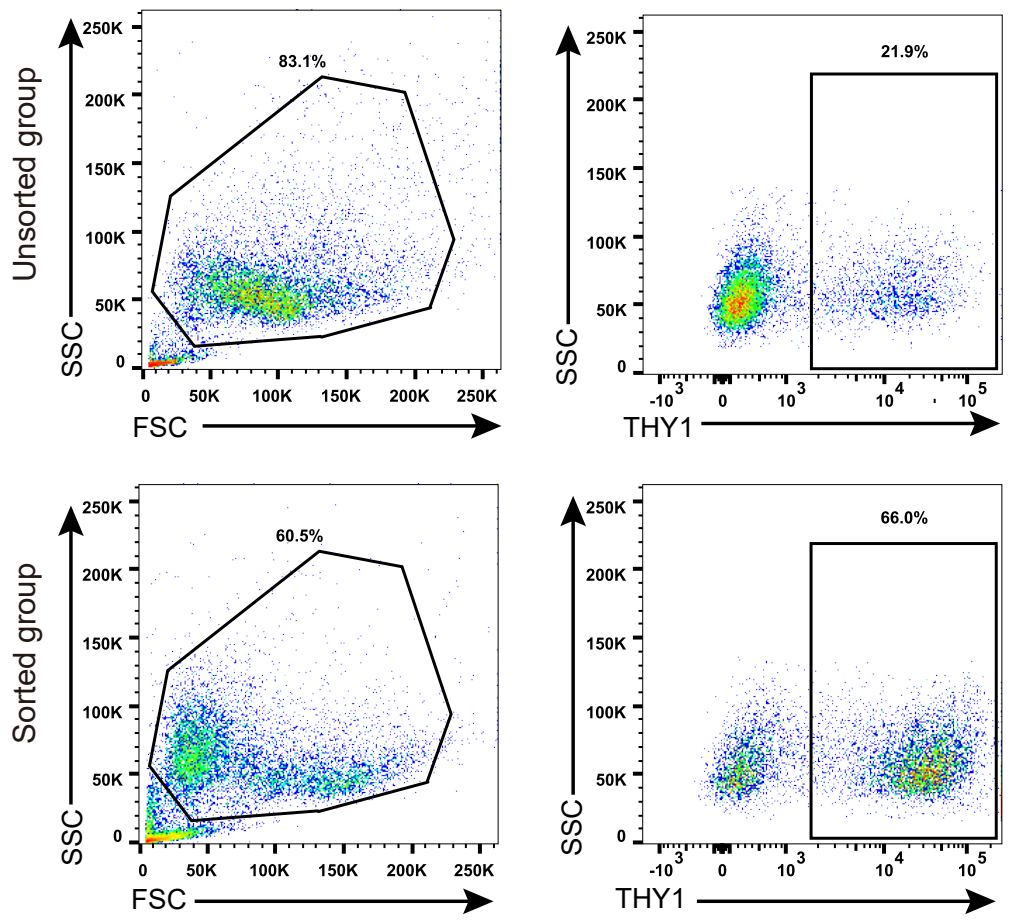

B
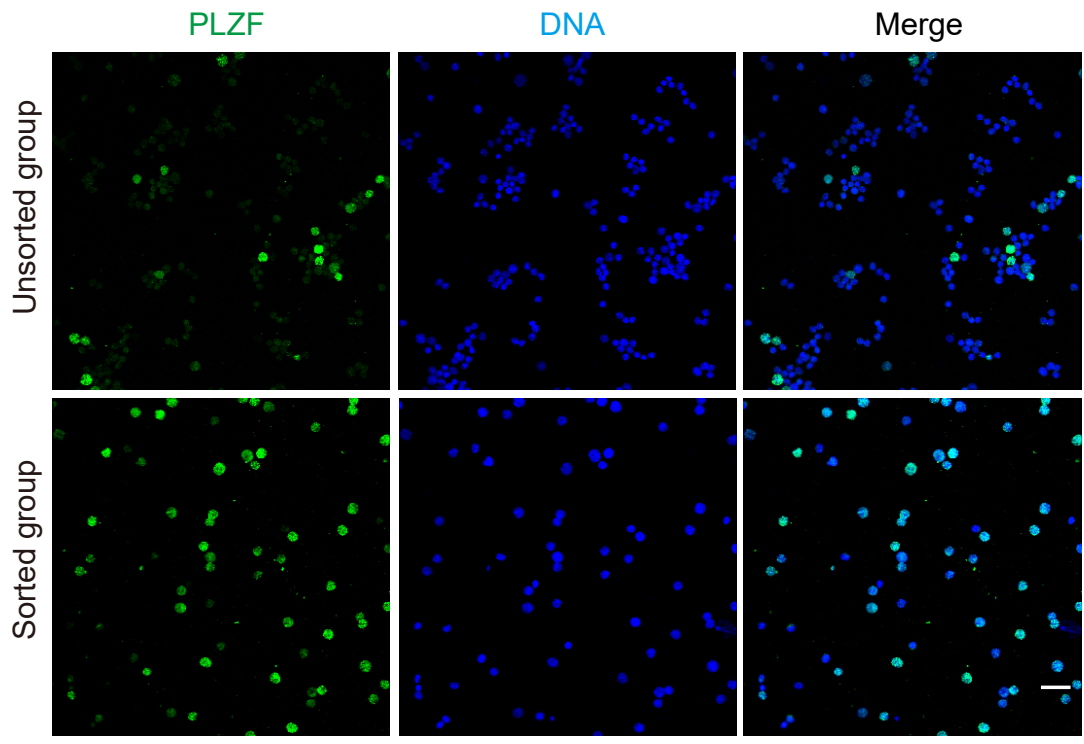

C

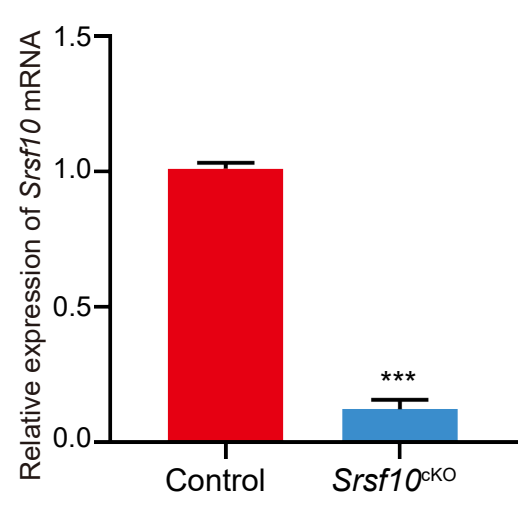

D

SRSF10

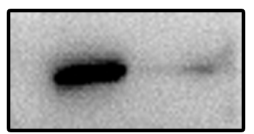

$\beta$-actin

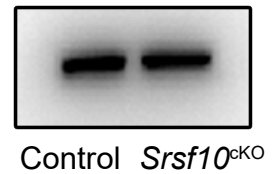


bioRxiv preprint doi: https://doi.org/10.1101/2022.03.06.483179; this version posted March 6, 2022. The copyright holder for this preprint (which was not certified by peer review) is the author/funder, who has granted bioRxiv a license to display the preprint in perpetuity. It is

Figure 7-figure supplement 2 made available under aCC-BY 4.0 International license.

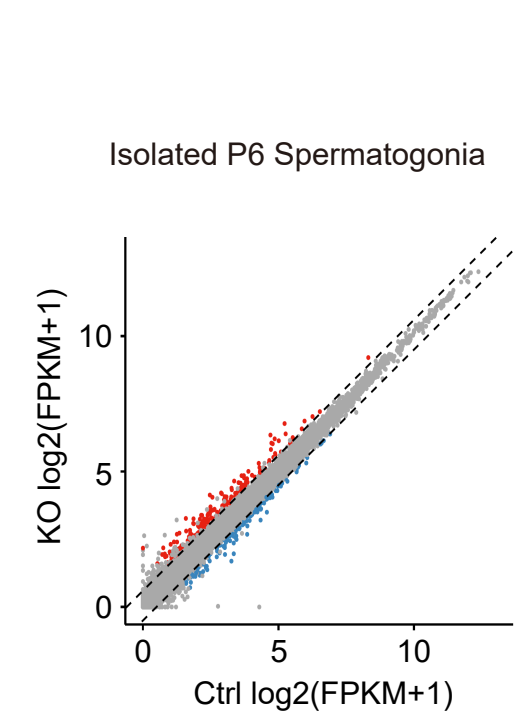

Up: 299

Immune response

Cell adhesion

Positive regulation of GTPase activity ERK1 and ERK2 cascade

Cadm4, Cd74, Cd7, Inpp5d, Clec4n, Cx3cr1, Hepacam Itga7, Fermt3, Itgb2, Ccl4, Cdkn1a, Nefl, TIr2

\section{Down: 206}

\section{Spermatogenesis}

Meiotic cell cycle

Cell differentiation

Male germ-line stem cell asymmetric division

Pxt1, Nanos2, Piwil4, Ddx25, Nanos3, Rfx2, Dbil5, Cdc25c, Chtf18 Tdrd1, Stra8, Brdt, Neurog3, Zbtb16, Rec8, Rad50, Foxc2, Lin28a 
bioRxiv preprint doi: https://doi.org/10.1101/2022.03.06 483179; this version posted March 6, 2022. The copyright holder for this preprint (which was not certified by peer review) is the author/funder, who has granted bioRxiv a license to display the preprint in perpetuity. It is

Figure 7- figure supplement 3

A

Exon Skipping in CDS region $(n=132)$

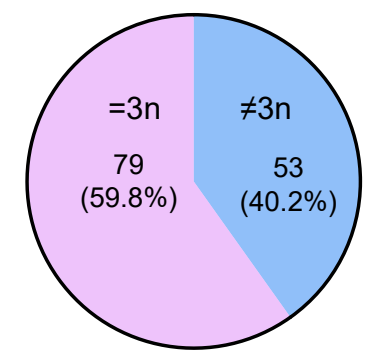

C

Bora

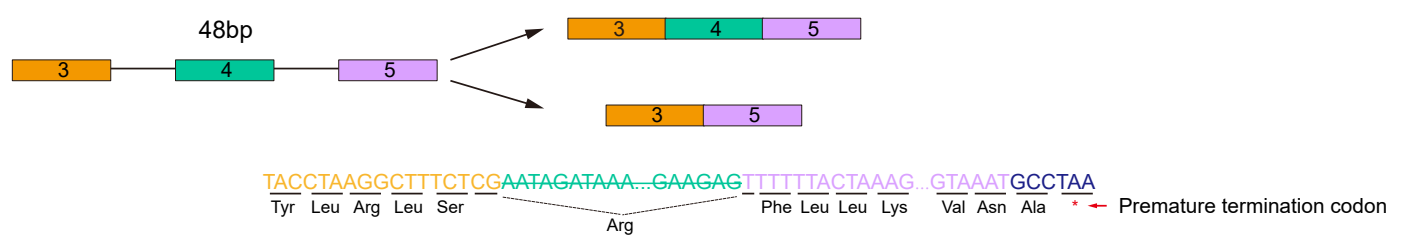

Kat7

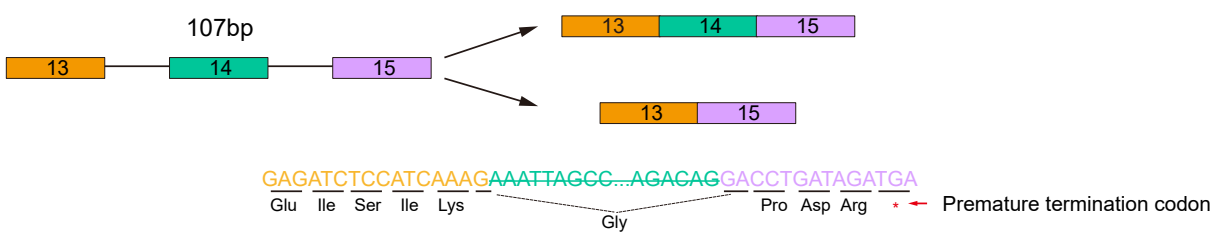

Clk1

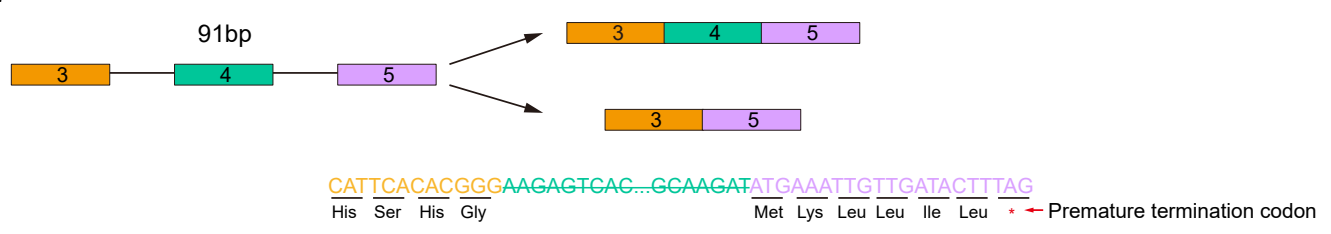


bioRxiv preprint doi: https://doi.org/10.1101/2022 03 06 483179; this version posted March 6, 2022. The copyright holder for this preprint (which was not certified by peer review) is the author/funder, who has granted bioRxiv a license to display the preprint in perpetuity. It is made available under aCC-BY 4.0 International license.

\section{Figure 7- figure supplement 4}

A

Alternative last exon

C

Acly
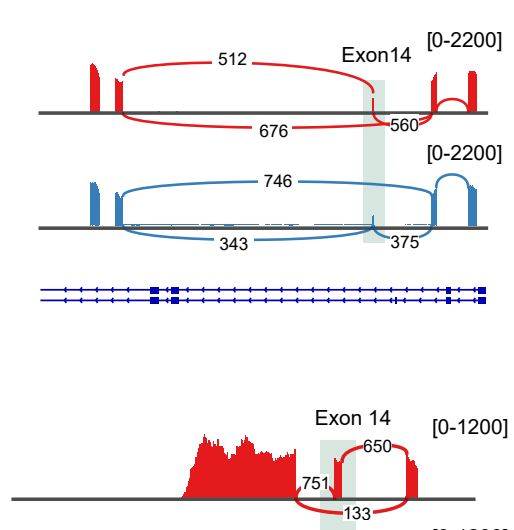

Kat7

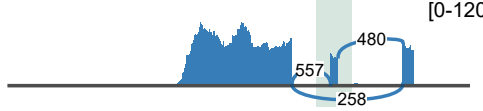

Exing
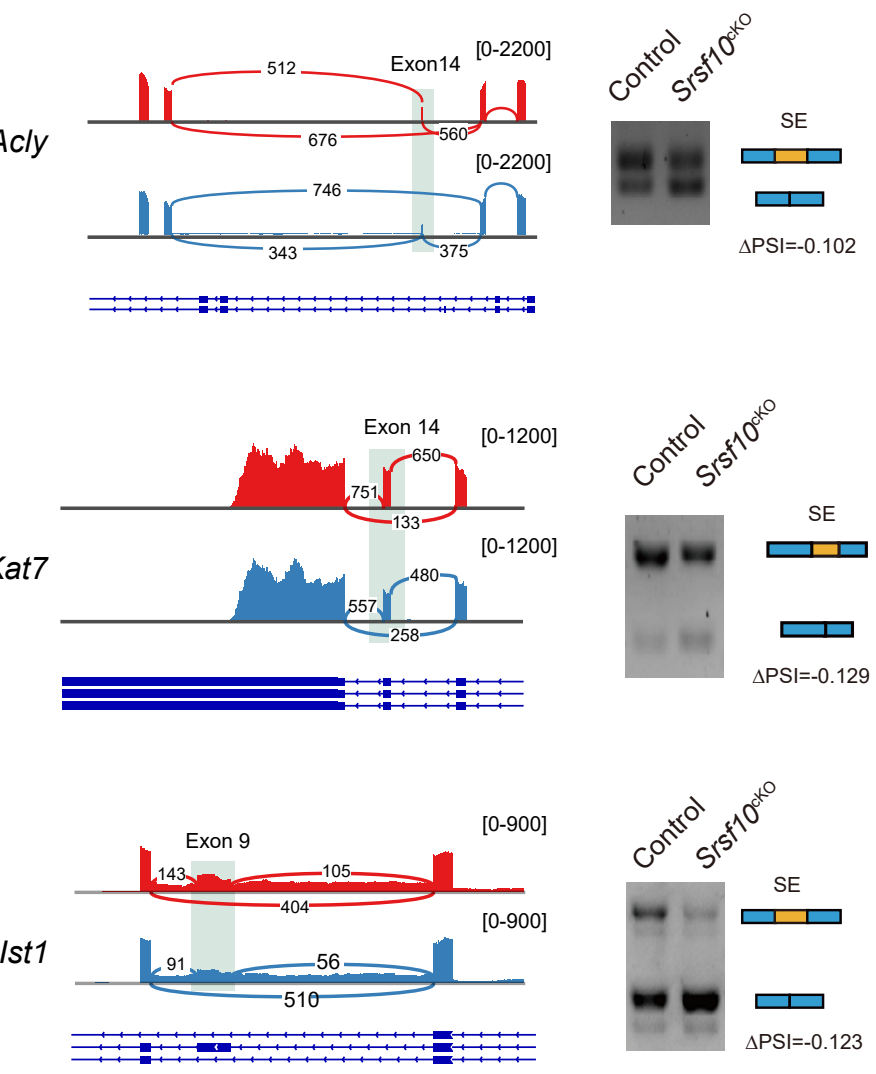

NGS data using $\mathrm{CASH}$ analysis

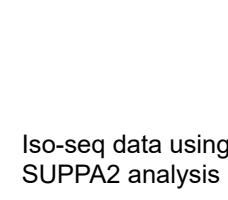

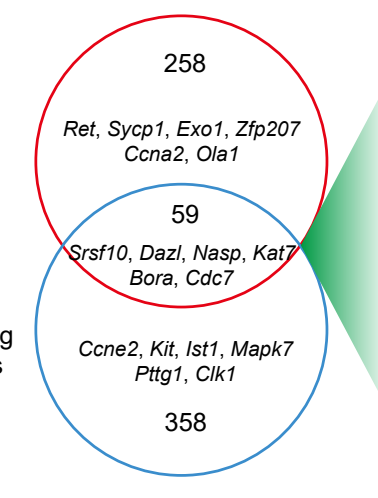

DNA replication

Kat7, Mcm4, Nasp and Ssrp1

\section{Cell Cycle}

Bora, Cdc7, Mcm4, Nasp, Stag3 and Uhrf

Spermtid development $X I r 5 a, X \mid r 5 b$ and XIr5c
Zfp207
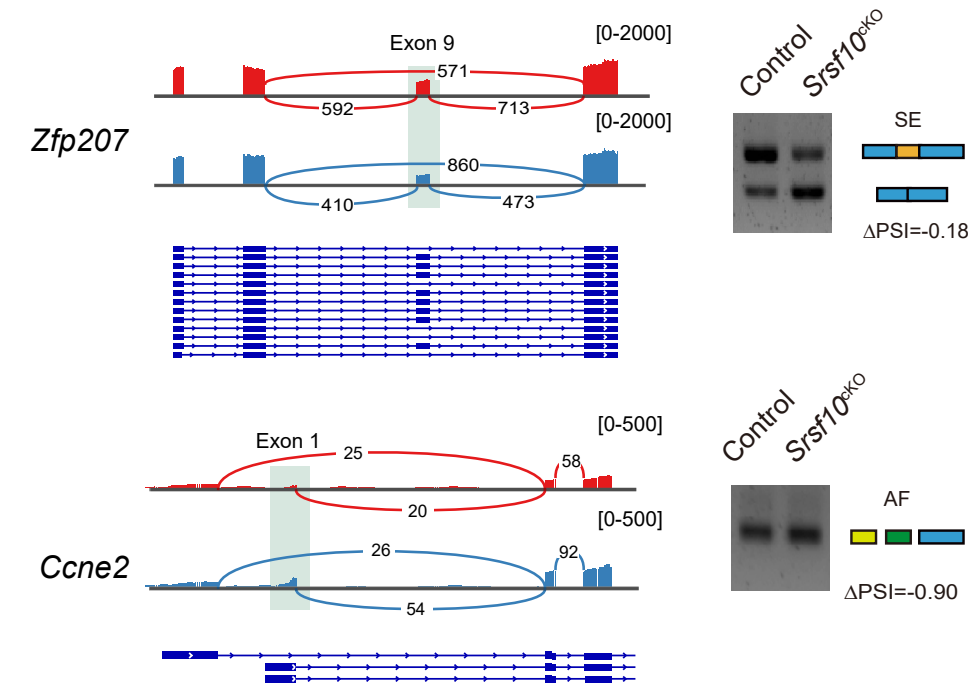

Ccne2

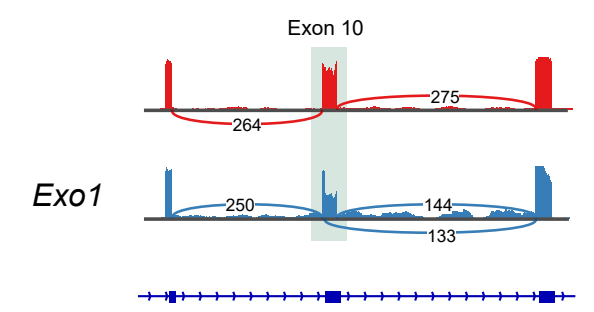

Exo1

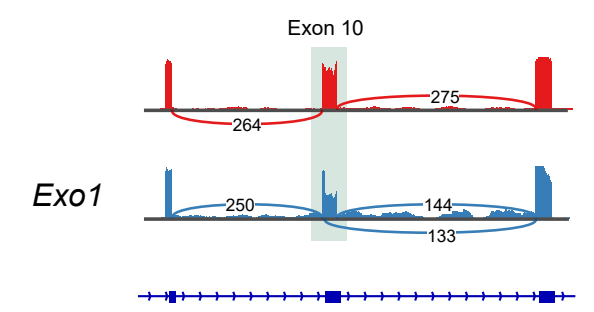

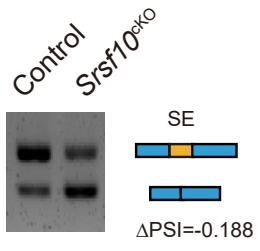

$\Delta \mathrm{PSI}=-0.188$

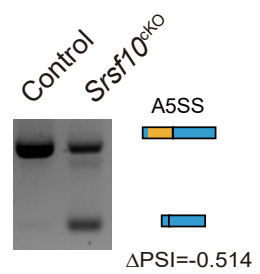

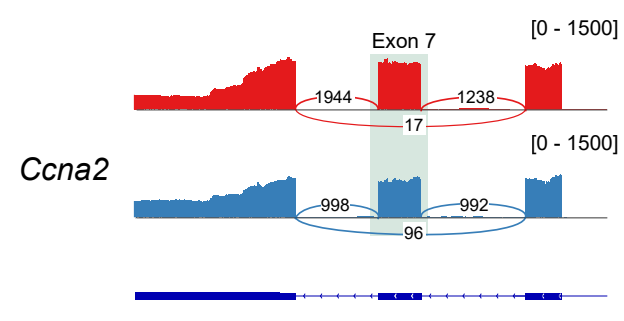

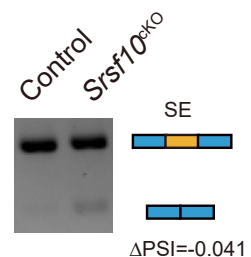

